Check for updates

Cite this: Chem. Soc. Rev., 2020, 49,5473

Received 14th October 2019

DOI: $10.1039 / c 9 c s 00199 a$

rsc.li/chem-soc-rev

\section{Half a century of amyloids: past, present and future $\dagger$}

\author{
Pu Chun Ke, (D) ${ }^{\text {ab }}$ Ruhong Zhou, ${ }^{\text {cd }}$ Louise C. Serpell, (D) e Roland Riek, ${ }^{\dagger}$ \\ Tuomas P. J. Knowles, (D) gh Hilal A. Lashuel,' Ehud Gazit, (D) Ian W. Hamley, \\ Thomas P. Davis, (D) ${ }^{\text {bl }}$ Marcus Fändrich, ${ }^{m}$ Daniel Erik Otzen, (D) ${ }^{n}$ Matthew R. Chapman, \\ Christopher M. Dobson, ${ }^{9}$ David S. Eisenberg ${ }^{p}$ and Raffaele Mezzenga (D) *ar
}

\begin{abstract}
Amyloid diseases are global epidemics with profound health, social and economic implications and yet remain without a cure. This dire situation calls for research into the origin and pathological manifestations of amyloidosis to stimulate continued development of new therapeutics. In basic science and engineering, the cross- $\beta$ architecture has been a constant thread underlying the structural characteristics of pathological and functional amyloids, and realizing that amyloid structures can be both pathological and functional in nature has fuelled innovations in artificial amyloids, whose use today ranges from water purification to 3D printing. At the conclusion of a half century since Eanes and Glenner's seminal study of amyloids in humans, this review commemorates the occasion by documenting the major milestones in amyloid research to date, from the perspectives of structural biology, biophysics, medicine, microbiology, engineering and nanotechnology. We also discuss new challenges and opportunities to drive this interdisciplinary field moving forward.
\end{abstract}

\section{Introduction}

The X-ray diffraction pattern of filamentous amyloid from human liver and spleen, as described by Eanes and Glenner in 1968, contained "a sharp, intense ring at $4.75 \AA$ overlaying a diffuse halo at $4.3 \AA$ and a broad and less intense ring at $9.8 \AA$ ”. 1
This followed the first report by Astbury et al. in 1934 on the presence of the cross- $\beta$ motifs in chicken egg proteins. ${ }^{2}$ Much progress has been made since then. Within the realm of structural biology, the cross- $\beta$ structure of human amyloid first revealed in that seminal study has underpinned our understanding (or the lack thereof) of the aggregation of amyloid

\footnotetext{
${ }^{a}$ Zhongshan Hospital, Fudan University, 111 Yixueyuan Rd, Xuhui District, Shanghai, China

${ }^{b}$ ARC Centre of Excellence in Convergent Bio-Nano Science and Technology, Monash Institute of Pharmaceutical Sciences, Monash University, 381 Royal Parade, Parkville, VIC 3052, Australia

${ }^{c}$ Institute of Quantitative Biology, Zhejiang University, Hangzhou 310058, China

${ }^{d}$ Department of Chemistry, Columbia University, New York, New York, 10027, USA

${ }^{e}$ School of Life Sciences, University of Sussex, Falmer, East Sussex BN1 9QG, UK

${ }^{f}$ Laboratory of Physical Chemistry, Department of Chemistry and Applied Biosciences, ETH Zurich, Wolfgang-Pauli-Str. 10, 8093 Zurich, Switzerland

${ }^{g}$ Department of Chemistry, University of Cambridge, Lensfield Road, Cambridge CB2 $1 \mathrm{EW}$, UK

${ }^{h}$ Cavendish Laboratory, University of Cambridge, JJ Thomson Avenue, CB3 OHE, Cambridge, UK

${ }^{i}$ Laboratory of Molecular Neurobiology and Neuroproteomics, Brain Mind Institute, École Polytechnique Fédérale de Lausanne (EPFL), CH-1015 Lausanne, Switzerland

${ }^{j}$ Department of Molecular Microbiology and Biotechnology, George S. Wise Faculty of Life Sciences; Department of Materials Science and Engineering, Iby and Aladar Fleischman Faculty of Engineering, Tel Aviv University, 69978 Tel Aviv, Israel

${ }^{k}$ School of Chemistry, Food Biosciences and Pharmacy, University of Reading, Whiteknights, Reading RG6 6AD, UK

${ }^{l}$ Australian Institute for Bioengineering and Nanotechnology, The University of Queensland, Brisbane, Qld 4072, Australia

${ }^{m}$ Institute of Protein Biochemistry, Ulm University, 89081, Ulm, Germany

${ }^{n}$ Interdisciplinary Nanoscience Center (iNANO) and Department of Molecular Biology and Genetics, Aarhus University, Gustav Wieds Vej 14, 8000 Aarhus C, Denmark

${ }^{o}$ Department of Molecular, Cellular and Developmental Biology, Centre for Microbial Research, University of Michigan, Ann Arbor, MI 48109-1048, USA

${ }^{p}$ Departments of Chemistry and Biochemistry and Biological Chemistry, UCLA-DOE Institute and Howard Hughes Medical Institute, UCLA, Los Angeles, CA, USA

${ }^{q}$ Department of Health Sciences \& Technology, ETH Zurich, Schmelzbergstrasse 9, LFO, E23, 8092 Zurich, Switzerland. E-mail: raffaele.mezzenga@hest.ethz.ch

${ }^{r}$ Department of Materials, ETH Zurich, Wolfgang Pauli Strasse 10, 8093 Zurich, Switzerland

$\dagger$ This article is dedicated to the memory of our dear colleague Sir Christopher Dobson. Chris was an exceptional scientist, scholar, and a true pioneer of the field of amyloid studies as well as a wonderful mentor to his colleagues and students. He has inspired a whole generation of scientists and enriched the lives of so many people. He was widely admired and will always be remembered for his formidable contributions to the field of Chemistry, his sharp wit, and also his kindness and generosity.
} 
proteins as well as their associated pathologies, from cerebral amyloid angiopathy (CAA), tauopathies and synucleinopathies to amyloid light-chain (AL) amyloidosis, transthyretin (TTR) amyloidosis, ${ }^{3,4}$ amyotrophic lateral sclerosis (ALS) and rheumatoid arthritis (RA), and from the endogenous aggregation of insulin and human islet amyloid polypeptide (hIAPP) to the cross talk ${ }^{5}$ between amyloid proteins of different physiological origins and the transmission of prion diseases ${ }^{6}$ across animal species. Recent discovery of amyloid-like assemblies of metabolites and their associated toxicities ${ }^{7}$ has shed new light on the molecular mechanisms of human diseases, and blurred the boundary between functional and pathological amyloid. As bacterial multidrug resistance (MDR) has become a global health crisis, understanding and exploiting the structural and pathological roles of bacterial amyloid may offer new solutions for the development of novel therapeutics. The recent finding of a gutbrain neural circuit for nutrient sensory transduction ${ }^{8}$ points to a connection between the gut microbiome and neurological disorders, ${ }^{9}$ each of which is associated with amyloid architectures. Major discoveries have been made in recent years and months, implicating the gut microbiome as causative for obesity, type 2 diabetes (T2D), neurological disorders, cancer, depression and social behaviour. ${ }^{10-14}$

Amyloidosis refers to the accumulation and deposition of amyloid fibrils, ${ }^{15}$ whose aggregation kinetics contains contributions of both primary and secondary nucleation, ${ }^{16}$ giving rise to toxic intermediates of oligomers ${ }^{17,18}$ and protofibrils en route. The amyloid state is characterized by steric zippers of the amyloid cross- $\beta$ spine, ${ }^{19}$ and the state is proposed to be accessible by virtually all proteins under physiological or artificial conditions. The crystalline form of amyloid proteins has recently been identified as the absolute free-energy ground state ${ }^{20,21}$ over the native or amyloid state of proteins. On a mesoscopic scale, amyloid fibrils possess polymorphism, displaying a prevalent yet nonexclusive left-handedness likely originated from the biased chirality of amino acids. ${ }^{22}$ In engineering, amyloids of whey proteins have found new applications in iron fortification, water purification and in vivo sequestration of pathological amyloid proteins, ${ }^{23-25}$ while functional amyloid-nanocomposites yield new mechanical, thermal and electronic properties appealing to nanoelectronics, biotechnology and environmental engineering. ${ }^{26}$

To commemorate five decades of research since Eanes and Glenner's landmark study of human amyloid, ${ }^{1}$ here we reflect on major milestones in the field of amyloid to date, shared among the three major classes of amyloids: the pathological, functional and artificial amyloids, and we discuss emerging opportunities and grand challenges of the amyloid science moving forward, from the perspectives of basic science, medicine and engineering (Fig. 1).

\section{Amyloidosis, a prevalent yet peculiar form of protein misfolding}

Protein folding is one of the most perplexing problems in molecular biology, despite many decades of extensive research. ${ }^{27,28}$

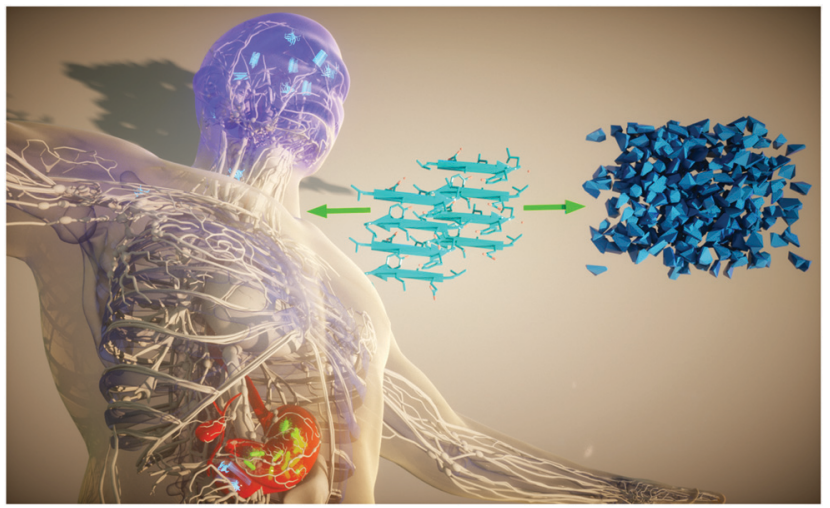

Fig. 1 Amyloidosis is a biophysical phenomenon of protein self-assembly under natural or artificial conditions, underpinned by a ubiquitous cross- $\beta$ architecture (middle, in cyan). For over a half century, or arguably much longer, investigations into the structures of pathological and functional amyloids within the human anatomy (left, in blue), the microbiota (left, in green) and beyond (right, in dark blue) have revealed their inner workings as well as their entangled implications for biology, medicine and engineering.

In short, protein folding is a complex process through which a protein molecule acquires the unique native structure for carrying out its specific biological functions. However, under certain pathological conditions, proteins can misfold, resulting in structures that expose the hydrophobic residues at the core of the folded protein to the solvent. These misfolded proteins can self-assemble into a variety of aggregate structures, including large, insoluble fibrillar entities known as the amyloids. ${ }^{28}$ As mentioned above, a number of diseases, including Alzheimer's disease (AD) and T2D, are associated with the presence of amyloid. Although proteins involved in amyloid diseases are dissimilar in both sequences and folds, the end-products of their aggregation bear striking structural similarities including the fibrillar structure and cross- $\beta$ backbone as revealed by X-ray diffraction. ${ }^{1,29}$ Since many proteins that are not associated with diseases also form amyloid fibrils, it has been suggested that under certain conditions, any protein is capable of forming an amyloid, ${ }^{30}$ indicating amyloidosis might be a prevalent yet peculiar form of protein misfolding (i.e., amyloid formation might represent a special type of evolving protein folding free energy landscape, more below). In addition to protein misfolding, it has also been recognized that some proteins have no single welldefined tertiary structure. These proteins are termed intrinsically disordered proteins (IDPs) which are often involved in cellular signaling and regulation. ${ }^{31,32}$ Given the very large number of degrees of freedom in an unfolded polypeptide chain, the protein molecule has an astronomical number of possible conformations. From one estimation, for a $\sim 100$ residue protein, it would take $\sim 10^{11}$ years to fold if the protein needs to explore all the possible conformation states, while in reality it takes merely milliseconds to seconds for a typical protein to fold in vivo. This is called the Levinthal paradox, ${ }^{33}$ proposed by Cyrus Levinthal five decades ago in 1969. To overcome this paradox, ${ }^{33}$ several folding models, from classical nucleation-propagation model to the folding funnel model, have been proposed to complement experiments towards better understanding of this complex folding process. 


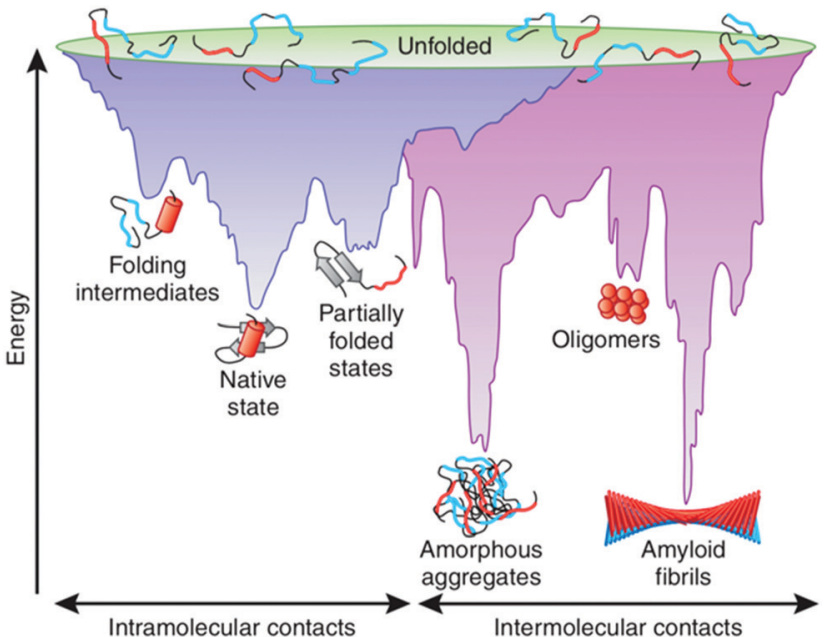

Fig. 2 Energy landscape of protein folding and aggregation. The purple surface shows the multitude of conformations 'funneling' to the native state via intramolecular contacts and the pink area shows the conformations moving toward amorphous aggregates or amyloid fibrils via intermolecular contacts. Both parts of the energy surface overlap. Aggregate formation can occur from intermediates populated during de novo folding or by destabilization of the native state into partially folded states and is normally prevented by molecular chaperones. Toxic oligomers may occur as off-pathway intermediates of amyloid fibril formation. Reproduced with permission from ref. 34, copyright 2009 Nature Publishing Group. ${ }^{34}$

The widely adopted protein folding funnel model has evolved from both experiment and theory through the use of simplified mechanical models developed by Wolynes, Onuchic, Dill and colleagues $^{35-37}$ and more recently by Mezzenga and coworkers. ${ }^{20,21}$ Fig. 2 illustrates the folding funnel which is a simplified $2 \mathrm{D}$ representation of the very high-dimensional conformational space accessible to a protein during its folding. ${ }^{34}$ The broad top of the funnel represents a vast number of conformations present in the fully unfolded or stretched state, while the narrow bottom of the funnel depicts the unique native structure of the protein. ${ }^{35}$ The separation between the top and bottom of the funnel represents other energies (solute enthalpy, solvent entropy and enthalpy) contributing to each protein conformation. However, the chaperone effect (chaperonin-mediated folding) or multi-protein co-folding effect (folding upon binding, etc.) is not included in this picture due to its simplicity. ${ }^{35,36,38}$ Starting from the ensemble of unfolded conformations, the folding funnel allows many different pathways to proceed rapidly to the global free energy minimum occupied by amyloids, recently refined into a series of closely-positioned local minima, occupied by different amyloid polymorphs, with the amyloid crystals alone occupying the absolute minimum (for an extended discussion on the energetic levels of different amyloid polymorphs see Section 4, "Mesoscopic structures of amyloids and the energy landscape"). ${ }^{20,21}$ As the chain folds to lower energy conformations, and before reaching the metastable local minima of the various amyloid polymorphs, intermediate states along the sides of the funnel are also populated. During this process, the kinetic traps might hinder or promote formation of native structures depending on their depths and the barriers between the traps and next energy minima. According to statistical mechanics, the number and depth of local kinetic traps on the funnel landscape correspond to the degree of frustration of the protein sequence. ${ }^{35}$ Following the concept of the folding funnel diagrams, an offpathway aggregation can be incorporated as second "aggregation funnel". ${ }^{39}$ Like intramolecular folding, the association of two or more non-native protein molecules can form an "amyloidosis formation funnel" through intermolecular contacts (Fig. 2). The process is largely driven by hydrophobic forces and primarily results in the formation of amorphous structures ("amorphous aggregates"; Fig. 2). ${ }^{34}$ Subsequently, aggregation can lead to the formation of amyloid fibrils. These simplistic folding funnel models provide a conceptual framework for understanding the complex process of amyloid formation..$^{20,21,34}$

Meanwhile, recent advances in experimental techniques that probe amyloid formation at different stages have shed light on the nature of both the kinetics and thermodynamics of this complex process (more in the following sections). However, many of the underlying molecular mechanisms and interactions involved in amyloid protein/peptide misfolding and aggregation pathways remain elusive. Computer simulations performed at various levels of complexity ranging from simple lattice models, models with continuum solvent, to all atom models with explicit solvent have been used to offer complementary and valuable insights that cannot be obtained by experimental methods alone. ${ }^{40}$ In particular, the important role of water molecules in promoting the formation of protofilaments, the basic building blocks of amyloid fibrils, has been investigated using fully atomic molecular dynamics (MD) simulations. ${ }^{41}$

Although the hydrophobic effect is known to have a significant impact on protein self-assembly in water, the precise mechanism of how it operates as well as the exact role of water in facilitating this assembly remains controversial. In a recent study, ${ }^{41}$ a model protofilament comprised of two parallel $\beta$-sheets of Alzheimer $\mathrm{A} \beta 16-22$ peptides $\left(\mathrm{Ac}-\mathrm{K}^{16}-\mathrm{L}^{17}-\mathrm{V}^{18}-\mathrm{F}^{19}\right.$ $\mathrm{F}^{20}-\mathrm{A}^{21}-\mathrm{E}^{22}-\mathrm{NH}_{2}$ ) was employed to study amyloid formation and the role of water molecules during the process using $\mathrm{MD}$ simulation. Each $\beta$-sheet presented a distinct hydrophobic face and a hydrophilic face, which together self-assembled into a stable protofilament with a core consisting of purely hydrophobic residues $\left(\mathrm{L}^{17}, \mathrm{~F}^{19}, \mathrm{~A}^{21}\right)$, with the two charged residues $\left(\mathrm{K}^{16}, \mathrm{E}^{22}\right)$ pointing to the solvent (Fig. 3A). The simulation results revealed a subtle interplay between a water mediated assembly and one driven by favorable energetic interactions between specific residues forming the interior of the protofilament. Overall, the role of water during the assembly can be viewed as "lubrication", namely it does not drive assembly but rather facilitate proper packing of the hydrophobic surfaces in the final stages of the assembly. In some of the MD trajectories, a nanoscale dewetting (or drying) was also observed in which water expulsion preceded hydrophobic collapse, providing a strong driving force for the hydrophobic collapse and hydrophobic patch assembly. This can be attributed to the fact that when two strongly hydrophobic surfaces, greater than $1 \mathrm{~nm}$ in length, are brought together to a critical distance, a nanoscale drying might occur between the two hydrophobic surfaces, 

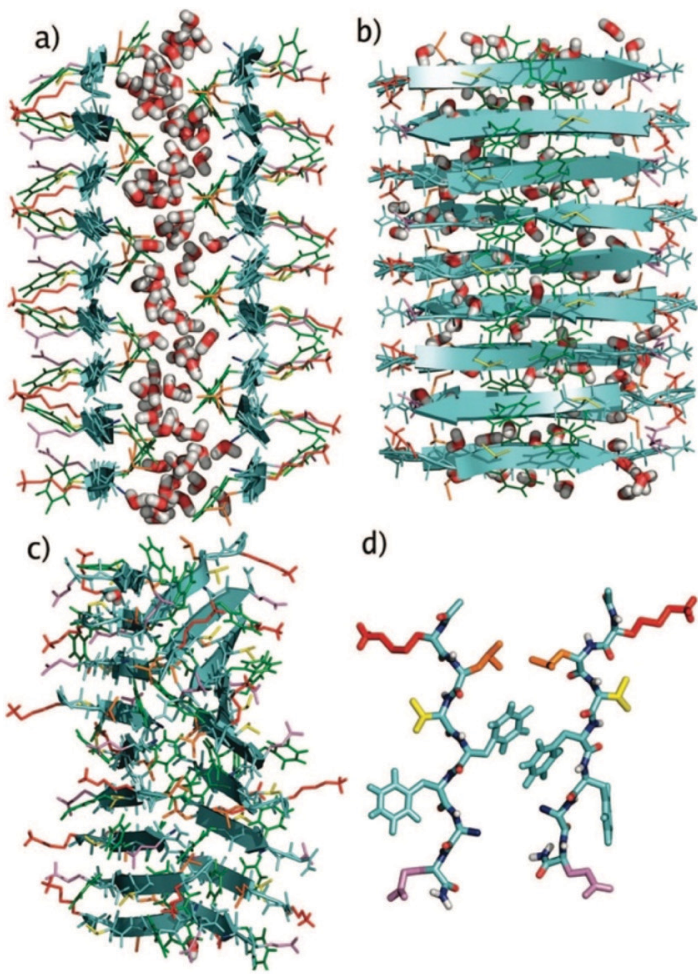

d)

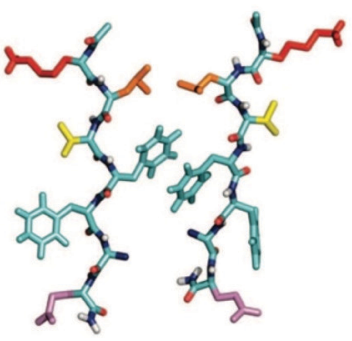

Full Potential $\left(\mathrm{D}_{0}=1.28 \mathrm{~nm}\right)$

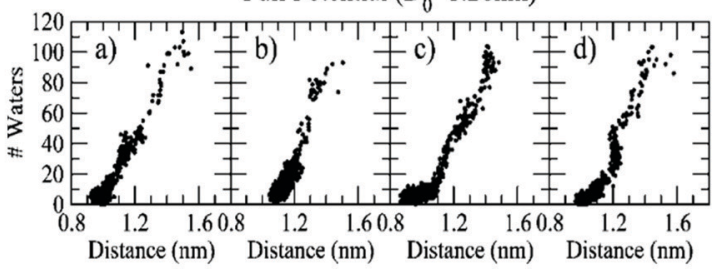

No Protein-Water Van der Waals Attraction $\left(\mathrm{D}_{0}=2.38 \mathrm{~nm}\right)$

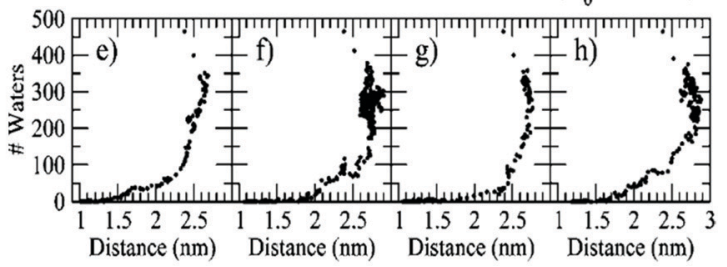

No Protein-Water Electrostatic Attraction $\left(\mathrm{D}_{0}=1.28 \mathrm{~nm}\right)$

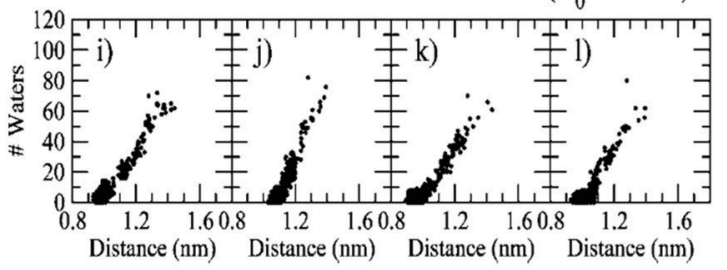

A

B

Fig. 3 (A) A $16-22$ model protofilament (left panel). The initial structure used to start the MD trajectory with initial inter- $\beta$-sheet separation distance $D_{0}$ of $1.28 \mathrm{~nm}$. Front (a) and side (b) views are shown. Side chains are colored as follows: (K) red, (L) orange, (V) yellow, (F) green, (A) blue, and (E) violet. For clarity, only water molecules in the interpeptide region have been shown. (c) The same structure after 1000 ps of unconstrained MD simulation at $300 \mathrm{~K}$, started from the structure shown in (a) and (b). (d) A single A $16-22$ peptide pair, one from each layer, is isolated from the protofilament shown in (c). (B) Number of interpeptide water molecules versus interpeptide distance (right panel). (a-d) Plots for each of the four trajectories at $300 \mathrm{~K}$ where $D_{0}=$ $1.28 \mathrm{~nm}$. Trajectories (a) and (b) do not appear to show a dewetting transition, while trajectories (c) and (d) do. (e-h) The peptide-water van der Waals interaction is turned off, and $D_{0}=2.38 \mathrm{~nm}$. (i-l) The peptide-water electrostatic interaction is turned off, and $D_{0}=1.28 \mathrm{~nm}$. Reproduced with permission from ref. 41, copyright 2008 American Chemical Society. ${ }^{41}$

resulting in a strong hydrophobic collapse. ${ }^{42,43}$ In the trajectories where no nanoscale drying was observed, water expulsion and hydrophobic collapse occurred roughly simultaneously (i.e., water acting as "lubricant"; Fig. 3).

The authors also studied the interaction energy decomposition to explore the contributions from various forces. ${ }^{41}$ Interestingly, turning off the protein-water electrostatic interaction only slightly slowed down the assembly speed without significantly affecting the nanoscale drying (Fig. 3B). Conversely, if the protein-water van der Waals attraction was switched off, a strong dewetting transition and hydrophobic collapse takes place in every simulation (Fig. 3B). These predictions were later validated by experimental (and theoretical) studies of other proteins with large hydrophobic patches. ${ }^{44}$ Overall, these computer simulations demonstrate that in general, when attractive van der Waals forces exist between the solute and solvent, these forces, though individually small, can be sufficient to compensate for the loss of hydrogen bonds due to the confinement of water between the two plates. However, in extreme cases, such as those highly hydrophobic and rough surfaces in-between the amyloid protofilaments, some nanoscale dewetting might occur which can provide strong driving force for the hydrophobic collapse of amyloid peptides and their subsequent aggregation and fibril formation. ${ }^{45}$

\section{Towards atomic structures of amyloid fibrils}

As briefly introduced, amyloid fibrils are identified by a characteristic X-ray fibre diffraction pattern which is termed cross- $\beta$ (Fig. 4). This pattern was first described for poached egg-white ${ }^{2}$ and later the data from the silk egg stalk from the green lacewing fly was interpreted to provide a detailed description of this repetitive structure. ${ }^{46}$ The cross- $\beta$ diffraction pattern gives a strong, sharp diffraction signal at 4.76-4.78 A on the meridional (vertical) axis, which was interpreted to arise from the distance between hydrogen bonded $\beta$-strands. On the equator, (horizontal axis) several signals may be observed but the dominant intensity is thought to arise from the spacing of several $\beta$-sheets. ${ }^{47,48}$ For the silk from the egg stalk, the equatorial spacing was only $5 \AA$ A. However, the spacing arising from amyloid fibrils is more often larger to accommodate larger and more variable side chains, from around $8 \AA$ for polyQ containing peptides ${ }^{49,50}$ to 11-12 $\AA$ for those containing aromatic residues. ${ }^{51,52}$ 

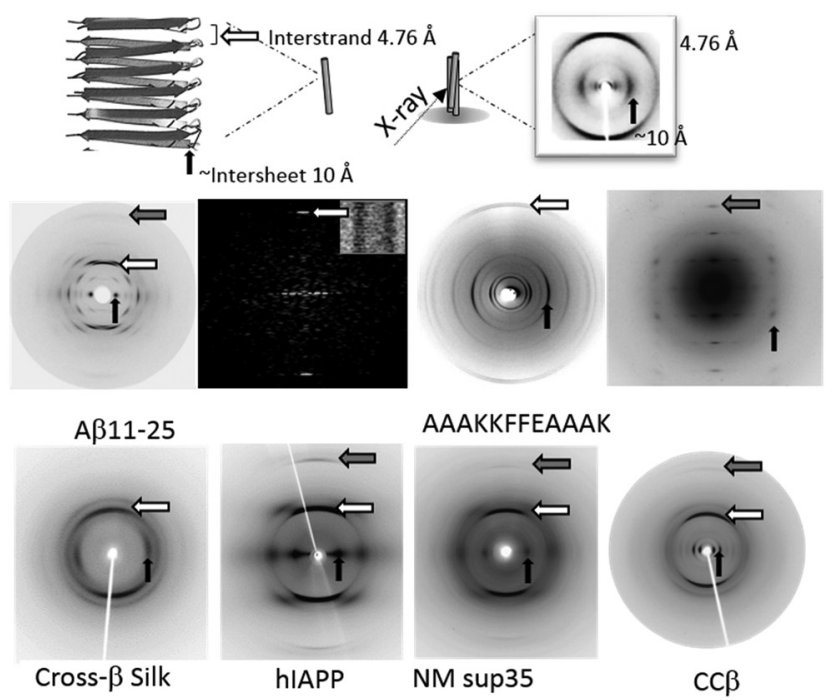

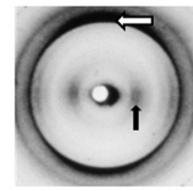

Met30 TTR

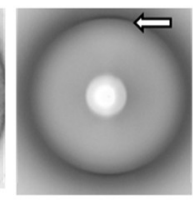

Ex-vivo PHF

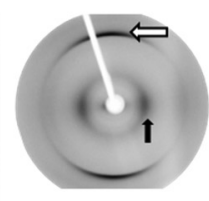

Core PHF

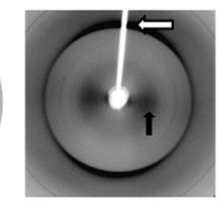

$\beta 2 \mathrm{M}$ synthetic

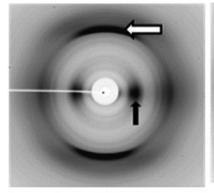

$A \beta 1-42$

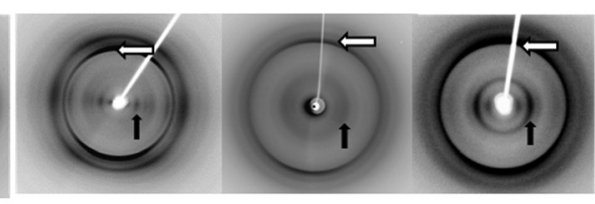

GNNQQNY Fibrinogen A $\alpha$ chain RVFNIM
Fig. $4 X$-ray fibre diffraction provides the characteristic cross- $\beta$ pattern for amyloid. Top panel shows a schematic showing the features of the cross- $\beta$ pattern and structure. Lower panels show the cross- $\beta$ diffraction patterns collected from amyloid fibrils formed by a diverse range of amyloidogenic proteins and peptides. A $\beta 11-25^{72-74}$ AAAKKFFEAAAK, ${ }^{52}$ silk, $^{75}$ hIAPP, $^{76} \mathrm{NM}$ Sup35, ${ }^{77} \operatorname{cc} \beta{ }^{78}$ Met30 TTR, ${ }^{79} \mathrm{Tau}^{80}$ Core PHF, ${ }^{81} \quad \beta 2 \mathrm{M}^{82} \mathrm{~A} \beta 42,{ }^{73,83}$ GNNQQNY, $^{84}$ fibrinogen, ${ }^{85}$ RVFNIM. $^{86}$ White arrow - major meridional, H-bond spacing: 4.7-4.8 $\AA$; grey arrow - meridional $2.4 \AA$; black arrow - major equatorial, sheet spacing (10-12 $\AA$; $5 \AA$ for silk). Reproduced with permission from ref. 72, copyright 2000 The American Chemical Society. ${ }^{72}$ Reproduced with permission from ref. 73, copyright 2003 Elsevier. ${ }^{73}$ Reproduced with permission from ref. 74, copyright 2000 Elsevier. ${ }^{74}$ Reproduced with permission from ref. 52, copyright 2005 National Academy of Sciences. ${ }^{52}$ Reproduced with permission from ref. 75, copyright 2007 Wiley- $\mathrm{VCH}^{75}$ Reproduced with permission from ref. 76, copyright 2004 Elsevier. ${ }^{76}$ Reproduced with permission from ref. 77, copyright 2000 American Association for the Advancement of Science. ${ }^{77}$ Reproduced with permission from ref. 78, copyright 2008 Elsevier. ${ }^{78}$ Reproduced with permission from ref. 79, copyright 1996 Ciba Foundation. ${ }^{79}$ Reproduced with permission from ref. 80, copyright 2003 National Academy of Sciences. $^{80}$ Reproduced with permission from ref. 81, copyright 2017 Elsevier. ${ }^{81}$ Reproduced with permission from ref. 82, copyright 2008 American Society for Biochemistry and Molecular Biology. ${ }^{82}$ Reproduced with permission from ref. 87, copyright 2012 American Society for Biochemistry and Molecular Biology. ${ }^{87}$ Reproduced with permission from ref. 84, copyright 2010 Elsevier. $^{84}$ Reproduced with permission from ref. 85, copyright 2007 Informa Healthcare. ${ }^{85}$ Reproduced with permission from ref. 86, copyright 2013 Portland Press. ${ }^{86}$

Transmission electron microscopy was a valuable asset and in 1959, Cohen and Calkins ${ }^{53}$ provided images of amyloid fibrils extracted from liver. Eanes and Glenner showed the cross$\beta$ diffraction pattern from amyloid extracted from liver and spleen $^{1}$ and then created "amyloid" in vitro from Bence Jones proteins (excreted immunoglobulin light chains, LCs) or their fragments. ${ }^{54}$ This disease, arising from the formation of LCderived amyloid fibrils, is now known as AL amyloidosis. ${ }^{55,56}$ As early as 1946, Waugh reported precipitation of insulin under high temperature, acidic conditions. ${ }^{57}$ In 1972, synthetic amyloid fibrils were made from insulin by repeated heating and cooling under acidic conditions. This process generated longstraight, unbranching fibrils that resisted degradation ${ }^{58}$ and gave a cross- $\beta$ diffraction pattern as well as the characteristic $\beta$-sheet signals by circular dichroism (CD) spectrophotometry and Fourier transform infrared (FTIR) spectroscopy. Following this advance, it became possible to create amyloid fibrils from many disease-related peptides such as $A \beta,^{59,60} \mathrm{hIAPP}^{61}$ and peptides related to larger amyloidogenic precursors such as TTR. $^{62}$ This paved the way for further structural characterisation to reinforce the description of the amyloid core cross- $\beta$ structure. The cross- $\beta$ pattern from ex vivo Val30Met variant TTR provided a model structure, composed of repeating $\beta$-strands running perpendicular to the fibre axis and associated to several sheets that twisted with a helical pitch of $115.5^{\circ} .^{63}$ This model was found to be representative of a collection of extracted amyloid fibrils leading to the generic cross- $\beta$ model for amyloid. ${ }^{64}$

Atomic force microscopy, transmission electron microscopy and cryo-transmission electron microscopy (AFM, TEM and cryoTEM) provided further macromolecular details and showed that amyloid fibrils were formed of individual protofilaments ${ }^{65-68}$ and that different precursor proteins may lead to different numbers of protofilaments. It was also becoming clear that synthetic fibrils grown under different conditions could lead to structural polymorphism. For example, insulin fibrils analyzed by cryoTEM showed multiple variations in the number of protofilaments from two to six, ${ }^{69}$ while $A \beta 40$ was later shown to form even more different classes. ${ }^{70}$ AFM was instrumental in demonstrating the growth of the fibrils and generally showed that the diameters did not change, but that the growth was additive elongation at the growing ends. ${ }^{71}$

$\mathrm{X}$-ray fibre diffraction from a short amyloidogenic region of A $\beta 11-25$ gave exceptional detail and these fibrils were also analyzed by cryoTEM to directly visualize the cross- $\beta$ structure ${ }^{74}$ (Fig. 4). High-resolution cryoTEM revealed striations that were $4.7 \AA$ apart, reinforcing the previous interpretation from the X-ray data and providing new insights into the stability of the fibrils. ${ }^{74} 4.7 \AA$ appeared to be the largest repeating unit and no long-range repeat was apparent. Interestingly, later studies have shown quite considerable variation in the helical twist for fibrils and often very long-range repeats that can vary even within a single filament. This variation goes some way to explaining why longer-range repeats were not observed in diffraction patterns.

Amyloid fibrils are made from a large variety of precursor proteins, ranging from the $\beta$-sheet sandwich structures of TTR, immunoglobulin LC and $\beta 2$ microglobulin, to the $\alpha+\beta$ structure of lysozyme and the $\alpha$-rich structure of serum amyloid A. ${ }^{55}$ Natively unfolded proteins and peptides assemble in diseases such as T2D, 
$\mathrm{AD}$ and Parkinson's disease (PD). Despite this diverse range of starting native structures, all amyloid fibrils share the cross- $\beta$ structure and all precursor proteins, even those rich in $\beta$-sheet, undergo a significant conformational change upon forming amyloid. Early work assumed that antiparallel sheets were formed allowing different length polypeptide chains to access this repetitive structure. ${ }^{72}$ Intriguingly, electroparamagnetic resonance pointed to a parallel, in-register structure for amyloid fibrils formed from large proteins and this appeared to suggest that the proteins needed to unfold almost entirely to form a layer which then stacked to render the fibrils. ${ }^{88}$ It seemed improbable, but structural models were put forward showing a $\beta$-spine. ${ }^{89}$ It was not until the first solid-state NMR (ssNMR) models were provided of $A \beta$ fibrils that it was shown that the $\beta$-sheets were formed by bending of two strands that stacked to assume a parallel, in register set of $\beta$-sheets. ${ }^{90,91}$ This structure, held together by hydrogen bonding, provided a stack of identical amino acid side chains along the length of the fibrils. It was clear then, that the side chains played an important role in the structure. $\mathrm{X}$-ray and electron diffraction were combined to provide a model for an amyloidogenic novel sequence AAAKKFFEAAAK, showing that the side chains associated across the sheets. ${ }^{52,92}$

The first atomic-resolution X-ray crystal structures of amyloidlike fibrils, formed in vitro from short adhesive segments of amyloid-forming proteins, revealed the basis of amyloid stability and provided atomic level insights into the amyloid core. ${ }^{19,94}$ The fibrils are formed from pairs of $\beta$-sheets, mated together by interdigitation of their amino acid sidechains. This zipper-like interdigitation of these structures suggested the term "steric zipper" for this motif, which has now been found in numerous X-ray, NMR, and cryoTEM structures ${ }^{19}$ (Fig. 5). In structures of full fibrils, steric zippers are frequently found at junctions of protofilaments (Fig. 5). Elsewhere in full fibrils, hetero zippers (formed by two different sequences) are found. Factors contributing to amyloid stability include: (1) the hydrophobic effect of releasing water molecules from the tight, dry interface between the sheets; (2) van der Waals stabilization of the interdigitating sidechains; (3) mutual polarization of stacked amide hydrogen-bonding groups parallel to the fibril axis; ${ }^{95}$ and (4) ladders of stacked sidechains such as the phenolic groups of tyrosine residues on the surface of the fibrils. The steric-zipper motif also explains the sequence specificity of amyloid formation: only compatible sequences can form steric zippers. Peptide inhibitors, designed on the basis of crystal structures of short segments, are effective in inhibiting aggregation and cell entry of full pathogenic amyloid fibrils. ${ }^{96}$

The technical challenge of determination of X-ray crystal structures of amyloid fibrils is that the crystals are invariably no larger than several microns in size. The hypothesis for the small crystal size is that $\beta$-sheets normally exhibit a slow twist but are held in amyloid crystals in untwisted form, producing a strain that builds as the crystal grows, limiting size. In fact, the crystals of the 11-residue NACore segment of $\alpha \mathrm{S}$ are only a few hundred nanometers in cross section, and hence invisible by light microscopy. Consequently their structure had to be determined by electron diffraction, for which small crystals are advantageous. ${ }^{93}$ Yet, as it will be discussed later, the untwisted form of amyloid crystals - compared to the twisted form of their homologue fibrils - opens for a different way to further decrease the overall free energy, placing them at the lowest minimum of the free energy landscape. ${ }^{20}$

Thanks to developments in SsNMR and cryoTEM, ${ }^{103,104}$ numerous near-atomic-resolution structures of much longer segments of amyloid fibrils are now available (Fig. 5 and 6). ssNMR yielded structures for a 22-residue fragment of $\beta 2$ microglobulin, ${ }^{105} \mathrm{~A} \beta 40$ by $2008,{ }^{106}$ for the more toxic $\mathrm{A} \beta 42$ by 2016, ${ }^{97,98}$ and for $\alpha$ S fibrils. ${ }^{107,108}$ Further advances in cryoTEM, largely helped by the invention of direct detectors and the treatment of helical structures as single particles ${ }^{109,110}$ have led to an explosion in atomic detail of amyloid structures. Nearatomic resolution structures were solved for amyloid fibrils of $\alpha \mathrm{S},{ }^{111-113} \mathrm{Tau},{ }^{101,114}$ and TDP-43. ${ }^{115}$ Paired helical filaments and straight filaments from $\mathrm{AD}$ brain showed the parallel in register structure with further exciting details at the bends between the sheets. Tau filaments from chronic traumatic encephalopathy patients ${ }^{114}$ and from Picks disease patients ${ }^{116}$ show intricate differences that may give us clues regarding the differences between the diseases. Immunoglobulin LC amyloid, ${ }^{117}$ $\beta 2$ microglobulin, ${ }^{118}$ acute phase protein amyloid A (AA) ${ }^{119,120}$ form similar core structures. Many proteins in the amyloid state are able to assume a variety of structural folds termed polymorphs.

Despite the variety of molecular structures displayed by amyloid proteins, they show common features. The proteins mainly form extended $\beta$-strands, and these are bent into a series of hairpin-shaped $\beta$-arches, and are confined essentially in a 2-dimensional slab or "layer". Backbone amide groups extend their hydrogen-bonding $\mathrm{C}=\mathrm{O}$ and $\mathrm{N}-\mathrm{H}$ groups up and down, parallel to the fibril axis, and the resulting hydrogen bonds stack the layers into slowly twisting protofilaments (Fig. 5). Most often, two or more protofilaments twist around each other, forming the fibril, but some fibrils are built from a single protofilament and some are formed from several protofilaments. The protein structures remain "cross- $\beta$ " displaying the expected distance of 4.76-4.78 $\AA$ between the hydrogen bonded $\beta$-strands which generally run perpendicular to the fibre axis.

Whereas pathological amyloid fibrils tend to be so stable as to be irreversible, considerably more labile amyloid-like fibrils have been found to form from low-complexity domains of proteins that participate in hydrogels and liquid-liquid phase separation. ${ }^{121-123}$ These low-complexity domains are especially rich in Gly, Ser, and Tyr residues, and poor in most apolar residues. Short segments of these domains have been crystallized and the resulting structures (Fig. 7) are similar to steric zippers in that they show pairs of stacked $\beta$-strands. But these weakly adhesive elements differ from steric zippers in that the backbones are usually kinked, with more polar and apparently weaker interfaces that account for the reversibility of the fibrils. These mildly adhesive interfaces have been termed LARKS, an acronym for low-complexity, amyloid-like, reversible, kinked segments. LARKS may contribute to the interactions between proteins with low-complexity domains that participate in transient subcellular bodies, such as stress granules.

Structural studies of amyloid and amyloid-like fibrils have opened understanding of these pathological and functional 


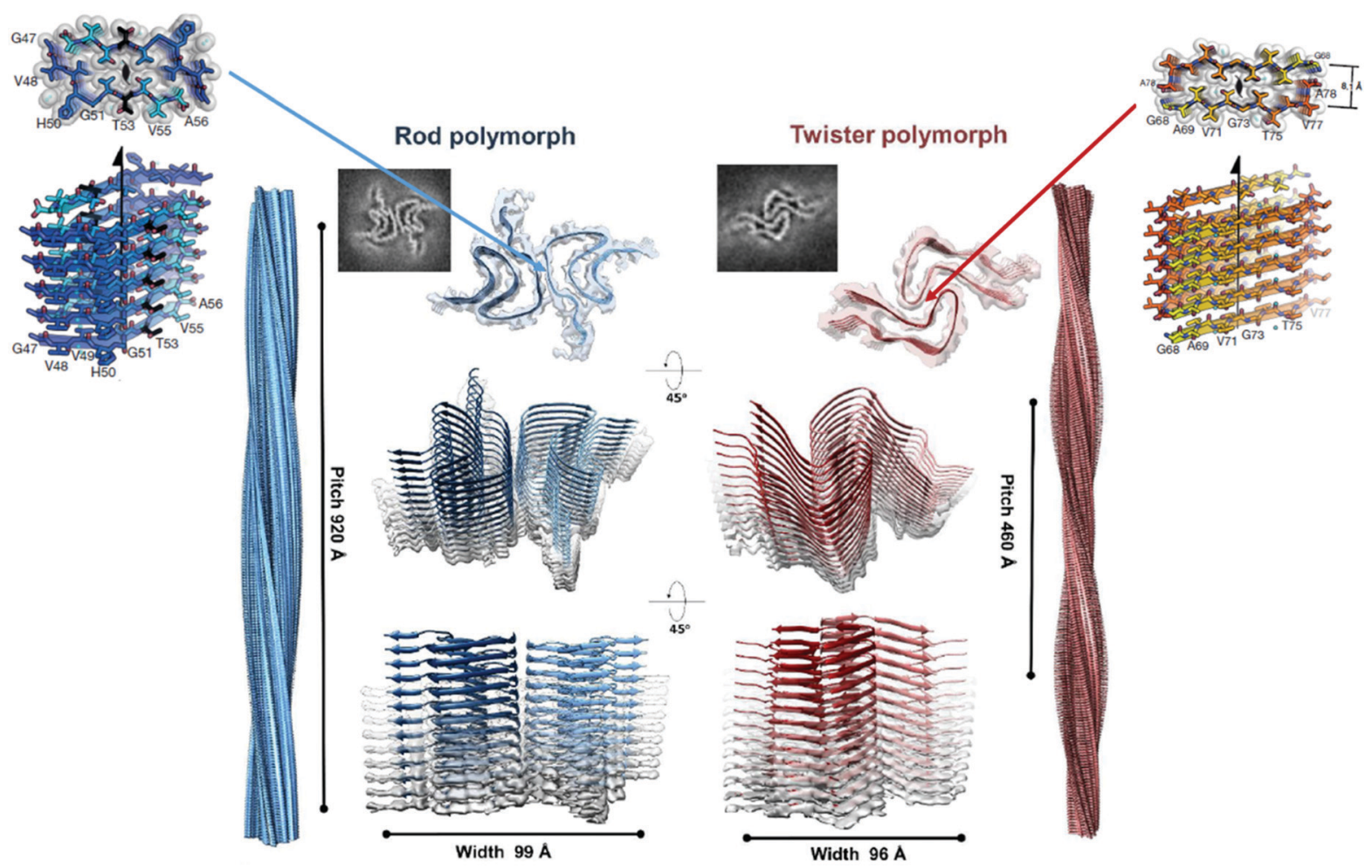

Fig. 5 Atomic-resolution crystal structures of two adhesive segments and two amyloid fibrils of the protein $\alpha$-synuclein associated with PD. Upper left: Crystal structure of the PreNAC segment with sequence ${ }^{47}$ GVVHGVTTVA ${ }^{56}$ (the first $\mathrm{T}$ in this sequence is a hereditary early-onset disease mutation A52T). The upper view is down the axis of this steric zipper, showing atoms with van der Waals radii forming a tight, dry interface. Upper right: Crystal structure of the NACore segment with sequence ${ }^{68}$ GAVVTGVTAVA ${ }^{78}$. The center shows two amyloid-like fibrils formed by $\alpha$-synuclein ( $\alpha$ S). In the top of the left center, one layer of the Rod polymorph is viewed down the fibril axis, showing that it contains two identical $\alpha \mathrm{S}$ chains each bent into a double hairpin shape. The two chains meet at a steric zipper formed by the PreNAC segments of the two chains. Identical layers are stacked on each other, forming a two-protofilament, slowly twisting fibril. In the top right center, one layer of the twister polymorph is viewed down the fibril axis. The fold of the two $\alpha \mathrm{S}$ molecules is similar to that of the Rod polymorph but the two chains meet at a different point than those of the Rod polymorph. They meet at an interface similar to that of the NACore crystal structure. That is, the steric zipper interfaces that pair the $\beta$-sheets in the crystal structures are similar to the interfaces between paired protofilaments in the fibrils. Notice that the slowly twisting twister fibril is formed by stacking identical layers on each other, with a slight twist. Reproduced with permission from ref. 93, copyright 2018 Springer Nature. ${ }^{93}$

architectures at the atomic level. The hope is that continued studies will contribute to the development of diagnostics and therapies for the numerous diseases associated with these fibrils.

\section{Mesoscopic structures of amyloids and their position in the energy landscape}

The mesoscopic features of amyloids, obtained from rabbit and human kidney tissues affected by primary amyloidosis, were first described by Cohen and Calkins in 1959 with a negativestain electron microscope. ${ }^{53}$ The authors marveled that "in the rabbit kidneys, the appearance of the amyloid was striking... (showing) delicate filaments". Although limitation imposed by sectioning prevented the precise delineation of fibril dimensions, they appeared to range in length from 1200 to $5000 \AA$, and in width from 50 to $120 \AA$. The biopsy specimen of the patient with extensive primary amyloidosis also showed wavy bundles of delicate fibrils in the electron microscope.
These correlated with the areas of amyloid as seen in the phase microscope and in stained sections. The dimensions were similar to the ones seen in the rabbit amyloid. The width varied from 70 to $140 \AA$ and long strands up to $16000 \AA$ Aere measured. No cross-bundling was apparent. The amyloid in the kidney of the patient with parenchymatous involvement also demonstrated fine bundles of filaments similar to those noted above.

The mesoscopic structure of amyloid fibrils has since been extensively characterized, primarily with TEM, cryoTEM and AFM, and similar fibrils have been documented for amyloids and amyloid-like entities including functional and pathological amyloids as well as engineered peptide and protein amyloids of various lengths as short as several amino acid residues, with di-phenylalanine being likely a minimum motif for fibrillization. ${ }^{7,124-126}$

The repeating 3D structures of these amyloids are composed of many (usually hundreds to thousands) copies of a peptide/ protein. As discussed earlier, at the atomic level amyloids are arranged in a one-dimensional ordered cross- $\beta$-sheet motif, which consists of two or more layers of intermolecular $\beta$-sheets that run along the fibril axis. ${ }^{127}$ The polypeptides often 

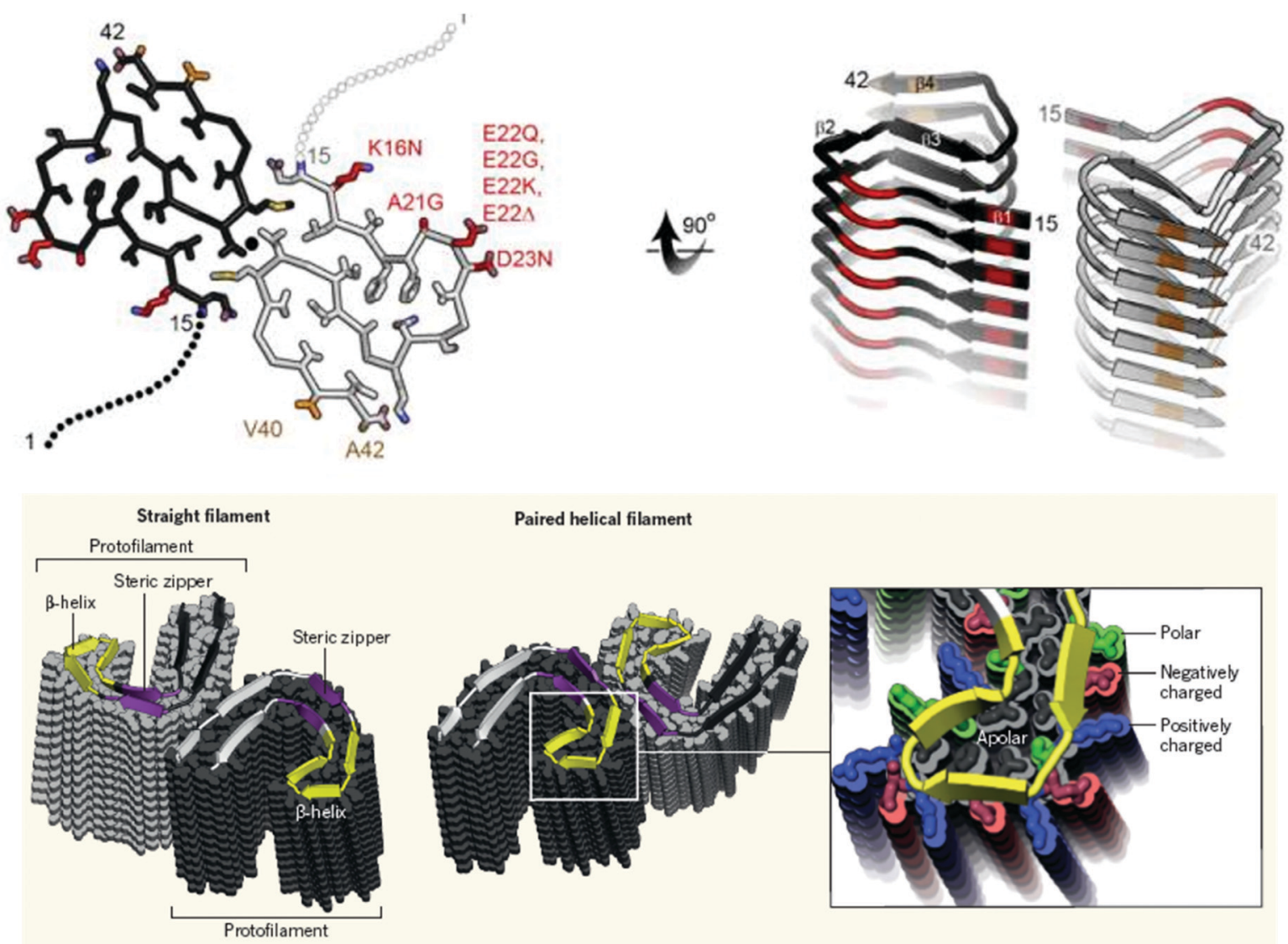

Fig. 6 Example ssNMR and cryoTEM structures for amyloid fibrils. Upper panel: ssNMR structure of A 442. ${ }^{97,98}$ Two S-shaped molecules of A 442 (black and gray) are related by a twofold axis (marked by a circle), which runs down the center of the fibril. The $\mathrm{N}$-terminal 14 residues are disordered; one possible conformation is shown here by dotted lines. Many of the known hereditary mutations are carried by residues located on the outer surface (red). The surface hydrophobic patch formed by residues V40 and A42 (orange) may explain the greater rate of secondary nucleation by the 1-42 species compared with 1-40.99,100 Bottom panel: CryoTEM structures of two amyloid fibrils of Tau. ${ }^{101}$ These two polymorphs of Tau amyloid fibrils were purified from the autopsied brains of AD patients. In both polymorphs, individual Tau proteins form C shapes, as shown by the cartoon ribbons with arrows that lie nearly in a plane perpendicular to the fibril axis. The protein layers are stacked up to form a protofilament. For each polymorph, there are two protofilaments, but they meet at different interfaces. Steric zippers are noted in the straight filament polymorph. The $\beta$-helical feature is enlarged in the right-hand panel where it is shown in yellow. ${ }^{102}$ Reproduced with permission from ref. 100, copyright 2016 National Academy of Sciences. ${ }^{100}$ Reproduced with permission from ref. 101, copyright 2017 Springer Nature. ${ }^{101}$ Reproduced with permission from ref. 102, copyright 2017 Annual Reviews. ${ }^{102}$

render unbranched fibrils, $6-12 \mathrm{~nm}$ in width and up to several micrometers in length, ${ }^{128}$ and are in general composed of several protofilaments. ${ }^{129}$ The protofilaments may twist around each other but not exclusively in a left-handed fashion. Straight fibrils composed of several filaments as well as right-handed fibrils have also been documented, though rarely for the latter. ${ }^{130}$ The left-handed twist is attributed to the underlying $\beta$-sheet secondary structure conformation composed of L-amino acid residues (correspondingly, amyloids composed of peptides of synthetic D-amino acids are usually right handed), although the transfer of chirality of amyloid fibrils across length scales is not conclusively solved, since protofilaments of a given handedness may merge to form mature amyloid fibrils of opposed handedness. ${ }^{131}$ Irrespective of the final handedness, a full rotation of a filament within a fibril may be in the order of tens to several hundred nanometers requiring a $\sim 0$ to a few degrees of rotation per $\beta$-strand. This imposes a limitation on the twist periodicity as the hydrogen bond network of the $\beta$-sheet important for the stabilization of the 3D structure is slightly perturbed by the twist.

In general, the twist of amyloid fibrils results from propagation of the chiral $\beta$-sheet secondary structure to higher hierarchies, and thus is intrinsically related to the topology of the fibrils; yet extrinsic parameters have also been found to contribute to the overall observed twist. For example, the charged side chains on the fibrillar surface induce a torsion per unit length which is directly proportional to the overall charge. Since the extent of this kind of charge repulsion can be tuned by salt concentration and composition of the buffer medium, the twist periodicity can be manipulated by the salt concentration of the system under study, as demonstrated for $\beta$-lactoglobulin first grown at a low ionic strength and then exposed to a high ionic strength post fibrillization. ${ }^{132,133}$ According to this scenario, the "electrostatic" contribution to the twist can be relaxed by screening electrostatic 


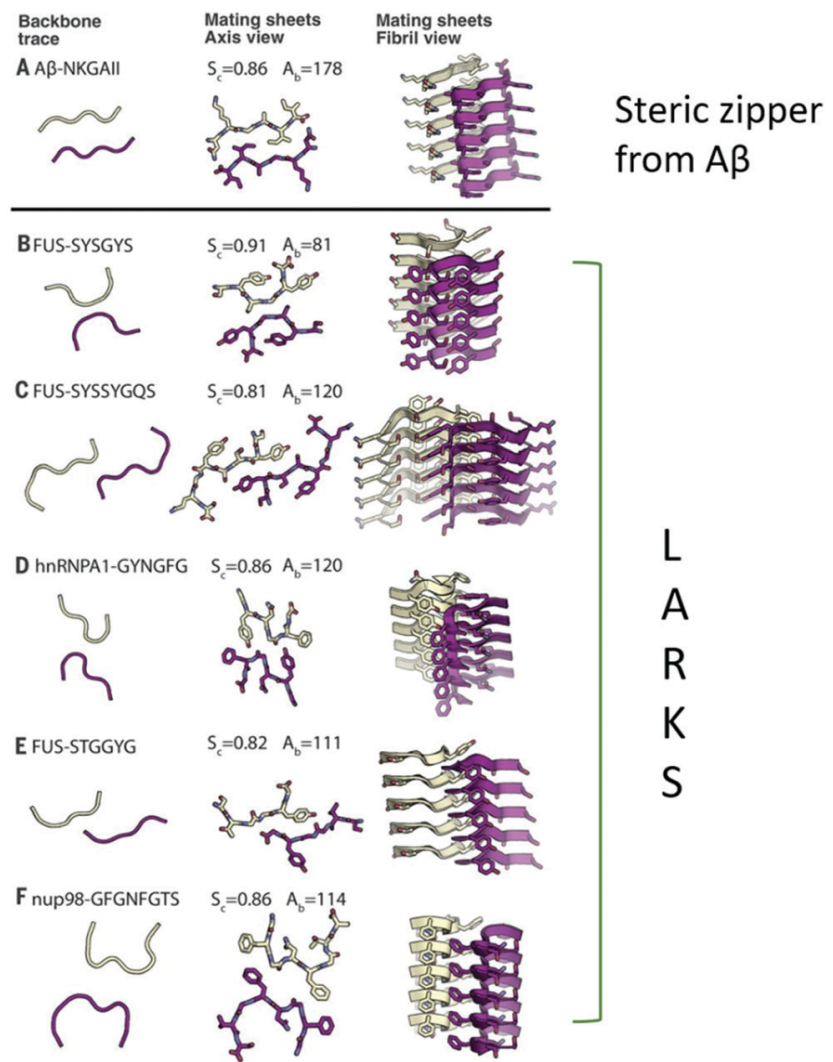

Fig. 7 Atomic-resolution crystal structures of five LARKS contrasted with the structure of a steric zipper from the segment with sequence NKGAll from $A \beta$. The right-hand column shows the paired $\beta$-sheets of the steric zipper at the top and of the five LARKS below. For each structure, five layers are shown of the thousands in the crystals, with the fibril axes vertical. The view in the middle column is down the fibril axis and shows all atoms of the interfaces. The view in the left column is also down the fibril axis and shows the tracings of the protein backbones. The tight interface of the steric zipper offers a strong interaction. The kinked interfaces of the LARKS are weaker. Each interface is characterized by its shape complementarity score ( $\mathrm{SC}=1.0$ for perfect complementarity) and buried solventaccessible surface area $(A \beta)$ in $\AA^{2}$ between the mated sheets. Nitrogen atoms are blue, and oxygen atoms are red. ${ }^{123}$ Reproduced with permission from ref. 123, copyright 2018 American Association for the Advancement of Science. ${ }^{123}$

charges via the presence of salts or buffers, until nearly complete untwist of the fibrils is achieved. The same scenario was observed for the functional amyloid hormone $\beta$-endorphin grown in the presence and absence of NaCl: while the fibrils were flat when grown in salt, they appeared twisted when grown in the absence of salt albeit displaying practically the same $3 \mathrm{D}$ atomic structure resolved by ssNMR spectroscopy. ${ }^{134}$

The twist periodicity may vary between fibrils within the same sample and, to some extent, even within a single fibril. In the same sample there may be both straight fibrils as well as twisted fibrils, sheet-like structures, as well as helical ribbons (see below for definitions, as well as Fig. 8). These heterogeneous morphologies are at the core of the so-called "mesoscopic polymorphism", which arises from distinct structures at the atomic level (also referred to as "molecular polymorphism"), ${ }^{113}$ distinct protofilament packings, ${ }^{113}$ local salt concentrations during the nucleation events, or distinct nucleation sites on heterogeneous surfaces. The origin of the polymorphisms is therefore attributed to the (local) environmental conditions, but may also indicate a kinetically trapped origin of the amyloid. ${ }^{135}$ Nonetheless, the large amount of polymorphism that can be observed at the mesoscopic level, as exemplified by A $\beta 40$, is regarded both a typical property as well as a conundrum of amyloids.

In detail, the mesoscopic polymorphism of amyloid fibrils includes various topologies which can be classified directly by the mean $(H)$ and Gaussian $(K)$ curvatures of the amyloid fibril surface, defined as:

$$
H=\frac{1}{2}\left(c_{1}+c_{2}\right) ; \quad K=c_{1} c_{2},
$$

where the two principal curvatures, $c_{1}$ and $c_{2}$, are the inverses of the main radii of curvatures $R_{1}$ and $R_{2}$ describing the surface at each point. Helical ribbons can approximately be wrapped around a cylinder of radius $R$ and at every protofilament, the principal curvature are $c_{1} \approx \frac{1}{R} ; \quad c_{2} \approx 0$; helical ribbons are therefore characterized by $H \approx \frac{1}{2 R} ; \quad K \approx 0$. In twisted ribbons, the situation is quite different. Bending of protofilaments is very small, and external protofilaments must describe helical trajectories which introduce an increasingly large stretching when moving from the center to the external protofilaments, as recently described in the context of the morphogenesis of other topological objects, including plant leaves. ${ }^{137}$ Since the mesoscopic bending of twisted ribbon amyloids is minimal, these objects are well approximated by $H \approx 0$, whereas $K$ deviates from zero, due to a torsion which is a function of the width-to-thickness ratio of the ribbon. ${ }^{138}$ Thus, the twisted ribbon topology is well described by the geometry of a helicoid, i.e. the ruled minimal surface in between the helical trajectories of the two external protofilaments placed at a distance $R$ from the central axis. For such a ruled minimal surface, $H=0$ and $K=-\left[\frac{P}{2 \pi} /\left(\left(\frac{P}{2 \pi}\right)^{2}+R^{2}\right)\right]^{2}$, where $P$ is the full pitch length (periodicity) of the twisted ribbon. Since in amyloid twisted ribbons generally $P \gg R{ }^{133,139}$ this can be further approximated by $H \approx 0$ and $K \approx-\frac{1}{(P / 2 \pi)^{2}}$. The combined negative Gaussian curvature and zero mean curvature endow twisted ribbons with saddle-like topological features. In contrast, flat ribbons and amyloid crystals (achiral, no twist) both possess $H=0 ; K=0$ by definition. Nanotubes are topologically similar to helical ribbons, and the exact relation $H=\frac{1}{2 R} ; \quad K=0$ holds for them.

The overall elastic energy per unit length of amyloid fibrils is a complex interplay of torsional and bending energies, ${ }^{20,21}$ whose contributions change differently with the lateral dimensions of amyloid fibrils. As a consequence, different structures of amyloid fibrils are found as a function of the number of constitutive protofilaments: at a critical width to thickness ratio or for a specific number of protofilaments, a transition from 


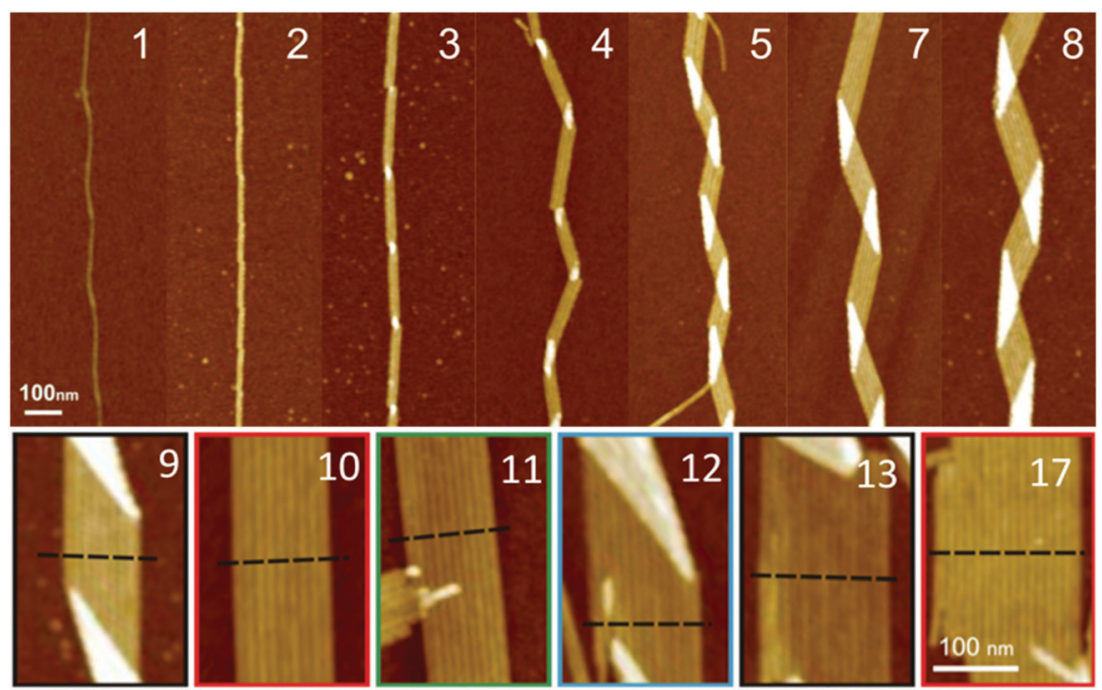

Fig. 8 Structure of amyloid fibrils as a function of the constitutive number of protofilaments in HEWL lysozyme as observed by AFM. The number of protofilaments is indicated in each panel. Up to 3 protofilaments, the fibrils remain straight and in a twisted ribbon configuration $(H=0)$. Starting from 4 protofilaments, amyloid fibrils change into a helical ribbon configuration, as revealed by the characteristic zig-zag contour shape associated with a nonzero mean curvature $(H \neq 0)$. Reproduced with permission from ref. 136, copyright 2011 American Chemical Society. ${ }^{136}$

twisted to helical ribbons occurs, ${ }^{136}$ in analogy to the behavior observed for chiral liquid crystalline films undergoing similar transitions at a critical film width ${ }^{138}$ or leaves undergoing identical twisted-helical ribbon transition for a critical differential strain. ${ }^{137}$ In other words, in a twisted ribbon morphology, the twist periodicity itself limits the number of protofilaments per fibril possible, as the outer protofilaments must go a longer way around the central one. A consequence of this fact is that the number of protofilaments per fibril in a twisted ribbon is approximately proportional to the twist periodicity and actually appears to be proportional to the twist periodicity for fibrils with several protofilaments. ${ }^{133,139}$ Conversely, in a helical ribbon, no universal feature relating the periodicity to the number of protofilaments is observed. This is because helical ribbons can close into nanotubes, thereby reducing the line tension of external protofilaments by virtually maintaining their mean curvature $H$ unchanged and rendering them a metastable precursor to nanotubes. Fibrils composed of two to several protofilaments have been documented. In the case of straight fibrils or helical ribbons, however, the number of protofilaments or ribbons may increase significantly towards a sheet-like entity composed of up to 10 or more filament entities, ${ }^{136,140}$ with a record-large number of protofilaments in a single flat amyloid ribbon reported for the case of the R3 fragment of Tau protein. ${ }^{141}$

Recent studies of the elastic energies of twisted ribbons, helical ribbons, nanotubes, flat ribbons and crystals ${ }^{21}$ have allowed positioning each of these polymorphs in a relative scale of energy (Fig. 9, right panel). Specifically, the absolute minimum in the free energy of the protein folding landscape previously attributed to amyloid fibrils has been refined into a series of relative minima where each polymorph has a specific energy level. ${ }^{20,21}$ Twisted ribbons occupy a relative minimum in the protein folding energy landscape and must overcome a precise energy barrier to fully untwist and enter the absolute minimum occupied by (achiral, untwisted) amyloid crystals; helical ribbons need to overcome a larger energy barrier to fully untwist and enter the same minimum as amyloid crystals: the extra energy barrier compared to the amyloid twisted ribbons is provided by the twist-bending coupling energetic term existing for helical ribbons but missing for twisted ribbons. Accordingly, no helical ribbon-amyloid crystal transitions have yet been observed, whereas twisted ribbon-amyloid crystal transitions have been well documented. ${ }^{20}$ Because the energy level of a fully untwisted helical or twisted ribbon is equivalent, this places helical ribbons on a lower energy level than twisted ribbons. Thus, rather than overcoming this larger energy barrier, helical ribbons tend to further evolve by closing into nanotubes, which are further down the energy level reduced by the line tension associated with the external protofilaments found in helical ribbons. Only flat amyloid crystals, for which the translational symmetry associated with a lack of macroscopic chirality accepts reduction of surface tension by lateral aggregation, are allowed to (indefinitely) sink into an energy minimum funnel which is associated with the ground state of the protein folding landscape.

A question rises spontaneously of why amyloid crystals which are postulated the ground state in the protein folding energy landscape, are so rarely observed in vivo. As already observed by Adamcik et al., ${ }^{21}$ the protein folding process in vivo occurs in non-conservative energy ensembles, with energy injected into and/or dissipated by the system during biological processes and with chaperone proteins assisting protein folding. This is in stark contrast to in vitro processes, where the lack of chaperone proteins and the closed (conservative) ensemble allow revealing the presence of amyloid crystals.

\section{Primary and secondary nucleation}

The formation of amyloid structures from a solution of peptide or protein molecules can be viewed as a phase transition where 


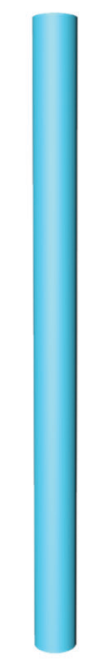

Nanotubes

$H=\frac{1}{2 R} ; K=0$

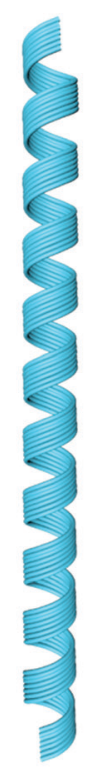

Helical Ribbon $H \approx \frac{1}{2 \mathrm{R}} ; K \approx 0$

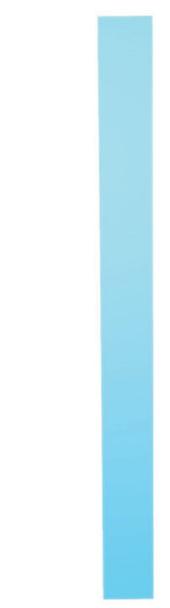

flat ribbon, crystals $H=0 ; K=0$
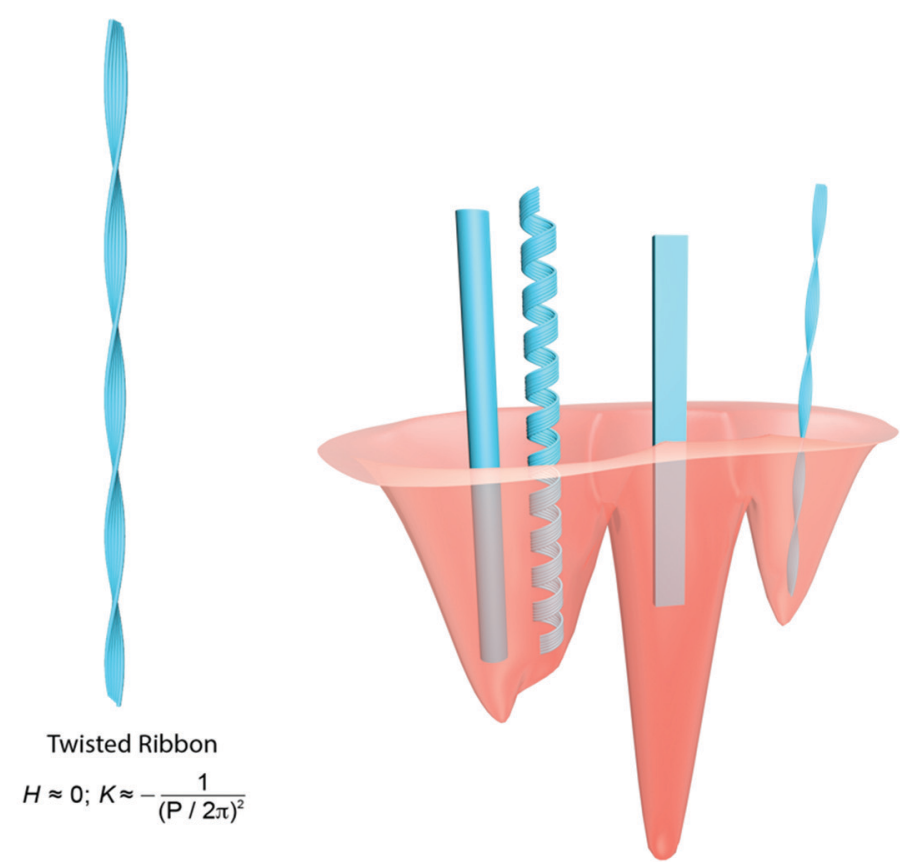

Fig. 9 (left) Schematic representation of the main mesoscopic polymorphs observed for amyloid fibrils and their approximate mean $(H)$ and Gaussian $(K)$ curvatures. (right) Sketch of the protein folding landscape in the region around the amyloid minimum: different polymorphs occupy different energy levels, with amyloid crystals populating the absolute minimum. The right panel is redrawn with permission from Adamcik et al. ${ }^{21}$ Reproduced with permission from ref. 21, copyright 2018 Wiley- $\mathrm{VCH}^{21}$

a more ordered phase is formed within a less ordered solution phase. Much attention has focused on the very early stages of the formation of the amyloid phase. In general, the formation of a new phase can be triggered either through spinodal decomposition or nucleation. Spinodal decomposition takes place under conditions where the solution phase is unstable and even small density fluctuations are amplified and the formation of a new phase takes place very rapidly. By contrast, nucleation takes place under conditions where the solution phase is metastable rather than unstable; this situation arises when the newly formed phase has a lower free energy than the soluble phase, but kinetic barriers slow down its initial formation. The early stages of amyloid formation have been found to follow the physics of nucleated processes. ${ }^{142,143}$ The stability of the amyloid phase is determined by the thermodynamic solubility of the amyloid forming protein; this is the critical concentration $C_{\mathrm{c}}$ that remains in equilibrium with the amyloid phase, and is in turn directly related to the standard free energy $-\Delta G$ of transfer from the solution to the amyloid phase, $C_{\mathrm{c}}=\exp \left(-\Delta G / k_{\mathrm{B}} T\right)$, where $T$ is the temperature and $k_{\mathrm{B}}$ the Boltzmann constant. As such, when the concentration of soluble protein remains below the critical concentration, there is no thermodynamic driving force for forming the amyloid phase. When this threshold is exceeded, the amyloid phase is now more stable than the solution phase, and slow nucleation can take place. Once an initial fibril has been formed, further monomeric protein molecules can add on at a much faster rate, a feature which is common to nucleation-growth phenomena in nature, a special case of which is nucleated polymerization which results in elongated structures such as amyloid fibrils. ${ }^{144}$

There is a rich history of studies focusing on elucidating the principal features of nucleated polymerization. Much of the early work was carried out in the context of understanding the polymerization of cytoskeletal filaments, including actin and tubulin, which have a similar linear geometry to amyloid fibrils. ${ }^{146}$ Studies in the 1960 s established the principal features of this type of process, including the fact that for early times $t$ the increase in the aggregate mass $M$ follows generically a polynomial behavior $M \sim t^{n}$, where $n=2$ for simple nucleated polymerization and can have a higher value when the nucleation process is multi-step in nature. ${ }^{146}$ An important feature of this type of classical nucleated polymerization is that there is only a weak lag phase due to the polynomial time dependence.

Commonly, however, for amyloid formation, the reaction starts with a very marked lag phase during which no or only very low concentrations of aggregates are detected. After the lag phase, the growth and formation of new amyloid fibrils takes place rapidly; this type of process has therefore the features of a highly cooperative transition, where the presence of aggregates facilitates the formation of further aggregates. A central challenge therefore in the mechanistic studies of amyloid formation is to relate the macroscopic observations of protein aggregation to the underlying microscopic mechanisms. A powerful tool in this context is chemical kinetics, a formalism that captures a series of molecular events into a rate law that describes the overall progress of the reaction (Fig. 10A). Application of chemical kinetics to protein aggregation has revealed that in many cases the apparent high level of cooperativity originates from a 

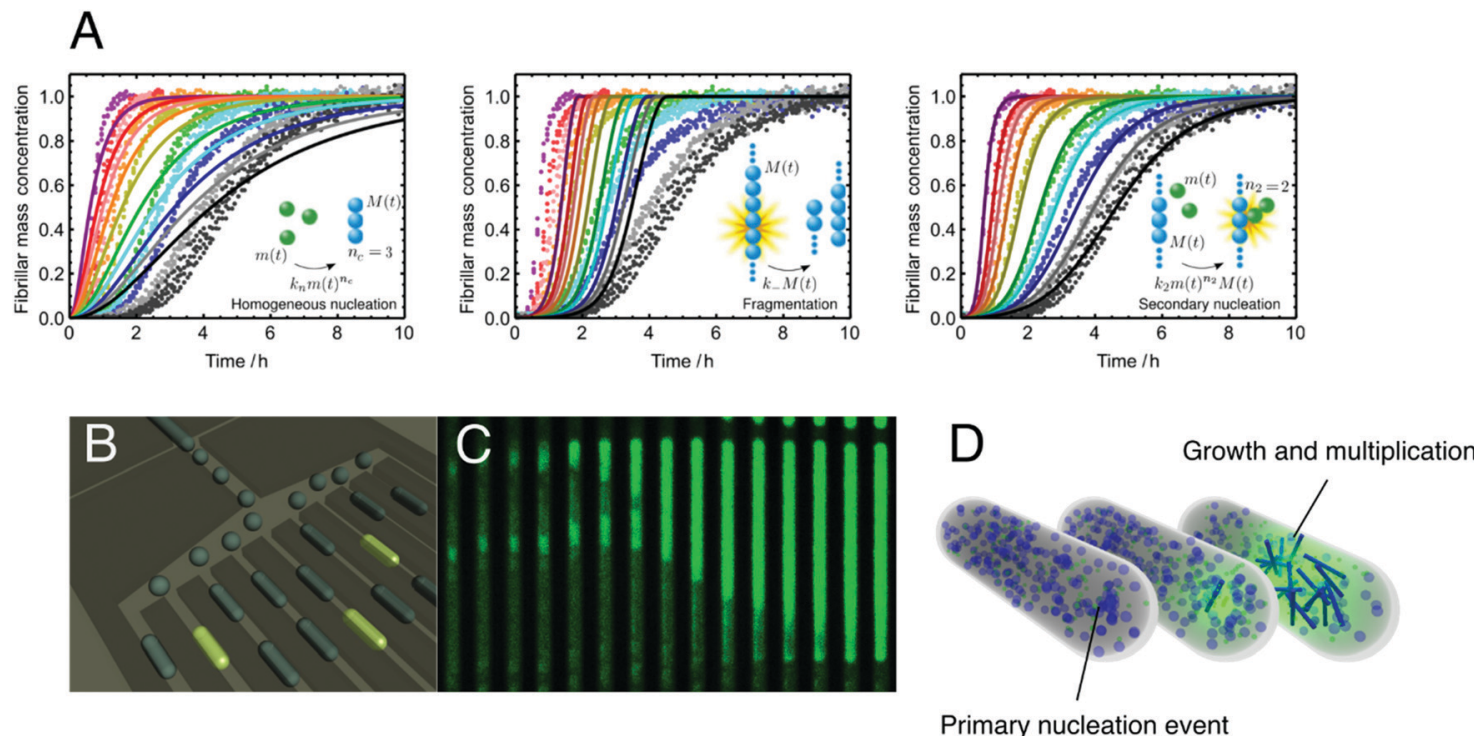

Fig. 10 Primary and secondary nucleation and their verification with microfluidics. (A) Illustration of the power of chemical kinetics to elucidate microscopic mechanisms. Experimental data for the aggregation of the A 42 peptide fitted to an integrated rate law where the dominant source of new aggregates is, from left to right, primary nucleation, fragmentation and secondary nucleation, respectively. (B) Schematic illustration of the microfluidic strategy to detect directly single primary nucleation events and monitor the aggregation reaction in both time and space. (C) Time-lapse microscopy of a single microdroplet trapped in the array shown in panel B. (D) Schematic illustration of the primary and secondary nucleation events and subsequent aggregate multiplication which can be measured directly in microfluidic experiments. Reproduced with permission from ref. 16, copyright 2013 National Academy of Sciences. ${ }^{16}$ Panels B-D adapted from ref. 145, copyright 2011 National Academy of Sciences. ${ }^{145}$

non-classical secondary nucleation process. ${ }^{16,147,148}$ In secondary nucleation, the existing amyloid fibrils act as catalytic surfaces for the formation of new amyloid nuclei which can then grow further themselves. This type of process was originally described for crystal nucleation where under many conditions growing crystal faces can favour the formation of new nuclei. Secondary nucleation was also found to be the key process controlling sickle haemoglobin polymerization, ${ }^{149}$ a non-amyloid related pathological protein assembly process. It has now been identified as a key mechanism for the formation of amyloid fibrils from systems as diverse as $\mathrm{A} \beta 40,{ }^{147} \mathrm{~A} \beta 42,{ }^{16} \alpha \mathrm{S}^{148}$ and hIAPP. ${ }^{150}$ Recent evidence suggests that the sites for secondary nucleation and growth are distinct and that secondary nucleation takes place preferentially at the sides of amyloid fibrils. ${ }^{151}$

The existence of secondary nucleation challenges a number of intuitive assumptions about amyloid formation, and perhaps most strikingly that of the nature of the lag phase. Indeed, under conditions where secondary nucleation is a dominant factor, the lag phase is only very weakly dependent on the time to form the initial nuclei, but rather depends on the rate at which these nuclei can grow through elongation and multiply through secondary nucleation. ${ }^{152,153}$ This observation implies that primary nucleation can be very challenging to study in bulk systems as it has only a very weak effect on the overall kinetics. This picture changes, however, when aggregation takes place in very small volumes, a regime that can be probed through droplet microfluidics (Fig. 10B-D). Microfluidic experiments have allowed the study of single nucleation events, as well as the rate at which amyloid conformations of proteins can propagate in space and time from the site of the original nucleation event. ${ }^{145}$
The role of secondary nucleation in the development of amyloid diseases remains an active area of investigation. There are indications that this process could be key in generating toxic oligomers that are responsible for neuronal death associated with the aggregation of the $A \beta$ peptide in the central nervous system. ${ }^{154}$ Indeed, microscopy studies have revealed that the concentration of oligomers is highest in the vicinity of higher molecular weight aggregates such as plaques. ${ }^{155}$ If the formation of such oligomers was driven by primary nucleation, their concentration would be lowest in the vicinity of plaques as the latter can sequester monomer through their growth, thus leaving less monomer available for primary nucleation. Secondary nucleation, by contrast, is highest in locations which contain both monomer and aggregates, ${ }^{16}$ in agreement with experimental observations of oligomer localization in vivo. These considerations highlight secondary nucleation therefore as a potential new target for curtailing the accumulation of $\mathrm{A} \beta$ oligomers in vivo. Finally, it has become apparent that nature has evolved molecular chaperones that are able to inhibit secondary nucleation in a highly specific and effective manner. ${ }^{154}$ This inhibition has furthermore been shown to lead to a significant reduction in toxicity associated with protein aggregation, even when the overall concentration of aggregates is not affected, as it significantly reduces the concentration of oligomeric species.

\section{The "oligomer hypothesis"}

The lack of tools that allow visualizing the different stages of amyloid formation led initially to the thinking that amyloid formation was a two-state process that involved the conversion 
of soluble native proteins into highly ordered cross- $\beta$ sheet fibrillar structures, similar to the polymerization of tubulin monomers into microtubules. Hence, the original versions of the amyloid hypothesis stipulated that amyloid diseases were caused by the formation and accumulation of amyloid fibrils in the brain or other affected organs. ${ }^{156}$ However, several consistent pathological observations suggested that amyloid fibrils may not be the culprits and led to reconsideration of this hypothesis. ${ }^{157-161}$ These observations include: (1) amyloid fibrils derived from different proteins were found in the post mortem tissues of individuals who died without exhibiting any symptoms of amyloid diseases; ${ }^{162}$ (2) the amyloid load did not always correlate with disease onset or severity; (3) several studies did not find a clear correlation between the extent of fibril formation and neurodegeneration in $\mathrm{AD}$ animal models; ${ }^{163-165}$ and (4) therapeutic interventions that successfully cleared amyloid plaques in humans did not result in reversal or improvement in clinical symptoms of $\mathrm{AD} .{ }^{166,167}$ The emergence of these findings coincided with reports from biophysical studies on $\mathrm{A} \beta$, the key component of amyloid plaques, suggesting that amyloid fibril formation may be more complex than initially thought and involves the formation of protein assemblies other than the amyloid fibrils.

The ability to generate amyloid fibrils in cell-free systems has provided unique opportunities to investigate and dissect the mechanisms of amyloid formation. These studies, performed on $A \beta$ peptides by the Teplow and Lansbury groups, ${ }^{168,169}$ revealed for the first time that amyloid formation did not follow a twostate mechanism but rather occurred through a series of soluble oligomeric intermediates of variable size and morphologies. The observation that these oligomeric intermediates disappeared upon fibril formation suggested that they were on pathway to amyloid formation. As of today, oligomers have been observed during the fibrillization of nearly all amyloid-forming proteins, suggesting that they are obligate intermediates on pathway to amyloid formation.

Although the great majority of studies have focused on characterizing oligomers that form on the pathway to amyloid formation, increasing evidence suggests that oligomers could also form through fibril-mediated mechanisms or during processes aimed at promoting fibril clearance. Several studies have suggested that oligomers could form during the disassembly or fragmentation of fibrils or upon their interactions with membranes. ${ }^{170-172}$ The surfaces of fibrils have also been shown to nucleate the formation of oligomers via secondary nucleation mechanisms. ${ }^{173,174}$ Furthermore, it has also been proposed that amyloid plaques and proteinaceous inclusions may also serve as reservoirs for toxic oligomers. ${ }^{175-179}$ However, whether oligomers are simply sequestered during the formation of amyloid-rich deposits/ inclusions, represent the byproducts of cellular process aimed at dissociating and clearing fibrils, or are formed within these deposits/inclusions remains unknown.

Together, these observations sparked a huge interest in the field because they offered a possible explanation for the lack of correlation between amyloid load and disease onset or severity. This gave rise to an alternative amyloid hypothesis, the oligomer hypothesis, which stipulates that oligomeric prefibrillar intermediates, rather than the amyloid fibrils, are the primary cause of toxicity and cell death in $\mathrm{AD}, \mathrm{PD}$ and systemic amyloid diseases.

Oligomeric intermediates on pathway to amyloid formation are by definition transient in nature, as already largely discussed above in the context of the protein folding landscape. They do not accumulate and are usually converted rapidly to higher order aggregates, and eventually to fibrils. Although it is possible to capture and detect oligomers during the process of amyloid formation using imaging techniques such as AFM or TEM, isolation of such oligomers during the fibrillization process has proven to be difficult for most proteins. To address this challenge, several protocols have been developed to enhance oligomer formation and/or slow their conversion to fibrils by manipulating solution condition or the use of mutant forms of the proteins that exhibit higher propensity to aggregation (e.g. $\mathrm{A} \beta 42$ vs. $\mathrm{A} \beta 40$ and variants linked to early onset or severe forms of relevant amyloid disease). Other protocols relied on the use of chemical or radical-mediated crosslinking approaches to trap and/or stabilize transient oligomers to facilitate their characterization or isolation. ${ }^{180-186}$

At the structural level, on-pathway oligomers tend to exhibit a mixture of secondary structure contents, ${ }^{187-189}$ often dominated by $\beta$-sheet conformations. ${ }^{190}$ Compared to amyloid fibrils, oligomeric intermediates of most amyloid forming proteins exhibit weak binding to the amyloid specific dyes thioflavin T/S (ThT/S) and Congo red, ${ }^{191,192}$ suggesting that they have not acquired the cross- $\beta$ structure that is characteristic of amyloid fibrils, although studies on $A \beta$ oligomers using $\mathrm{X}$-ray fiber diffraction have suggested that some oligomers possess cross- $\beta$-like conformations. ${ }^{193}$ Unlike amyloid fibrils, which despite their polymorphism still share a common core structure, cross- $\beta$ sheet, amyloid oligomers exhibit large differences in their dynamic properties and structural diversity, suggesting that it is unlikely that one specific molecule or antibody would recognize all types of oligomers formed by one protein. In 2003, Kayed et al. reported that it was possible to generate antibodies that not only recognized different types of oligomers and but also oligomers derived from different amyloid proteins (A $\beta$, hIAPP, $\alpha \mathrm{S}$ and Tau) and suggested that amyloid oligomers derived from these proteins shared common structural features. ${ }^{194}$ This hypothesis was supported by subsequent findings showing that oligomeric preparations from these amyloidogenic proteins were toxic to cells and neurons. However, subsequent studies by Glabe and colleagues and other groups revealed that the different aggregate and oligomer specific antibodies stained different types of pathological aggregates in the brain and that there was no universal antibody capable of recognizing all type of A $\beta$ oligomers. ${ }^{195-197}$

The heterogeneity and dynamic properties of the oligomers have thus precluded studies aimed at resolving their structural properties at the atomic level. Oligomers rapidly interconvert between different forms and exhibit high propensity to transition to higher order aggregates, thus making it difficult, if not virtually impossible, to isolate and investigate the structural, 
functional and toxic properties of a single oligomeric species. Several attempts have been made to achieve this goal, but without any success. The use of sequential chromatography separation methods or other protein separation techniques has enabled the generation of oligomer preparations that are enriched in specific morphologies, ${ }^{169,187,198-201}$ but generation of homogeneous preparation consisting of one oligomeric species of a defined size and morphology has not been possible. This explains why, despite two decades of active research, it has not been possible to ascribe toxicity to a specific oligomeric entity or develop tools and strategies that target distinct types of oligomers. Furthermore, the diversity of the protocols used to produce oligomers, which leads to oligomer preparations of different size, structure and morphology distribution, combined with the lack of tools and methods that enable precise assessment of oligomer heterogeneity, has made it difficult to compare and reproduce results across different laboratories. Despite these challenges, such oligomer preparations have been used to gain insights into the dynamic properties of oligomers and to elucidate the sequence and structural determinants of oligomer formation and stability using solution and ssNMR, hydrogen deuterium exchange methods and other biophysical techniques. ${ }^{189,202-208}$

\subsection{The amyloid pore}

Among all the different types of amyloid oligomers and prefibrillar aggregates that have been isolated, the only type of oligomers that suggest a specific mode of action and mechanism of toxicity are the annular pore-like oligomers, which have been observed for most amyloid forming proteins. Annular pore-like oligomers have been observed during the aggregation of both disease-associated (e.g. A $\beta$ peptides, ${ }^{18,198,209} \alpha \mathrm{S}$, SOD1 ${ }^{209}$ exon1 of the huntingtin protein, Tau, ${ }^{210} \mathrm{TTR}^{211}$ and serum amyloid $\mathrm{A}^{212}$ ) and non-disease-associated amyloid forming proteins. ${ }^{213-218}$ They have been found in the absence of membranes and also upon addition to lipid bilayers or reconstitution of amyloid proteins and peptides with membranes. Furthermore, several AFM studies have provided direct evidence of amyloid-pore formation in synthetic vesicles or membrane mimics by several amyloid forming proteins. ${ }^{219-223}$ Their shape and dimensions, combined with extensive literature demonstrating that $A \beta$, hIAPP and other amyloid proteins exhibit channel-like activity on membranes, ${ }^{219,222,224-226}$ have led to the amyloid-pore/channel hypothesis, which suggests that channel/pore formation represents one of the key mechanisms by which oligomers cause toxicity and cell death in amyloid-related diseases. Evidence in support of this hypothesis comes primarily from in vitro studies. For example (1) mutations linked to early-onset $\mathrm{AD}$ and $\mathrm{PD}$ promote the formation of amyloid pores and increase the channel and membrane permeabilization activity of $A \beta$ and $\alpha S$; (2) mimicking cellular stress conditions associated with neurodegenerative diseases, such as oxidative stress and metal induced oxidation also promotes the formation of annular pore-like structure $;^{209}$ and (3) several amyloid oligomers exhibited channel-like activity and size-selective membrane permeabilization. ${ }^{227,228}$ Structurally, several studies have shown that amyloid pore oligomers or oligomers that exhibit channel-like activity exhibited $\beta$-sheet rich conformations that were distinct from that of mature fibrils. ${ }^{187,229,230}$ Although different types of oligomeric preparations of $A \beta$ induced calcium uptake and disruption of ion homeostasis in cells, the exact mechanisms by which these preparations exerted their effects on cellular membranes remain unclear.

\subsection{Toxic oligomers}

The search for a toxic oligomer species has been the focus of active research in both academia and industry. The hope is that identifying a specific toxic species will pave the way for developing novel therapeutic drugs and antibodies that prevent their formation, induce their disassociation or block their activity. During the past two decades, many studies have shown that amyloid oligomers induce different types of toxic insults when added to different types of cells, organotypic slice cultures or injected into rodent brains. The extent and type of toxicity observed vary depending on the size distribution of oligomers and the assay and model systems used to assess their toxicity. However, for all amyloid-forming proteins, the nature of the oligomeric toxic species associated with each disease and their mechanism of action remain elusive. In addition to the complexity and heterogeneity of oligomer preparations, the lack of tools that allow monitoring amyloid oligomer formation and dynamics in cells makes it very difficult to attribute any toxic effects or phenotype directly to specific type of oligomers. The great majority of toxicity assays are based on addition, treatment or injection of in vitro oligomer preparations into culture media or directly into the brain, and toxicity is assessed hours to days or even months after treatment with oligomers. During this time, the extent to which the oligomer preparations retain their original properties or change their conformation and structural properties in response to changes in their environments remains unknown. Therefore, better understanding of the structure-function relationship of amyloid oligomers requires the deployment of assays that allow for rapid assessment of the cellular responses upon treatment with well-characterized preparations of different types of amyloid species.

\subsection{Post-translational modifications}

Post-translational modifications (PTMs) such as phosphorylation, proteolytic cleavage, nitration and ubiquitination play central roles in the aggregation and pathology formation in the majority of amyloid-related diseases, including $\mathrm{AD}, \mathrm{PD}$, Huntington's disease (HD), and prion diseases. Amyloid fibrils, which are among the major constituents of these pathological inclusions are subjected to different types of PTMs, which very often co-occur on the same fibrils. Despite the fact that these modifications are used as pathological markers and antibodies, and assays targeting modified forms of pathological amyloid fibrils are commonly used to assess pathology formation and spread and to monitor disease progression, the role of PTMs in regulating the different steps along the amyloidosis pathway remains poorly understood. The roles of PTMs in amyloid oligomer formation, dynamics and the transition to fibrils have not been investigated. Indeed, all of the amyloid oligomer 
preparation protocols used to investigate amyloid oligomer structure and toxicity are devoid of PTMs because they are usually derived from recombinant and synthetic proteins. Although several studies have reported on the use of oligomers isolated from tissues, cells or model organisms, the biochemical properties of these oligomers and whether or not they are posttranslationally modified have rarely been investigated. Given the increasing evidence demonstrating that PTMs could significantly influence oligomerization, amyloid formation and clearance, it is crucial to devote more attention and resources to map the PTM profiles of native oligomers from human tissues and biological fluids and to assess their effects on oligomer formation, structure and toxicity. It is reasonable to speculate that PTMs may act as molecular switches for regulating the equilibrium between different types of oligomers and/or transitions from oligomers to fibrils. Recent advances in protein synthesis of amyloid proteins have enabled site-specific introduction of single or multiple PTMs into amyloid proteins such as $\mathrm{A} \beta, \alpha \mathrm{S}$, Tau, N-terminal fragments of the HTT protein and the prion protein, among others. Such homogeneously modified proteins can be prepared in milligram quantities, which should enable generation of modified amyloid oligomers with specific PTMs or patterns of PTMs, thus paving the way to elucidate the role of PTMs in regulating oligomer formation, stability, dynamics, and their transition to amyloid fibrils.

\subsection{Evidence for oligomer formation in vivo}

Unlike fibrils which can be easily visualized and characterized by several EM techniques in cells or in pathological inclusions, ${ }^{231-234}$ visualization of oligomers in pathological aggregates remains challenging, as protocols for specific and efficient immunolabelling of oligomers, including amyloid oligomer pores in vivo, in postmortem brain tissues or on biological membranes, are lacking. Evidence for oligomers come primarily from: (1) studies demonstrating lack of correlation between amyloid fibril formation and toxicity, under conditions that favor fibrillization; (2) studies employing oligomer-specific antibodies; and (3) detection of HMW SDS-resistant oligomers by western blots. ${ }^{235}$ Even when solution-based methods such as size exclusion chromatography are used to isolate fractions rich in oligomers, estimations of the size of oligomers are then made on the basis of SDS-PAGE analysis of these fractions, due to the presence of other proteins. Furthermore, we have very limited insight into the biochemical and structural diversity of oligomers in vivo and it remains unclear to what extent the oligomers produced in vitro reproduce the landscape of conformational and quaternary structures of native amyloid oligomers. This is largely due to the fact that oligomers are (1) meta-stable; (2) present in low abundance; (3) heterogeneous; and (4) difficult to distinguish from other proteins in complex biological environments.

Several assays and methods have been developed to measure the level of oligomers in biological fluids, but the level of these oligomers is usually too low to allow interrogation of their size and conformational properties and thus these studies are usually limited to correlating oligomer concentrations to disease progression. One of the most commonly used oligomer-specific immunoassays is based on using the same antibody to capture and detect the amyloid protein of interest. However, these assays do not differentiate between oligomers and fibrils and may not provide an accurate quantitative assessment of oligomer levels due to the lack of the proper calibrants or calibrants that capture the diversity of oligomers in biological samples.

\subsection{Targeting amyloid oligomers}

The lack of correlation between amyloid fibril formation and disease onset and severity in several amyloid diseases combined with increasing evidence of amyloid oligomer toxicity has led to oligomers emerging as one of the primary targets for developing therapies to treat amyloid diseases such as $\mathrm{AD}$ and PD. The field of amyloid oligomers and the toxic oligomer hypothesis was initially driven by research on $A \beta$ peptides mainly because (1) $A \beta$ oligomers could be populated in large quantities; (2) validated protocols for producing $A \beta$ oligomers were quickly developed and made accessible and; (3) the A $\beta$ peptides were also readily accessible through commercial vendors. Despite this, A $\beta$ preparations were still characterized by great variability in terms of their size, structure and morphology distribution. To reduce such variability or enrich oligomers of specific size or structure, heterogeneous preparations were further separated using different protein separation methods. Nonetheless, several academic labs and pharmaceutical companies used such oligomer preparations to develop large number of "A $\beta$ oligomer-specific antibodies", many of which advanced to clinical trials, but none of which has proven to be effective in significantly slowing or reversing the clinical course of AD. ${ }^{236-239}$ The same approaches have been extended to other amyloid proteins such as $\alpha \mathrm{S}$ and Tau, ${ }^{240-244}$ but with limited success thus far, although several antibodies are still being evaluated in different stages of clinical trials (more see Section 7). ${ }^{239,245,246}$ One possible reason for the failure of oligomer-specific antibodies could be the fact that these antibodies may target only one oligomeric form or subset of the different types of oligomers that exist in vivo, ${ }^{247,248}$ or that post-translational modifications on native oligomers may interfere with antibody recognition. To address these limitations, it is crucial to gain more insight into the biochemical and structural properties of native amyloid oligomers and develop strategies that enable isolation and characterization of as many native oligomeric species as possible from patient-derived tissues or biological fluids.

\section{Amyloidosis mitigation in vitro and in vivo}

Amyloidosis originates from protein misfolding, triggered by protein metastasis and abnormal physiological conditions and manifested by the production of protein aggregates possessing rich polymorphism and evolving physicochemical properties. ${ }^{249}$ Amyloid inhibition, in essence, works against the downward free-energy landscape of protein folding and aggregation ${ }^{250,251}$ by stabilizing disordered monomers, driving toxic oligomers and protofibrils off pathway or sequestering them into elimination, 
and remodelling mature fibrils into biologically inert, amorphous aggregates.

The past decades have witnessed active development of mitigation strategies against amyloidosis, involving peptidomimetics (1990's onwards), ${ }^{252}$ monoclonal antibodies (2000's onwards), ${ }^{159}$ small molecules (2000's onwards) ${ }^{253}$ and, more recently, organic and inorganic nanoparticles and nanocomposites (2010's onwards) (Fig. 11). ${ }^{2,254}$ Specifically, peptide inhibitors, such as the $\beta$-sheet breaker $\mathrm{KLVFF},{ }^{255}$ draw inspiration from the structural characteristics of $A \beta^{256}$ to initiate hydrophobic interaction with the latter and act in a chaperone-like manner. However, enzymatic degradation and poor blood-brain-barrier translocation are the notable undoing of this strategy. Monoclonal antibodies, such as Bapineuzumab (Pfizer, J\&J), Aducanumab (Biogen, Eisai), Solanzumab (Eli Lilly) and Ponezumab (Pfizer) targeting the $\mathrm{N}$-terminus, amyloidogenic fragment and $\mathrm{C}$-terminus of $\mathrm{A} \beta,^{257-259}$ failed to pass phase-II/III trials and evoked the question whether amyloidosis inhibition through peptide targeting and clearance is a viable strategy against neurological disorders. Small molecules identified by microarrays, ${ }^{260}$ such as 2,8-bis-(2,4-dihydroxyphenyl)-7-hydroxy-phenoxazin-3-one (O4), ${ }^{253}$ or derived from natural compounds, such as epigallocatechin-3-gallate (EGCG), ${ }^{261,262}$ ameliorated the toxicities of $\mathrm{A} \beta$ and hIAPP in vitro via inhibited (and, occasionally, accelerated) aggregation. A major shortcoming with small molecules, however, is their often limited water solubility and, hence, low bioavailability and poor delivery efficacy.

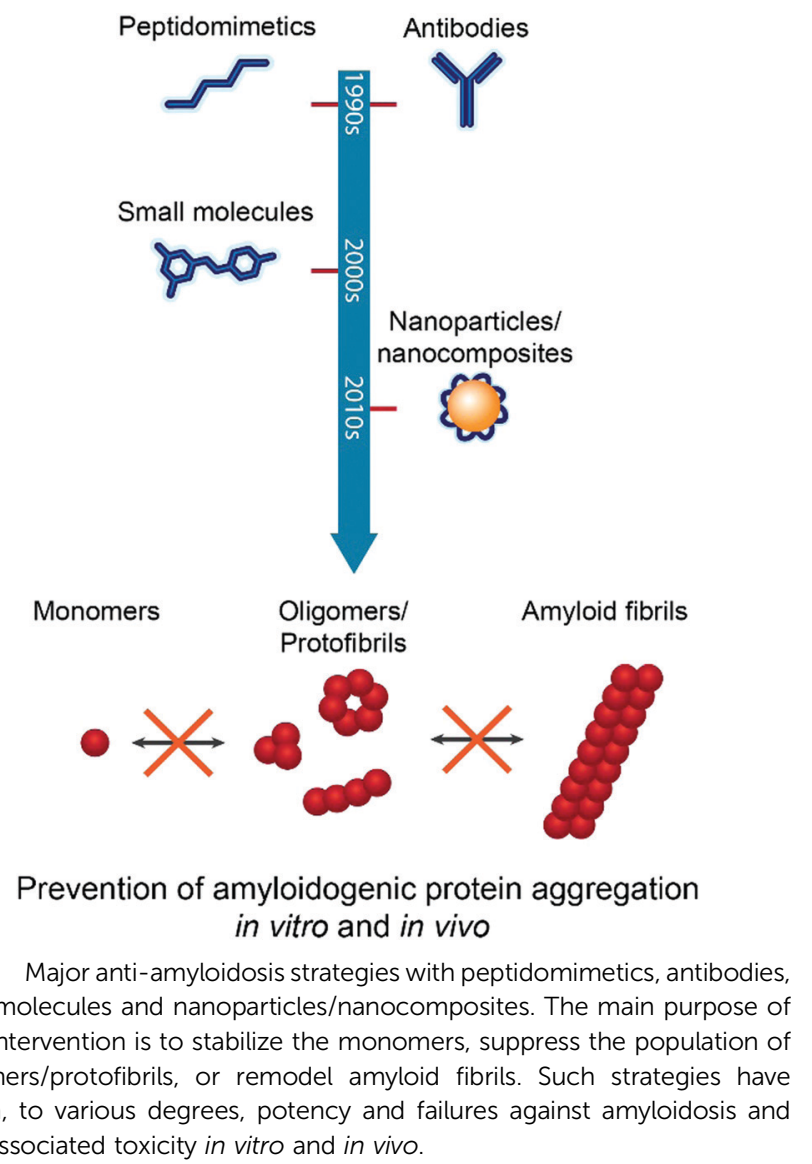

Prevention of amyloidogenic protein aggregation in vitro and in vivo

Fig. 11 Major anti-amyloidosis strategies with peptidomimetics, antibodies, small molecules and nanoparticles/nanocomposites. The main purpose of such intervention is to stabilize the monomers, suppress the population of oligomers/protofibrils, or remodel amyloid fibrils. Such strategies have shown, to various degrees, potency and failures against amyloidosis and their associated toxicity in vitro and in vivo.
Nanomaterials and multifunctional nanocomposites are engineered/synthetic structures possessing versatile surface area, functionality and architecture, and can be tailor-designed to alter protein aggregation and match amyloid in size, morphology and physicochemical properties. As a result, amyloidosis inhibition with biocompatible/biomimetic nanoparticles and multifunctional nanocomposites has become an emerging frontier, driven by the rapid development of nanotechnology and accumulating knowledge on nano-bio interactions. ${ }^{254}$ Simple polymeric nanoparticles, such as dendrimers and star polymers, as well as condensed ceria nanocrystals, graphene quantum dots, graphene oxide, gold nanoparticles, carbon nanotubes, transition-metal dichalcogenide nanosheets (e.g., tungsten disulphide and molybdenum disulphide), multifunctional peptide-polymer nanosweepers, proteinKLVFF-polymers, hIAPP19-29S20G and mesoporous silica nanocomposites, have shown potency in mitigating the amyloidoses and pathogeneses of $\mathrm{A} \beta, \alpha \mathrm{S}$ and hIAPP in vitro and in $\mathrm{AD}, \mathrm{PD}$ and $\mathrm{T} 2 \mathrm{D}$ animal models. ${ }^{23,263-273}$ In recent years, it has been increasingly realized that, as with molecular inhibitors, the endpoint of amyloidosis mitigation with nanoparticles is not necessarily inhibition of protein fibrillization per se, but suppression of protein toxicity. Indeed, accelerated protein assembly may reduce the population of toxic oligomers and protofibrils, ${ }^{253,274}$ analogous to Pmel17 aggregation in melanin synthesis in the skin. ${ }^{275}$ However, no systematic understanding is currently available to predict whether an exogenous substance, nanoparticles included, inhibits or accelerates protein aggregation, and if accelerated protein aggregation leads to a beneficial or a detrimental effect on cell viability.

Experimental studies of amyloidosis inhibition often involve a ThT or Congo red fluorescence assay to assess the cross- $\beta$ content and kinetics in protein fibrillization; ${ }^{276}$ TEM or AFM to characterize the mesoscopic morphology of protein aggregates (see Section 4); CD and FTIR spectroscopies to infer the peptide secondary structure and their time evolution; NMR and beamdiffraction (X-ray crystallography, EM) to reveal the atomic structures of amyloid fibrils (see Section 3); gel electrophoresis, dot blotting and immunohistochemistry to confirm proteininhibitor binding and amyloid/plaque formation; in vitro assays to quantify cell viability and mitochondrial activity in conjunction with alleviated production of reactive oxygen species (ROS); and in vivo assays to target and clear amyloid oligomers, fibrils and plaques via autophagy, ${ }^{277}$ improve cognitive function and mobility, and stimulate recovery of gene dysregulation.

Under in vivo conditions, inhibitors may be administered through systemic circulation, or via direct injection into the brain of transgenic mouse models in the cases of AD, PD and HD. The peripheral circulation of nanoparticle inhibitors, for example, may acquire a plasma protein "corona",278 through nonspecific adsorption, which ascribes a new biological identity to the nanoparticle inhibitors to evade opsonization. Here, the design usually aims at extending the circulation and improving the delivery of the inhibitors. Upon binding with amyloid proteins, nanoparticle inhibitors perturb the aggregation kinetics resulting from nanoparticle-protein interactions in competition with protein-protein self-assembly, mediated by hydrophobic interaction, hydrogen bonding and electrostatic interaction. A major 
indicator of strong amyloid protein-inhibitor interaction is changes induced in the protein secondary structure, which accordingly shift the high $\beta$-sheet contents of protofibrils and fibrils to render disordered structures, coils, or alpha helices. While this strategy may be easily demonstrated in test tubes or cell cultures, binding of inhibitors with amyloid proteins occurs far less frequently in vivo due to the much reduced concentrations of amyloid proteins and inhibitors, environmental $\mathrm{pH}$, as well as binding of the interactants with other intra- or extra-cellular proteins, chaperones/chaperone-like proteins (such as serum albumin), ${ }^{279}$ enzymes, ligands, biometals, membranes and other cellular organelles. Each type of interaction may influence the conformation and/or toxicity of amyloid proteins and impact their associated pathogeneses downstream. Furthermore, it has been shown that hIAPP amyloid fibrils, owing to their strong capacity in initiating hydrogen bonding, can acquire a protein corona in culture medium, enriched mostly by linear proteins and multi-domain proteins of structural plasticity. ${ }^{280}$ The immune response to corona-shielded amyloids and their precursors, however, remains unclear. The nonspecific amyloid proteinenvironmental protein association, further complicated by the transient and heterogeneous nature of the toxic oligomeric species (see Section 6) - with the exception of the structurally better defined $\beta$-barrels which are unfortunately of a small population ${ }^{281}$ - implies that morphology-based in vivo recognition of amyloid oligomers, fragments or plaques may be inherently problematic. In addition, the hallmarks of amyloid pathologies, such as inclusions and plaques, are highly heterogeneous enriched by tens to hundreds of types of proteins and metabolites, ${ }^{282-286}$ including extracellular matrix glycoprotein serum amyloid P (SAP), which is thought to stabilize amyloid from degradation, ${ }^{287-289}$ and membrane-bound heparan sulphate proteoglycans (HSPGs), which mediate A $\beta$ aggregation and cell uptake. ${ }^{290,291}$ The in vivo origin, dynamics and mechanisms of such hetero-aggregation and cross-seeding (see Section 8) are largely unknown, posing a tremendous challenge to the design and implementation of amyloidosis inhibitors targeting multiple amyloid proteins.

In addition to the aforementioned strategies, chiral molecules $^{292-294}$ or nanostructures, ${ }^{295}$ carbon nanotubes coated by sonicated fragments of whey protein $\beta$-lactoglobulin, ${ }^{23}$ gold nanoparticles coated with milk protein $\beta$-casein, ${ }^{296}$ and polyoxometalateDawson derivatives (POMDs) functionalized with histidine-chelating metals (Cu, Fe, Ni, Co and Mn), ${ }^{297}$ have been utilized as inhibitors against amyloidosis in cell cultures and with zebrafish models (embryos, larvae and adults), exploiting the chirality of amyloid fibrils, protein-metal coordination, chaperone-like inhibition of protein aggregation, as well as functional-pathological double protein coronae mediated by hydrogen bonding and $\beta$-sheet stacking. Zebrafish, in particular, have been validated as a high-fecundity alternative to AD, PD and T2D (transgenic) mouse models, ${ }^{298-300}$ and are especially suited for testing a library of nanoparticle inhibitors to render significant statistics at low cost and high throughput. As multiple abnormalities occur in the homeostasis of essential endogenous biometals, ${ }^{301}$ cellular delivery or liberation of biometals $\left(\right.$ e.g., $\mathrm{Zn}^{2+}$ and $\left.\mathrm{Cu}^{2+}\right)$ with functional amyloids ${ }^{24}$ or metal-binding compounds ${ }^{302}$ may offer new breakthroughs against amyloid diseases. Although not directly targeting amyloidosis, personalized antisense oligonucleotide (ASO) therapy against a mutation in RNA-binding protein fused in sarcoma (FUS) is being implemented to ameliorate a severe form of $\mathrm{ALS},{ }^{303}$ a motor neuron amyloid disease. Furthermore, neurotrophic factor (NTF)-based therapies, such as the delivery of cerebral dopamine neurotrophic factor (CDNF), have shown promise in stopping and reversing neurodegeneration. ${ }^{304,305}$

\section{Cross-seeding of amyloid proteins}

Cross-seeding refers to the stimulation of aggregation of one amyloid protein/peptide by another. Fig. 12 contrasts selfseeding (homologous seeding) with cross-seeding (heterologous seeding). This subject has been discussed in previous reviews. ${ }^{306-310}$ In the following, we highlight a number of studies which present important findings or address key challenges on this topic. Cross-seeding has been observed for $A \beta$ with several amyloid proteins including $\alpha \mathrm{S}$, Tau and prion protein PrP. This may be relevant in vivo since co-deposition of $\mathrm{A} \beta$ with PrP occurs in amyloid plaques observed in brain sections from $\mathrm{AD}$ patients. ${ }^{311}$ Studies using transgenic mice that overexpress the amyloid precursor protein and which develop typical amyloid (A $\beta$-rich) plaques show that inoculation with prions leads to a significant enhancement of both the onset of prion disease symptoms and a concomitant increase in the level of misfolded prion protein along with a notable increase in amyloid plaque deposition. $^{312}$ In the same study, in vitro fibrillization kinetics assays also showed substantial acceleration of $\mathrm{A} \beta 42$ fibrillization by $\mathrm{PrP}^{\mathrm{Sc}}$ (aggregated prion protein). ${ }^{312}$ In an early study, double transgenic mice were developed that expressed $\mathrm{A} \beta$ and $\alpha \mathrm{S}$ in neurons, displaying enhanced motor defects compared to single $\alpha \mathrm{S}$ transgenic mice and more $\alpha \mathrm{S}$ neuronal inclusions. ${ }^{313}$ Cell-free studies also showed that $\mathrm{A} \beta$ peptides promoted aggregation of $\alpha \mathrm{S}$, and intra-neuronal accumulation of $\alpha \mathrm{S}$ in cell culture. ${ }^{313}$ In a similar fashion, exacerbated $A \beta$, Tau and $\alpha \mathrm{S}$ pathologies have also been observed in studies using mice genetically engineered to exhibit both AD and DLB (dementia with Lewy bodies, which contain $\alpha S$ ). ${ }^{314}$ This suggests that $\mathrm{A} \beta$, Tau and $\alpha \mathrm{S}$ interact in vivo to promote the aggregation and accumulation of each other and accelerate cognitive dysfunction. ${ }^{314}$ These studies indicate that $\mathrm{A} \beta$ peptides may contribute to the development of Lewybody diseases by promoting $\alpha \mathrm{S}$ aggregation and exacerbating $\alpha$ S-dependent neuronal pathologies.

Different strains of $\alpha \mathrm{S}$ (self-seeded or not) have a differential effect on Tau inclusion in neurons. ${ }^{315}$ Both $\mathrm{A} \beta$ and $\alpha \mathrm{S}$ oligomers cause Tau aggregation and lead to the development of neurotoxic Tau oligomers that are rich in $\beta$-sheet structure. ${ }^{316}$ In vitro studies revealed that the $\mathrm{A} 53 \mathrm{~T} \alpha \mathrm{S}$ mutant enhanced the fibrillization of both Tau and $\alpha \mathrm{S}$ itself. $^{317}$ It was therefore proposed that such effects may be an important contributor to the heterogeneity in amyloid characteristics and symptoms among different individuals. Using the ThT amyloid fibrillization kinetic assay and EM, cross-seeding of $\mathrm{A} \beta 40$ or $\mathrm{A} \beta 42$ and $\alpha \mathrm{S}$ has been examined. ${ }^{318}$ The greatest enhancement of 


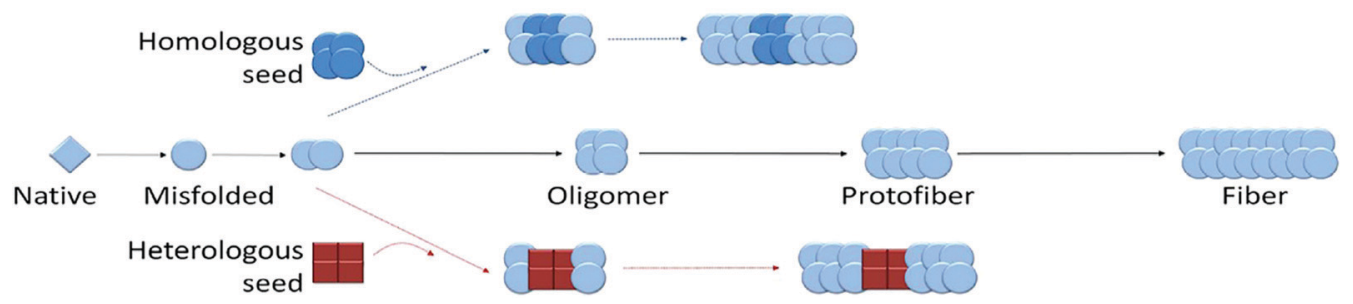

Fig. 12 Schematic contrasting homologous seeding with heterologous seeding where the seed oligomer (in red) stimulates the growth of oligomers and ultimately fibrils of a different protein or peptide. ${ }^{308}$ Reproduced with permission from ref. 308, copyright 2013 Morales et al. ${ }^{308}$

fibrillization kinetics was observed for cross-seeding with fibrils of $\alpha \mathrm{S} .{ }^{318}$ Other amyloid forming proteins, such as the DNA-binding protein TDP-43, can cross-seed $\mathrm{A} \beta$ and suppress the aggregation of the latter into toxic amyloid oligomers. ${ }^{319}$ Such oligomers are found in the brains of frontotemporal lobar dementia, pointing to the important role of crossseeding in pathogenesis in this neurodegenerative disease. ${ }^{319}$ Cross-seeding has been demonstrated in vivo with $A \beta$ and hIAPP. ${ }^{320,321}$ In vitro studies indicated that hIAPP fibrils are poor seeds for $\mathrm{A} \beta 40$ fibrillization (this paper also reported weak seeding efficiency of $A \beta 40$ by a number of other peptides). ${ }^{320}$ On the other hand, preformed fibrils of $A \beta 42$ were injected into hIAPP transgenic mice leading to hIAPP amyloid formation in the pancreas. ${ }^{321}$ Co-localization was also observed with hIAPP and pro-hIAPP (hIAPP precursor protein) being co-localized in cerebral and vascular $A \beta$ deposits although in the converse situation, $\mathrm{A} \beta$ was not detected in islet amyloid from T2D patients. ${ }^{321}$ Cross-seeding effects have also been studied for the two different forms of $\mathrm{A} \beta, \mathrm{A} \beta 40$ and $\mathrm{A} \beta 42^{87,322}$ and for point mutants of $A \beta 40$ with $A \beta 40 .{ }^{320}$

Cross-seeding of prion proteins from one species to another has been suggested to be a mechanism behind the propagation of specific amyloid strains. ${ }^{323}$ This has also been observed for yeast prions such as Sup35 where the conformational switch that led to domains rich in glutamine and/or asparagine such as $\left[\mathrm{PSI}^{+}\right]$was promoted by heterologous proteins containing a similar domain (as in several other yeast prions) or by overexpression of proteins with prion-like $\mathrm{Q}-, \mathrm{N}-$ or $\mathrm{Q}-/ \mathrm{N}$-rich domains. ${ }^{324}$ Mutual cross-seeding has also been observed for Sup35 with the Rnq1 prion domain protein RnqPD, with extended lag periods compared to the self-seeding processes. ${ }^{325}$ Hybrid morphologies of Sup35 fibrils sprouting from globular RnqPD structures and RnqpD spherical aggregates coated with Sup 35 seed fibrils were observed. ${ }^{325}$

Cross-seeding of subunits of insulin (A- or B-chain peptides) with the parent protein was found to be less efficient than selfseeding of the full-length insulin. ${ }^{326}$ The cross-seeded fibrils had features of the parent insulin protein, the morphology being distinct from that of the seeding peptides. Despite the observed cross-seeding, soluble forms of the A- and B-chain peptides were found to be able to inhibit insulin fibrillization. ${ }^{326}$ In another study, it was suggested that cross-seeding of hen lysozyme with other proteins was promoted by sequence similarity. ${ }^{327}$ The ThT fluorescence kinetics were enhanced for other forms of lysozyme compared to unrelated proteins (insulin and $\alpha$-lactalbumin), even though, for example, hen lysozyme and $\alpha$-lactalbumin share the same native state fold. ${ }^{327}$

\section{Metabolite amyloidosis}

While amyloid formation has been studied extensively with proteins and polypeptides and even ultrashort peptides, a major assumption in the field was that the minimal requirement for the formation of amyloid structures by a protein fragment is a dipeptide. ${ }^{328}$ This is due to the unique planar nature of the peptide bond, which stems from the electron resonance in the structure that results in a partial double bond between the alpha carbon and the amine nitrogen. To test this assumption and following the extensive work on diphenylalanine $(\mathrm{FF})^{124}$ and other self-assembling ultrashort aromatic peptide such as triphenylalanine ( $\mathrm{FFF})^{329}$ and phenylalaninetryptophan (FW), ${ }^{124}$ the ability of a single amino acid, phenylalanine, to form amyloid fibrils was evaluated. ${ }^{7}$ Surprisingly, it has been found that at concentrations above $1 \mathrm{mM}$ phenylalanine readily forms toxic fibrillar assemblies in aqueous solution (as indicated by EM). The fibrils showed amyloid-characteristic binding to ThT and green-gold birefringence between crossed polarizers upon staining with Congo red. ${ }^{7}$ Moreover, it was shown that antibodies could be raised against the assemblies by immunization of rabbits and those antibodies could deplete the toxicity of the amyloid-like assemblies by pull-down of the toxic species. $^{7}$

Following this unexpected discovery, there began an immediate quest to understand its significance, which was initially unclear considering the rather high concentration of phenylalanine required for the self-assembly of amyloid-like fibrils. While the normal concentration of phenylalanine in healthy individuals is only a few tens of $\mu \mathrm{M}$, there are affected individuals with blood and tissue concentration of phenylalanine in the $\mathrm{mM}$ range. The medical condition is known as phenylketonuria (PKU), which is the result of a mutation in the gene coding for the phenylalanine hydroxylase enzyme. ${ }^{330}$ Individuals affected by the mutation are unable to convert the phenylalanine amino acid into tyrosine. This results in the accumulation of phenylalanine as well as an insufficient amount of tyrosine. Intriguingly, unless treated by a very strict diet, PKU patients show severe neurological symptoms similar to neurodegenerative patients. ${ }^{331}$ After years of follow-up on PKU patients and close monitoring of the correlation between 
phenylalanine levels and neurological abnormalities, it is clear that concentrations of phenylalanine above $0.5 \mathrm{mM}$ are strongly associated with severe neurological damage. To validate the relevance of the observed phenylalanine fibrils to the disease, their occurrence in mice model of PKU has been tested. Mice have the same biosynthetic pathway for the production of tyrosine as humans and a mutation in the same enzyme results in the accumulation of the amino acid. ${ }^{332}$ It was indeed found that antibodies which recognized the fibrillar assemblies, just as in the case of the immunized rabbits, emerged spontaneously in the model mice. ${ }^{7}$ Moreover, antibodies that recognize the phenylalanine assemblies could allow the detection of phenylalanine deposits in the brains of PKU patients post mortem. These deposits are very similar to the amyloid deposits found in those suffering from neurodegenerative diseases such as $\mathrm{AD}$, and could also be co-stained with the antibodies and Congo red. $^{7}$ Taken together, these results suggested a typical amyloid etiology in PKU and an extension of the list of amyloidassociated disorders.

Follow-up studies have been conducted to understand the organization of phenylalanine into ordered assemblies and the possible occurrence of oligomeric structures of phenylalanine. Using mass spectrometry, Bowers and co-workers discovered that under physiological $\mathrm{pH}$ phenylalanine could form oligomeric structures, in which the phenyl groups were being exposed to the solution. ${ }^{33}$ This interesting organization could be associated with a tendency to interact with membranes as a result of the exposed hydrophobic patches in the oligomeric form, as has also been predicted theoretically by MD simulations, ${ }^{334}$ thus explaining the high toxicity of the assemblies. An additional immediate follow-up study by Salmona and co-workers indicates the organization of phenylalanine into order assemblies using small angle and wide angle X-ray scattering as well as AFM. ${ }^{335}$ Moreover, the researchers show that doxycycline, a known protein amyloid formation inhibitor, hinders effectively the formation of fibrillar assemblies by phenylalanine. ${ }^{335}$

While phenylalanine accumulation in the case of PKU is well-known, there are dozens of additional medical conditions known as inborn error of metabolism disorders, in which other metabolites are being accumulated. ${ }^{336}$ In order to test whether the formation of metabolite amyloids in PKU represents a unique case, a larger collection of other metabolites has been screened for the ability to form amyloid-like structures. It was revealed that additional metabolites, including tyrosine, orotic acid, adenine, uracil and cysteine could form fibrillar assemblies with amyloid-like morphology, which bound ThT and Congo red and presented notable cytotoxicity. ${ }^{337}$ Furthermore, this broader study also demonstrates that the mode of toxicity of these metabolite assemblies, as well as that of phenylalanine assemblies, is by late apoptosis, exactly as in the case of protein and polypeptide amyloids. ${ }^{337}$ Later studies indicated that additional metabolites, including tryptophan, glycine, and quinolinic acid, could form amyloid-typical fibrillar assemblies in aqueous solutions. ${ }^{338-340}$

Another interesting property of classical protein amyloids that has recently been discovered is their intrinsic fluorescence in the visible range of the electromagnetic spectrum, as was shown by Kaminsky and co-workers. ${ }^{341}$ The researchers explain the fluorescence by proton delocalization over terminal hydrogen bonds, which results in the formation of an essentially supramolecular emissive electronic state. Intriguingly, similar visible-range fluorescence has been observed for diphenylalanine nanostructures. ${ }^{342}$ It has recently been established that metabolite amyloids also possess such fluorescence properties, which also allow their detection in live cells. ${ }^{343}$ The observed fluorescence of the fluorescence in the context of hydrogen bond networks is also in line with the crystal structure of phenylalanine in its zwitterionic form at neutral $\mathrm{pH}$, as was determined by synchrotron X-ray crystallography in $2014 .{ }^{344}$ The structure shows a network of hydrogen bonds and $\pi-\pi$ interactions, layered with remarkably similar morphology and zig-zag arrangement as compared to protein $\beta$-sheet structures. Hydrogen bonds occur between polar layers and the charged moieties of the amino acids, while edge-toface $\pi-\pi$ interactions exist between the charged parts of the layers and parallel displaced $\pi-\pi$ interactions between the aromatic side chains. $^{344}$

Yet another property that is shared by protein and polypeptide amyloids and amyloid-like metabolite assemblies is the generic inhibition by polyphenols and other aromatic compounds. ${ }^{345,346}$ This common feature is also consistent with the earlier observation concerning the inhibition of phenylalanine fibril formation by doxycycline. ${ }^{335}$ Additionally, acetylsalicylic acid, which does not affect the organization of protein amyloids, similarly has no inhibitory effect on metabolite fibril formation. ${ }^{346}$ The metabolite amyloids also exhibit the capacity to interact with membranes similarly to protein amyloids, as determined by a highlycharacterized chromatic biomimetic membrane system containing phospholipids and polydiacetylene. ${ }^{347}$ Also in this sense, the similarity between metabolite and protein assemblies is remarkable.

The aggregation of metabolites appears to be directly linked with neurodegenerative disorders. An intriguing observation is related to the interplay between metabolite assemblies and the induction of protein amyloid formation in the context of seeding. It has been shown that phenylalanine fibrils could seed a large group of amyloidogenic proteins and polypeptides that are associated with amyloid diseases. ${ }^{348}$ It was suggested that the presence of metabolite seeds could have a triggering effect on the eruption of amyloid-associated neurodegenerative disorders. ${ }^{349}$ Indeed, it was shown that quinolinic acid, a wellestablished early marker of PD, could seed the aggregation of $\alpha \mathrm{S}$ into amyloid fibrils. ${ }^{340}$ This may provide the missing link between the metabolite profile and the development of various degenerative processes and may clarify certain unexplained epidemiological associations. ${ }^{349}$

All of the experiments in metabolite amyloids until 2019 have been performed in vitro or in cell culture. It was recently demonstrated that a yeast model of metabolite aggregation could be constructed. ${ }^{350}$ By blockage of adenine salvage pathways, a yeast model in which adenine accumulates was obtained. Feeding these model yeast with adenine exerted a toxic effect in a non-linear sigmoidal-shaped dose-dependent manner. ${ }^{350}$ Moreover, the addition of polyphenol inhibitors of 
amyloid rescued the yeast cells without lowering the level of adenine, indicating that the formation of aggregates, rather than the presence of a high concentration of the metabolite, resulted in the cytotoxicity. ${ }^{350}$ As protein amyloid models in yeasts have been extensively explored by many groups flowing the pioneering work of the late Susan Lindquist, ${ }^{351}$ the current use of yeast models allows to compare the cellular mechanisms of protein homeostasis (proteostasis) and that of metabolite homeostasis (metabostasis). The yeast system will allow further analysis of the cellular machinery that is involved in the response to abnormal accumulation of metabolites with and without self-assembly into amyloid-like structures.

Finally, another interesting parallelism can be found between protein and metabolite amyloids in the sense that as with protein amyloids, functional assemblies that are composed of metabolites can be formed. ${ }^{352}$ One key example is the formation of tapetum lucidum, a retroreflector layer that facilitates night vision. These assemblies are formed by simple metabolites that are very similar to major human risk elements, including a nucleobase (guanine) in reptiles, an amino acid (cysteine coordinated with zinc) in dogs, and a vitamin (riboflavin) in cats and lemurs. Other studies indicated the materials-like properties of amino acid assemblies and the piezoelectric properties of amino acid crystals. ${ }^{353}$ The overall organization of the metabolites in those systems seems to be related to metabolite amyloids, highlighting once again the similarity between the protein and non-proteinaceous selfassembling systems.

Taken together, the spectrum of amyloid building blocks appears to include not only proteins, polypeptides and short peptides, but also a large number of metabolites (Fig. 13). The full molecular determinants that facilitate the ability to form amyloids are still unclear as very similar metabolites could either form or not form amyloid-like structures. For example, phenylalanine and tyrosine readily form amyloid-like structures, whereas the structurally similar 4-hydroxyphenylpyruvate does not. Additional work should be performed to fully understand the structural, functional, and pathological significance of these new type of non-proteinaceous amyloidal assemblies.

\section{Systemic amyloidosis}

Systemic amyloidosis is defined as an amyloid disease, in which the synthesis of the fibril precursor protein and the deposition of the fibrils occur at different sites within the body. ${ }^{354}$ The fibril precursor protein is circulating in the blood, and the associated fibrils form deposits in multiple organs, such as heart, liver and kidneys. The deposits are often large-sized and exert physicomechanical effects that are a major factor of pathogenicity. ${ }^{355}$ For example, cardiac amyloidosis can compromise the natural contractility and pumping function of the heart, leading to severe cardiomyopathy. ${ }^{356}$ There is, however, evidence that toxic fibrillization intermediates play a role in these diseases, similar to their involvement in neurodegeneration. Systemic amyloidosis can cause major impairments to the affected patients, if not death, and these diseases probably constituted the most abundant protein misfolding diseases until the mid of the 20th century. Nevertheless, they are nowadays much in the shadow of their neurodegenerative relatives.

Several types of systemic amyloidosis can be distinguished depending on the fibril precursor protein. This dependence is reflected by the disease nomenclature. ${ }^{56}$ Systemic AA amyloidosis arises from the misfolding of SAA protein. Systemic AL amyloidosis involves fibrils from immunoglobulin LCs, while systemic ATTR amyloidosis originates from TTR fibrillization. There are several commonalities among the different types of
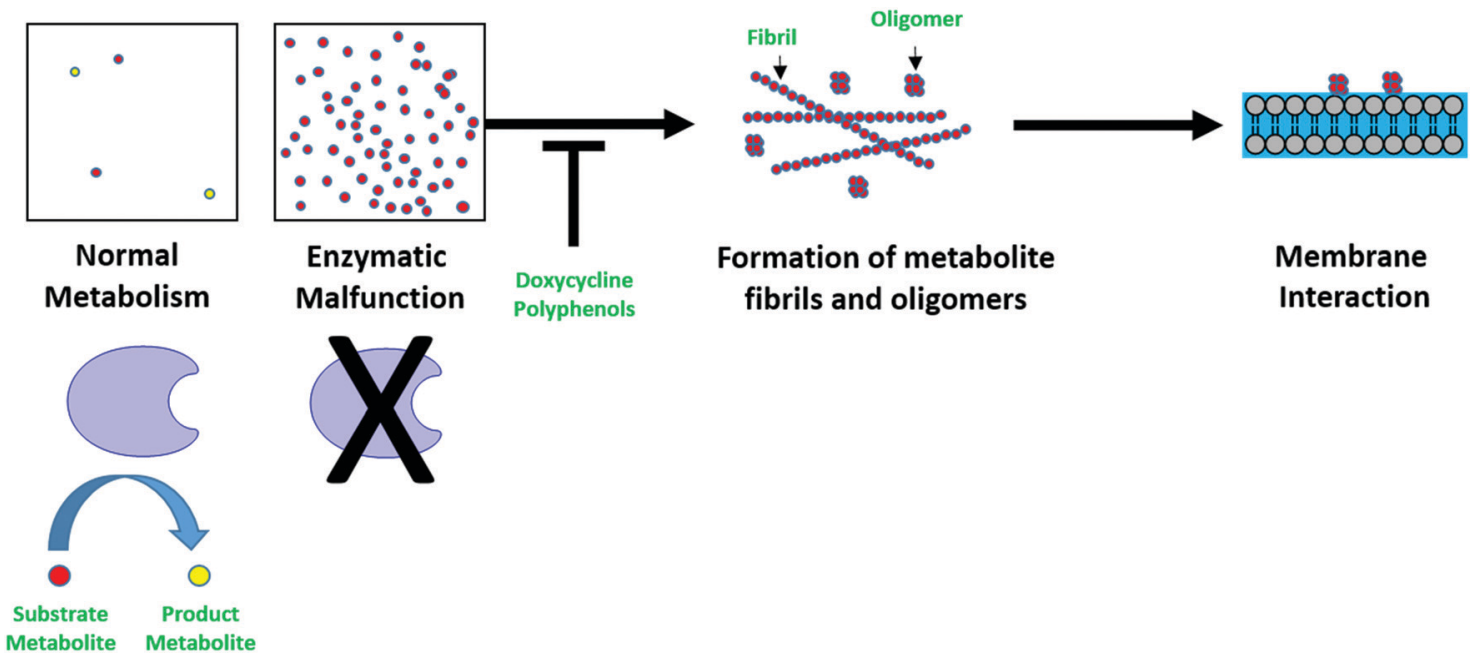

\section{Formation of metabolite fibrils and oligomers}

\begin{abstract}
Membrane
Interaction
\end{abstract}

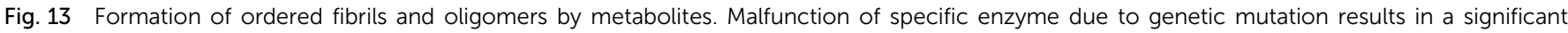

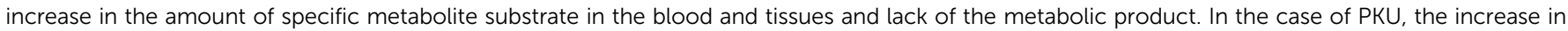

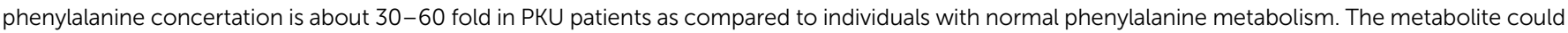

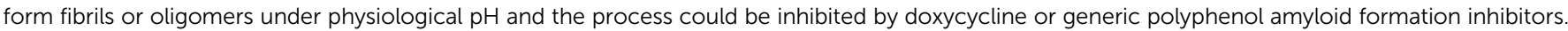

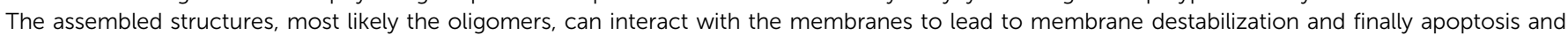
damage to cells and tissues. 
systemic amyloidosis. The precursor proteins are either constitutively or transiently present at high concentrations. ${ }^{354,356}$ They are proteolytically truncated in the fibrils, ${ }^{354,356,357}$ and their deposits are associated with non-fibril components, such as glycosaminoglycans, ${ }^{358}$ lipids $^{359}$ or non-fibril proteins, ${ }^{360}$ that are conserved across different diseases and possibly important for fibril formation ${ }^{358}$ or fibril stability in the tissue. ${ }^{355}$

Precisely 60 years after Cohen and Calkins revealed, with electron microscopy, the presence of fibrils in the tissue, ${ }^{53}$ cryoTEM structures became available for amyloid fibrils that were purified from the tissue of patients affected by systemic AA, AL or ATTR amyloidosis. ${ }^{120,361-363}$ These structures revealed that the fibril protein folds are, in all cases, substantially different from their conformation in the respective native proteins. The implication of this observation is that the conformation of the native state has to be almost entirely unfolded in order to enable the reorganization of the polypeptide chain into the fibril protein fold. This conclusion holds even in cases where the fibril precursor is $\beta$-sheet rich as in TTR. ${ }^{362}$ The fibrils that can be extracted from a patient or animal are typically polymorphic with one dominating fibril morphology. ${ }^{120,361-364}$ Consistent fibril morphologies are deposited at different sites/organs of the same patient or animal ${ }^{365}$ and even in different patients or animals, as long as they belong to the same subtype of systemic amyloidosis and possess the same sequence of the fibril precursor protein. ${ }^{119,362,365}$

Current ways of treatment of systemic amyloidosis are mostly focused on a reduction of the fibril precursor protein. Treatment in systemic AL amyloidosis typically involves a chemotherapy to remove the plasma cell that produces the amyloidogenic LC. ${ }^{356}$ Treatment in systemic AA amyloidosis involves anti-inflammatory treatments to reduce the serum levels of the acute phase protein SAA. ${ }^{354}$ Treatment of systemic ATTR amyloidosis can involve a liver transplantation to remove the main TTR-producing organ. ${ }^{366}$ In addition, there are recent advances to downregulate the expression of TTR protein by RNA interference therapy. ${ }^{366}$ These treatments, which target the precursor protein concentration, have to be combined, in some patients, with the removal of the compromised organ. An example hereof is the requirement of heart transplantation in many patients with cardiac amyloidosis. ${ }^{356}$ Finally, certain forms of systemic ATTR amyloidosis can be pharmacologically treated with the drug tafamidis, which binds into the surface pocket of TTR, stabilizing the native state of this protein. ${ }^{367}$ In summary, systemic amyloidosis represents an interesting and unique model system for studying the principles of protein misfolding diseases and for developing new medical approaches.

\section{Bacterial functional amyloid}

The preceding ten sections have focused on pathological amyloid. However, there is growing awareness of the impressively useful roles that the amyloid motif plays in many different biological contexts. As discussed in a recent review, ${ }^{368}$ 'functional' amyloid examples are found in many organisms, ranging from mammals and insects ${ }^{369}$ to fungi and bacteria (though not yet plants possibly due to the many metabolites in plants which are able to inhibit amyloid aggregation). ${ }^{370}$ Functional amyloids can participate in various cellular tasks, including serving as structural scaffolds, with examples like Pmel17 in melanosomes, curli and FapC in bacterial biofilms, and spidroins that enhance spider web tensile strength. Additionally, peptide hormones can be stored in an inert amyloid state, ${ }^{371}$ while amyloid formation by the P. anserina HET-s protein regulates heterokaryon incompatibility, transcription and translation can be regulated by prion proteins in yeast. ${ }^{372}$ Because space constraints prevent a more detailed exposition of every functional amyloid, here we will focus on the bacterial amyloid-forming proteins, CsgA and FapC. As functional amyloids, they are produced as the result of highly coordinated biosynthetic processes, and a great deal is now known about these biological systems as well as the principles promoting their optimized aggregation. Thus, functional amyloids serve as instructive examples of how nature can avoid the unwanted features of protein aggregation and instead exploit the amyloid fold for cellular good.

A critical component of bacterial biofilm is the extracellular matrix (ECM) that surrounds and protects cells. In many cases, the ECM is strengthened by bacterially produced amyloid. ${ }^{373,374}$ The best-studied example is curli, ${ }^{375-377}$ produced by Enterobacteriaceae, such as Salmonella and Escherichia coli (E. coli), as well as hundreds of diverse Gram-negative bacteria. ${ }^{378}$ Unlike pathological amyloids, bacterial amyloids are functional (i.e. biologically useful) and therefore produced as the result of highly coordinated biosynthetic processes. Much can be learned about the nature of amyloid formation by studying this fascinating group of proteins.

Curli are required for proper biofilm development ${ }^{376,379-381}$ and enhance biofilm strength, viscoelasticity, and resistance to strain. ${ }^{382}$ The main component of curli, CsgA, is a 120-residue IDP that is secreted into the extracellular milieu as an unfolded monomer and was the first 'functional' amyloid protein to be described. ${ }^{383,384}$ The minor curli subunit CsgB, also an IDP, nucleates CsgA fibrillization as an amyloid template. ${ }^{385}$ Additional CsgA subunits are added to the growing fibril end in a seeding process. ${ }^{386,387} \mathrm{CsgB}$ also helps anchor the fibrils to the membrane surface via CsgF (in whose absence both proteins simply "escape" from the cell). Both CsgA and CsgB must be "chaperoned" to suppress their high aggregation propensity and promote their transport as monomers to and across the outer membrane prior to amyloid fibril formation. They are secreted to the cell surface through what is called the type VIII secretion system (Fig. 14), in which CsgE targets them to the outer membrane secretion channel $\mathrm{Csg}^{388-391}$ via the two proteins' N-terminal 22 residues. ${ }^{392,393}$ Once polymerized, fibrils can interact with the dyes Congo red and ThT, leading to a spectral change that is often used to monitor amyloidogenesis. The resulting CsgA fibrils are unusually durable. Not only do they resist heat, proteases, and denaturing agents such as sodium dodecyl sulfate (SDS), ${ }^{394}$ they only dissociate to monomers at very high concentrations $(>50 \%)$ of the potent denaturant and solvent formic acid. ${ }^{395}$

CsgG is comprised of nine identical subunits, each lipidated at the N-terminal cysteine residue to promote localization and 


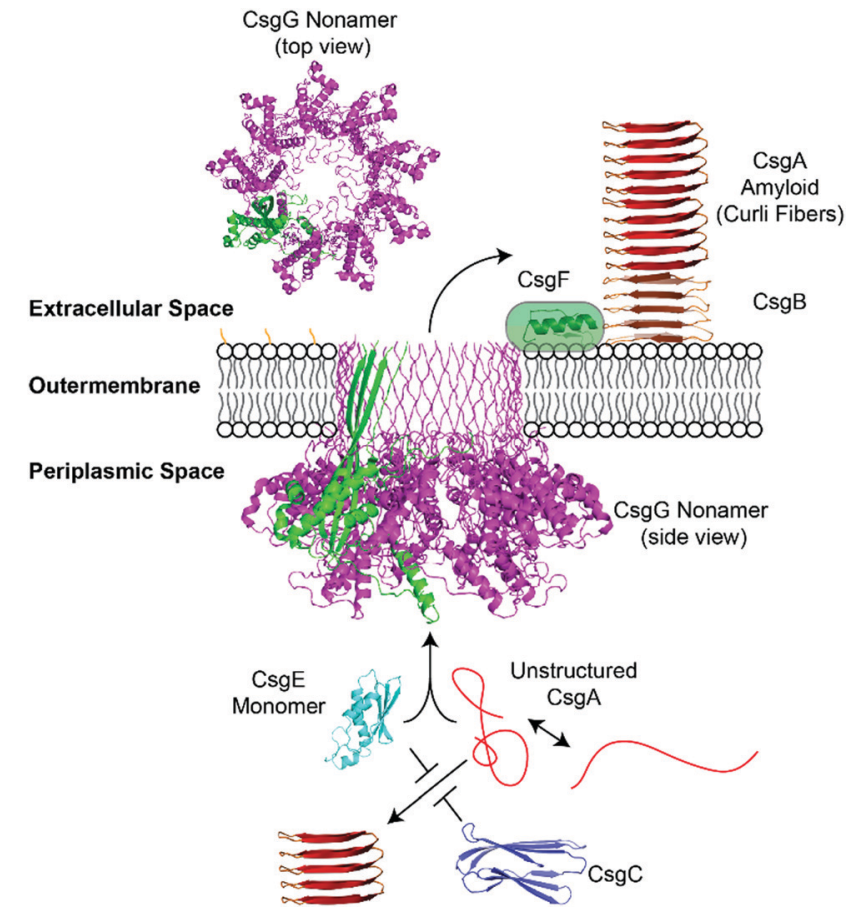

Fig. 14 Model of curli secretion. CsgE and CsgG facilitate secretion of unfolded CsgA across the outer membrane. Outside the cell, CsgA assembles into an amyloid via a nucleation precipitation reaction assisted by $\mathrm{CsgB}$ and $\mathrm{CsgF}$. The CsgE and CsgC proteins have been shown to prevent CsgA aggregation in vitro. The CsgG nonamer is shown in purple, and one of the CsgG subunits is colored green.

assembly in the outer membrane (Fig. 14). ${ }^{389,391}$ Each CsgG subunit within the membrane-embedded CsgG homononamer contributes four $\beta$-strands to a 36-strand transmembrane $\beta$-barrel, which sits atop a ring of globular periplasmic domains. The structure contains two vestibules separated by a series of constriction loops that restrict the pore diameter to $9 \AA^{390,396}$ The first vestibule, formed by the periplasmic domains, encloses $\sim 24000 \AA^{3}$, roughly the predicted volume occupied by a single unfolded CsgA monomer. The second vestibule formed by the $\beta$-strands spanning the outer membrane remains permanently open to the extracellular milieu, enclosing $\sim 41000 \AA^{3}$. This is consistent with the need for subunits to be largely unfolded during secretion into the extracellular space. $^{397}$ Besides binding and inhibiting the folding of CsgA, CsgE also forms a functional nonameric cap that binds to the CsgG pore and prevents unregulated transport across the outer membrane. ${ }^{388,390,398} \mathrm{CsgE}$ contains a mix of three stacked $\beta$-strands, $2 \alpha$-helices, and a prominent IDR. ${ }^{398}$ Once CsgA is confined to the space formed by periplasmic vestibule of CsgG and the CsgE cap, it is thought that the resulting entropic free energy gradient favors CsgA expulsion into the extracellular space. CsgF and CsgB are also apparently secreted through CsgG. A partial NMR structure of CsgF suggests it to be conformationally dynamic with exposed hydrophobic regions. CsgF contains an $\mathrm{N}$-terminal unstructured region, a 21-residue $\alpha$-helix, and a C-terminal antiparallel $4 \beta$-strands. ${ }^{399}$

According to "fishing expeditions" with amyloid-specific antibodies, many bacteria produce amyloid, ${ }^{400}$ and numerous operons coding for functional amyloid have been discovered since curli (see an overview in ref. 401). Despite differences in detail and independent evolutionary origins, there are common features. These include one main amyloid component and a secretion system to transport them to the outer membrane in a monomeric state that is ready for extracellular assembly. For example, the fap operon in Pseudomonas species directs the formation of fibrils mainly consisting of FapC, ${ }^{402}$ assisted by the (likely) nucleator FapB and transported through the outer membrane by FapF. ${ }^{403}$ The ensuing fibrils increase biofilm rigidity and resistance to drying out through increased hydrophobicity. ${ }^{404}$ However, given their independent origins, there will always be distinguishing features in each system. For example, the membrane-embedded part of FapF is a trimeric porin gated by a helical plug (much simpler than CsgG), while its periplasmic coiled-coil domain could potentially guide transport of FapC to the FapF channel as a dedicated "amyloid shunt". 405

The core of both CsgA and CsgB protein sequences is composed of 5 imperfect repeated sequences (R1-R5), each of around 20 residues. $^{375}$ Peptides corresponding to R1, R5 and R3 assemble into amyloid fibrils that are morphologically indistinguishable from those produced by WT CsgA, ${ }^{406,407}$ whereas R2 and R4, which are largely dispensable for fibril formation in vivo, ${ }^{406}$ do not fibrillate on their own. This indicates that CsgA consists of multiple amyloid-forming units, and indeed a combination of NMR data and secondary structure predictions suggest that each repeat sequence in CsgA forms strand-loop-strand motifs. ${ }^{393,408,409}$ Subsequently co-evolutionary analysis combined with computational force field analysis led to an atomic-level structure prediction in which the 5 hairpins stack on top of each other to form an $\alpha$-helix, ${ }^{410}$ although the handedness of this helix still is unresolved in the absence of experimental restraints. The repeats in CsgA are distinguished by the sequence Ser- $\mathrm{X}_{5}-\mathrm{Gln}-\mathrm{X}_{4}-\mathrm{Asn}^{-} \mathrm{X}_{5}-$ Gln; ${ }^{393,406}$ the Gln and Asn residues in R1 and R5 are critical for efficient amyloid formation ${ }^{393,406,411,412}$ while "gatekeeper" residues in R2, R3 and R4 slow CsgA amyloid formation both in vivo and in vitro. ${ }^{411}$ The structural convergence of CsgA and $\mathrm{Csg} \mathrm{B}$ is rooted in amino acid sequence similarities, including regularly spaced Ser, Gln and Asn residues. ${ }^{413}$

A similar situation is found with FapC, although it differs from CsgA in that it contains 3 longer imperfect repeats ( $\sim 35$ residues), separated by linkers of variable length. A computational-bioinformatic structure prediction, similar to that performed for CsgA, suggests that the FapC repeats form hairpin loops, while the linker regions constitute disordered regions that may lead to a "hydrophilic halo" around the fibril. ${ }^{414}$ The advantage of this repeat-based design, both for FapC and CsgA, is that each protein monomer constitutes an amyloid-forming unit, which will facilitate rapid initiation of fibrillization. No stable oligomers of either CsgA or FapC have been isolated (except when assisted by fibrillization inhibitors such as polyphenols $\left.{ }^{415,416}\right)$. This indicates that the repeat structure efficiently drives fibrillization from a small and stable nucleus and that there are no competing non-fibrillar 
structures, unlike e.g. the stable $\alpha \mathrm{S}$ oligomer. ${ }^{417,418}$ Consistent with this, fibrillization of both CsgA and FapC follows the simplest possible model, namely primary nucleation followed by elongation. ${ }^{419}$ This mechanism is ideal for the nucleationinitiated elongation of bacterial amyloid fibrils in vivo, where long (i.e. not fragmented) fibrils are likely required to strengthen the ECM. Remarkably, step-wise deletion of the repeats of FapC gradually increases the tendency of the fibrils to fragment, and this means that elongation of the new growing ends generated by fragmentation (rather than elongation of the nuclei formed by primary nucleation) becomes the dominant contribution to fibril growth. ${ }^{420}$ The resulting fibrils are also more prone to dissociation in formic acid, a direct indication of their reduced stability, and complete removal of all repeats, while not preventing formation of $\beta$-sheet rich fibrillary aggregates, catastrophically destabilizes the fibrils in terms of sensitivity to denaturants such as formic acid and surfactants. ${ }^{421}$ A further twist on in vivo fibrillization is that biomolecules in the milieu close to the outer membrane of Pseudomonas, such as the biosurfactant rhamnolipid and the outer membrane component lipopolysaccharide, strongly accelerate FapC aggregation and suppress accumulation of a transient aggregation intermediate. ${ }^{416}$ Thus, conditions have truly been optimized to facilitate rapid and direct fibrillization of these proteins.

Amyloidogenic proteins present significant challenges to the cell because of their strong tendency to aggregate. Uncontrolled amyloid formation can upset proteostasis, and is associated with significant cytotoxicity. ${ }^{422}$ Therefore, a fundamentally important question is: "How can aggregation-prone proteins such as CsgA be guided from the inside of the cell, through the periplasmic space, and across the outer membrane so that amyloid fibrils only form outside the cell?" The answer is: accessory proteins such as $\mathrm{CsgC}$, a small periplasmic protein made by curli-producing bacteria that helps discourage intracellular amyloid formation by CsgA and CsgB. Purified CsgC can inhibit amyloid formation at extremely substoichiometric 1 : 500 (CsgC : CsgA) molar ratio, both for WT CsgA, R1, R3 or R5 CsgA deletion mutants, along with synthetic peptides corresponding to R1 and R5. CsgC also inhibits amyloid assembly of E. coli CsgA and CsgB homologs, but not the AD-associated protein A 342 , suggesting some specificity. ${ }^{423}$ However, CsgC does inhibit amyloid assembly by the PD-associated protein $\alpha \mathrm{S},{ }^{423}$ possibly due to a 8-9 amino acid motif (D-Q- $\Phi-\mathrm{X}_{0,1}-\mathrm{G}-\mathrm{K}-\mathrm{N}-\zeta$ ) shared by both CsgA and $\alpha \mathrm{S} .{ }^{423}$ Structural homologs of $\mathrm{Csg} \mathrm{C}$ are found in almost all bacteria. ${ }^{424}$ The CsgC structure can even be seen in the human amyloid-forming protein TTR. Like CsgC, TTR can discourage CsgA and $\alpha \mathrm{S}$ amyloid formation. ${ }^{425}$ Therefore, it is likely that nature has many anti-amyloid chaperone proteins at its disposal that can help modulate amyloid formation.

Functional amyloids have much to offer going forward. Amyloid-associated diseases affect an estimated 50 million people annually. We need better approaches for combating diseases such as $\mathrm{AD}$ and $\mathrm{PD}$, which are twice as prevalent today as they were 20 years ago, a number that could quadruple by 2050. The rules governing amyloid fibril formation have been mostly defined through in vitro observations, because most disease-associated amyloids aggregate inefficiently or sporadically in vivo. It is not unreasonable to expect that next generation amyloid therapeutics will be inspired by the mechanisms that functional amyloid systems employ to temporally and spatially control amyloid formation. At the very least, the N22-based display system can be circumvented to target other amyloidogenic proteins to the CsgG secretion channel and provide a bacterial selection system for e.g. aggregation inhibitors. ${ }^{426}$ Furthermore, the robust fibrils produced by these bacteria may serve both as selectable display vehicles for $e$.g. peptides with different binding properties $^{427}$ and even as components in underwater glue when fused with mineral-binding proteins such as mussel foot proteins. $^{428}$

\section{Artificial amyloids and engineering opportunities}

In stark contrast to their original negative implications in neurodegenerative diseases, but in line with the positive role played by functional amyloids, artificial amyloids, that is amyloid fibrils artificially produced in vitro from non-toxic affordable proteins, have become a well-accepted building block of next generation functional materials and nanotechnologies. ${ }^{26,429}$ Particularly noteworthy for advanced materials and technologies are the following physical-chemical features of amyloid fibrils: (1) their extreme aspect ratio; (2) the amino acid functionalities of their surface chemistry; and (3) their Young's modulus comparable to high performance commodity plastics. These features have enabled unique and original applications of these systems into a multitude of fields, some of which have now entered the commercial realm. While the use of amyloid fibrils as templates for innovative materials, devices and nanotechnologies has already been discussed in detail in separate comprehensive reviews, ${ }^{26,429,430}$ here we highlight briefly how the features (1) to (3) of artificial amyloids allow their use in innovative material design.

The extreme aspect ratio of amyloid fibrils provides unique opportunities for assisting the self-assembly of materials templated by liquid crystalline interactions, for example. This has allowed the design of 2D materials for optoelectronic and biosensing applications, among others. The general strategy followed is that the $1 \mathrm{D}$ excluded volume interactions of amyloid fibrils can be exploited to drive the self-assembly of other higher dimensionality anisotropic objects, such as 2D organic and inorganic materials, starting at concentrations of the $2 \mathrm{D}$ objects well below their intrinsic isotropic-nematic transition composition. In other words, 2D objects can be ordered in their dilute, isotropic state, when amyloid fibrils above their isotropic-nematic transitions are present. In one example, amyloid fibrils above the isotropic-nematic transition were used to drive the alignment and stacking of graphene nanoflakes into layered structures and finally 2D nanocomposites with unconventional sensing, shape-memory and biodegradable properties. ${ }^{431}$ This offered the first opportunity to design amyloid-based devices for enzymatic biosensing. ${ }^{431}$ Similarly, replacing graphene 
nanoflakes with gold 2D single crystals allowed generating hybrids materials with innovative optoelectronic properties, conductivity and plasmonic properties. ${ }^{432}$ In a further example, inorganic gold single crystals were replaced by ad hoc synthesized 2D hydroxyapatite platelets, which once aligned by excluded volume interactions into layered composites were able to mimic bone structure, with amyloids replacing collagen fibrils. ${ }^{433}$ The further growth of osteoblasts onto these 2D hybrid materials brought the templates one step closer to mimic real human bones. ${ }^{433}$ In the dense phase, liquid crystalline interactions of amyloid fibrils were further used to design solid films with anisotropic absorption and fluorescence properties; ${ }^{434}$ furthermore, although not directly demonstrated, the role of highly anisotropic interactions and structure in amyloid-based films may lead to improved quantum efficiency of semiconductive polymers when embedded in amyloid solid matrices, ${ }^{435}$ as extensively demonstrated by the Inganas group, ${ }^{436-438}$ among others.

In the liquid state, the liquid crystalline interactions of the amyloids combined with their chiral nature have been recently shown to be responsible for the formation of chiral nematic phases, or cholesteric liquid crystals, in both a continuum (bulk cholesteric phase) and dispersed state (i.e. cholesteric droplets dispersed in a continuum isotropic phase). ${ }^{439}$ In both the solid and liquid states, the concepts discussed above can open the path to optical devices where the anisotropic nature of the amyloid-based materials can be used to alter the orientation of an electromagnetic field, as in filters for polarized fluorescence and low-power liquid crystal displays, or the collective diffusion of excitons or photons, in photovoltaic and organic/polymer lightemitting diode (OLED/PLED) applications, respectively.

An alternative way to exploit the extreme aspect ratio of amyloid fibrils is to generate gels, rather than liquid crystals, where the high aspect ratio is now used to reach a gel phase at extremely small percolation thresholds. This can be done by simply altering the interactions among amyloids fibrils in the colloidal state, by for example favoring attractive interactions via changes in ionic strength (charge screening) or $\mathrm{pH}$ (alteration of linear charge density). ${ }^{440-442}$ Amyloid-based gels of this type have been shown to work as efficient scaffolds for cell culture and growth, due to a noteworthy low cytotoxicity in the greatest majority of cases investigated. ${ }^{443-446}$ Remarkably, this spans over a wide range of amyloid building blocks, ranging from the 10-residue 105-115 fragment from the protein TTR, ${ }^{444,445}$ modified and engineered to carry the RGD integrin binding sequence of fibronectin, to the much simpler amyloid gels based on food proteins, such as lysozyme. ${ }^{44,448}$ These gels have been demonstrated to be efficient means for cell proliferation, to mimic the ECM environment, to perform tissue engineering, and, when stem cell precursors are used, to promote cell differentiation, as in the case of neural progenitor cells differentiating into mature neurons during cell growth. ${ }^{449}$ Of particular significance in this case is the fact that small variations in $\mathrm{pH}$, ionic strength and concentration can result in gels with significant changes in mechanical and rheological properties. ${ }^{450}$ This is understood to be the playground in which stem cell differentiation in vitro and in vivo occurs, and has been demonstrated to date in several types of amyloid-based gels of different amyloid sources, including peptides based on $\mathrm{A} \beta^{451}$ and $\alpha \mathrm{S} .^{452}$

The amino acid chemistry decorating the surface of amyloid fibrils further enables unique applications, some of which are highly specific to these systems. Indeed, the presence of peptide bonds opens for both versatile covalent and supramolecular chemical approaches. Examples of covalent grafting of organic moieties to amyloid fibrils include PNIPAM brushes grown from $\beta$-lactoglobulin amyloid fibrils to produce injectable temperatureresponsive hydrogels; ${ }^{453}$ photo-induced cross-linking of the lipase enzyme onto amyloid fibrils to produce biocatalysts with enhanced enzyme stability; ${ }^{454}$ and DNA-amyloid conjugates in which DNA provides the possibility of origami-driven colloidal assembly of amyloid fibrils. ${ }^{455}$ Supramolecular interactions between metal ions and amyloid fibrils have been shown to be particularly promising for applications. Metal-ligand supramolecular binding is at the origin of the strong adsorption of metal ions observed on the surface of amyloid fibrils, mediated by strong binding to a multitude of amino acids (see Fig. 15 for a schematic cartoon). ${ }^{25,456,457}$ By exploiting this effect, Bolisetty et al. were able to produce amyloidbased membranes for adsorption of heavy metals and radionuclides for efficient water purification. ${ }^{25}$ Due to the simultaneous presence of diverse amino acids and thus, a multitude of metalligand pair binding constants, these membranes act as "universal sponges", challenging the highly specific exchange resins traditionally used in water purification, for example. This has led to a commercial application of membranes based on artificial amyloids capable to remove a wide range of heavy metal ions such as gold,

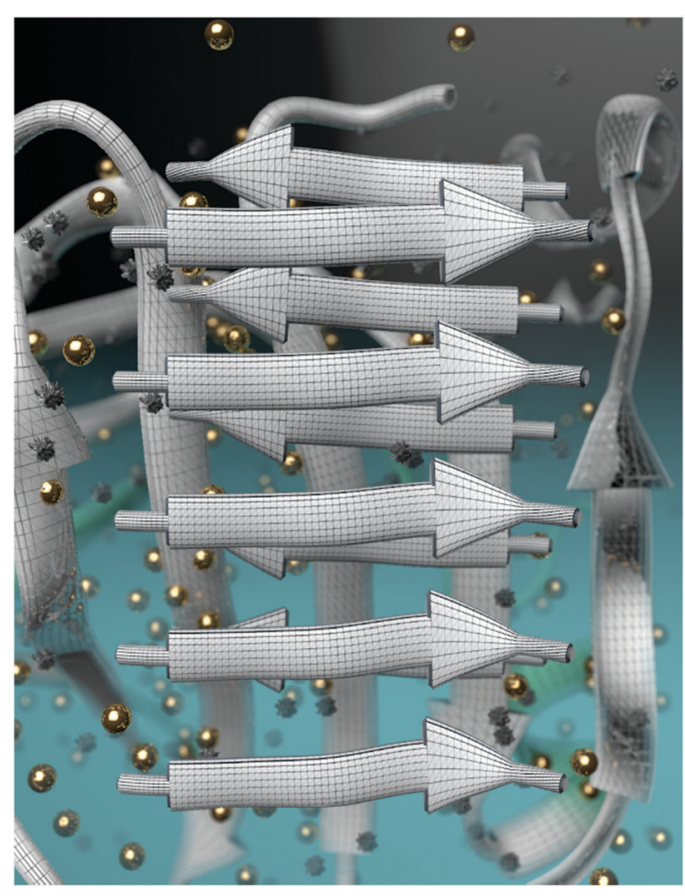

Fig. 15 Schematic illustration of the binding process of gold ions with the $\beta$-sheets of amyloid fibrils. The $\beta$-sheet structure is based on the molecular dynamic simulations of the self-assembly process of the LACQCL sequence, a fragment found on the $\beta$-lactoglobulin amyloid fibrils used for water purification properties. ${ }^{25}$ Image rights: R. Mezzenga. 
platinum, silver, copper, lead, mercury, uranium, aluminium, and even metalloids such arsenic. ${ }^{25,456,458}$

The concept has further been extended to remove halogen contaminants from water, such as in the case of fluoride, by first capturing transition metals on the fibrils, then growing them in situ into fine transition metal nanoparticles, which finally, by adhering to the amyloid surface, are capable of binding targeted fluoride contaminants. ${ }^{459}$

The growth of metal ions on the surface of amyloids into metal nanoparticles conjugated to the amyloid fibrils can be further exploited for applications as diverse as heterogeneous catalysis ${ }^{460}$ and human nutrition. For example, by growing iron oxide nanoparticles from $\mathrm{Fe}^{2+}$ bound on the surface of $\beta$-lactoglobulin amyloid fibrils, Shen et al. ${ }^{24}$ showed that the resulting hybrids maintained iron at the right oxidation state (i.e., the II form, which is more bioavailable than the III form), which could then be used to target iron deficiency in vivo. The authors further demonstrated that the $\beta$-lactoglobulin amyloid fibril-iron oxide nanoparticle hybrids could be used as efficient iron fortificants for nutrition purposes, with outstanding bioavailability features. Alternatively, by growing noble metal ions such as gold and palladium into nanoparticles, and using $\beta$-lactoglobulin amyloid fibrils as a sole reducing agent, the ensued metal nanoparticle-amyloid hybrids could be used to design membranes for continuous heterogeneous flow catalysis. ${ }^{460}$

The scope of artificial amyloids can be expanded significantly by combining some of the unique features discussed above: amyloid gels can be combined with the reducing properties of the amyloid fibrils to template gold aerogels with ultra-light density; ${ }^{461}$ the reducing properties of amyloids can be used to generate other types of oxide nanoparticles, such as $\mathrm{TiO}_{2}$ for dye cell units for energy conversion; ${ }^{462}$ engineered amyloid fibrils with specific binding sites can be used to target analytes and specific molecules; for example, the Eisenberg group ${ }^{463,464}$ has shown how amyloid templates can be used for efficient $\mathrm{CO}_{2}$ adsorption, thereby addressing another pressing environmental issue. It is the multitude of features highly specific to amyloid fibrils, which, when exploited synergistically, can give rise to an extremely vast range of beneficial applications ranging from the biomedical field, to environment preservation, energy management and alike, serving modern society and shifting paradigms away from the adverse tinge that amyloids have been mostly known for.

\section{Summary and future work}

Much progress has been made in the field of amyloid science. The atomic structures of extensively studied amyloid peptides/ proteins $\mathrm{A} \beta 42,{ }^{465} \mathrm{~A} \beta 40,{ }^{466} \mathrm{Tau}^{101}$ and $\alpha \mathrm{S}^{93,107,112}$ have been resolved with improved in vitro fibril preparation and breakthroughs in cryo-TEM and ssNMR technologies. Such progress, however, is contrasted by the lack of success in antiamyloidosis clinical trials and highlights this persistent question: just how much amyloidosis contributes to cell degeneration in amyloid diseases, alongside ageing, deficiencies in microglial activation and peripheral clearance, ${ }^{467,468}$ as well as other environmental and familial factors? The structural characteristics of amyloid fibrils are essential for clinical classification and, hence, the treatment of amyloid diseases. Indeed, while distinct prion strains are associated with different clinical and pathological phenotypes ${ }^{469-471}$ variations in $\mathrm{AD}$ phenotype correlate with variations in $\mathrm{A} \beta$ fibril structure. ${ }^{472-475}$ For example, among. $\mathrm{AD}$ clinical subtypes, the rapidly progressive form possesses rich polymorphism of $\mathrm{A} \beta 40$ fibrils, while the posterior cortical atrophy variant and typical prolonged-duration form shows dominance of a specific $\mathrm{A} \beta 40$ fibril structure from seeded growth of $\mathrm{AD}$ brain cortex extracts. On the other hand, all three subtypes displayed structural heterogeneity for $\mathrm{A} \beta 42$ fibrils. ${ }^{476}$ Clearly, amyloid structure offers a basis for deciphering the often nuanced clinical manifestations of amyloid diseases.

Amyloidosis occurs across different organs and biological barriers in vivo, as exemplified by systemic ATTR, AL and AA amyloidoses. On the other hand, amyloid proteins such as $A \beta$, $\alpha \mathrm{S}$ and hIAPP have been detected in systemic circulation, fuelling the hypotheses of cross-seeding, inflammation, the gut microbiota and metabolite amyloid as causative to amyloid diseases. ${ }^{5,477-479}$ Furthermore, $A \beta$ oligomers have shown a negative effect on constricting human capillaries in $\mathrm{AD}$ via signalling to pericytes. ${ }^{480}$ Accordingly, the structure and toxicity profiles of amyloid proteins may be examined across different compartments, physiological conditions and pathologies.

A major challenge in the clinical treatment of amyloidosis is to ensure early diagnosis of the disease. In T2D, for example, beta-cell mass accounts for only $1-2 \%$ of the pancreas but is a key indicator of the onset and severity of the disease. Accordingly, the development of molecular imaging probes and biomarkers based on antibodies/nanobodies, RNA sequencing and multimodal detection is an identified area of clinical importance. ${ }^{481-483}$ Aside from technological development, and in addition to solubility and efficacy in delivery, the dose and timing of therapeutics administration are crucial parameters for the treatment of amyloid diseases. This is because amyloid proteins in vivo undergo conformational changes on timescales vastly different from in vitro test conditions, depending upon the age, mutation, anatomy and body mass of the animal models. Fundamentally, this challenge arises from the transient and highly heterogeneous nature of toxic oligomers and protofibrils, compounded by cell membranes, $\mathrm{pH}$, ligands and chaperones to influence the protein aggregation energy landscape and toxicity. The evolution of amyloid fibrils in physical and toxicological properties ${ }^{484}$ adds another element of complexity for amyloidosis inhibition.

It should be noted that significant progress has been made in recent years with regard to the clinical diagnosis and effective management of systemic AL and ATTR amyloidoses. This is achieved by mass spectroscopy identification, chemotherapy, liver transplantation, gene sequencing, small-molecule (e.g., tafamidis and diflunisal) stabilization, antisense oligonucleotide therapy as well as RNAi to mitigate the production or misfolding pathways of amyloid proteins. ${ }^{485-487}$

Much remains to be understood concerning the structurefunction-pathogenesis relationship of amyloid proteins and 
their structural derivatives, as well as the co-aggregation and cross-seeding of amyloid proteins with environmental proteins. A large body of experimental evidence, particularly from genetics, indicates that the proteins associated with amyloidosis are the central player in pathogeneses. The toxicities of the oligomers and protofibrils are indisputable facts of amyloid proteins. Amyloid plaques first observed by Alzheimer in 1907 and their cross- $\beta$ structure first revealed by Eanes and Glenner a half century ago, ${ }^{1}$ are a major culprit for a wide range of debilitating human diseases which remain to be deciphered and, hopefully, eradicated in the coming decades.

Amyloids in current science and technology have evolved significantly beyond their original strictly pathological roles, taking up a novel original profile and illuminating new opportunities which were unthinkable only two decades ago. Two new classes of amyloids have emerged, the functional amyloids and the artificial amyloids, performing challenging and remarkably important roles in vivo as well as in modern nanotechnologies. The unique structural and physicochemical properties shared by pathological, functional and artificial amyloids, have evolved from the debilitating role of the former class in neurodegenerative diseases, to the beneficial tasks played by the two latter classes of amyloids, with a demonstrated and emerging role in modern technologies, and entailing a wealth of applications in environmental remediation, health, composite nanomaterials, energy devices, biosensors, soft matter and 3D printing. ${ }^{26,428-430,488}$

\section{Conflicts of interest}

DSE is SAB chair and equity holder in ADDRx, Inc.

\section{Acknowledgements}

We thank our funding sources for support (HHMI, NIH, and NSF for DSE, BBSRC, MRC, Alzheimer's Society and Alzheimer's Research UK for LCS, ARC for TPD and PCK, AFTAM Research Collaboration Award to TPD and EG, EPSRC for a Platform grant EP/L020599/1 to IWH, Independent Research Council Denmark-Natural Sciences grant 8021-00208B and Independent Research Council Denmark-Technical Sciences grant 611100241 to DEO, R01GM118651 from the NIH to MRC, FA 456/ 27 from the DFG to MF) and our co-workers for discussions. We thank the unanimous reviewers for their insights, opinions and comments which made our review more comprehensive. We thank Aparna Nandakumar, Aleksandr Kakinen and Kairi Koppel for their assistance with the manuscript preparation.

\section{References}

1 E. D. Eanes and G. G. Glenner, J. Histochem. Cytochem., 1968, 16, 673-677.

2 W. T. Astbury, H. J. Woods and W. L. Bragg, Philos. Trans. R. Soc., A, 1934, 232, 333-394.
3 P. Westermark, K. Sletten, B. Johansson and G. G. Cornwell, 3rd, Proc. Natl. Acad. Sci. U. S. A., 1990, 87, 2843-2845.

4 W. Colon and J. W. Kelly, Biochemistry, 1992, 31, 8654-8660.

5 I. Horvath and P. Wittung-Stafshede, Proc. Natl. Acad. Sci. U. S. A., 2016, 113, 12473-12477.

6 R. Riek, S. Hornemann, G. Wider, M. Billeter, R. Glockshuber and K. Wüthrich, Nature, 1996, 382, 180-182.

7 L. Adler-Abramovich, L. Vaks, O. Carny, D. Trudler, A. Magno, A. Caflisch, D. Frenkel and E. Gazit, Nat. Chem. Biol., 2012, 8, 701-706.

8 M. M. Kaelberer, K. L. Buchanan, M. E. Klein, B. B. Barth, M. M. Montoya, X. Shen and D. V. Bohórquez, Science, 2018, 361(6408), eaat5236.

9 T. R. Sampson, J. W. Debelius, T. Thron, S. Janssen, G. G. Shastri, Z. E. Ilhan, C. Challis, C. E. Schretter, S. Rocha, V. Gradinaru, M.-F. Chesselet, A. Keshavarzian, K. M. Shannon, R. Krajmalnik-Brown, P. Wittung-Stafshede, R. Knight and S. K. Mazmanian, Cell, 2016, 167, 1469-1480. 10 A. Koh, A. Molinaro, M. Ståhlman, M. T. Khan, C. Schmidt, L. Mannerås-Holm, H. Wu, A. Carreras, H. Jeong, L. E. Olofsson, P.-O. Bergh, V. Gerdes, A. Hartstra, M. de Brauw, R. Perkins, M. Nieuwdorp, G. Bergström and F. Bäckhed, Cell, 2018, 175, 947-961.

11 A. S. Meijnikman, V. E. Gerdes, M. Nieuwdorp and H. Herrema, Endocr. Rev., 2017, 39, 133-153.

12 M. Sgritta, S. W. Dooling, S. A. Buffington, E. N. Momin, M. B. Francis, R. A. Britton and M. Costa-Mattioli, Neuron, 2019, 101, 246-259.

13 M. Valles-Colomer, G. Falony, Y. Darzi, E. F. Tigchelaar, J. Wang, R. Y. Tito, C. Schiweck, A. Kurilshikov, M. Joossens, C. Wijmenga, S. Claes, L. Van Oudenhove, A. Zhernakova, S. Vieira-Silva and J. Raes, Nat. Microbiol., 2019, 4, 623-632.

14 M. R. Wilson, Y. Jiang, P. W. Villalta, A. Stornetta, P. D. Boudreau, A. Carrá, C. A. Brennan, E. Chun, L. Ngo, L. D. Samson, B. P. Engelward, W. S. Garrett, S. Balbo and E. P. Balskus, Science, 2019, 363(6428), eaar7785.

15 M. G. Iadanza, M. P. Jackson, E. W. Hewitt, N. A. Ranson and S. E. Radford, Nat. Rev. Mol. Cell Biol., 2018, 19, 755-773.

16 S. I. A. Cohen, S. Linse, L. M. Luheshi, E. Hellstrand, D. A. White, L. Rajah, D. E. Otzen, M. Vendruscolo, C. M. Dobson and T. P. J. Knowles, Proc. Natl. Acad. Sci. U. S. A., 2013, 110, 9758-9763.

17 S. T. Ferreira and W. L. Klein, Neurobiol. Learn. Mem., 2011, 96, 529-543.

18 H. A. Lashuel, D. Hartley, B. M. Petre, T. Walz and P. T. Lansbury, Jr., Nature, 2002, 418, 291.

19 M. R. Sawaya, S. Sambashivan, R. Nelson, M. I. Ivanova, S. A. Sievers, M. I. Apostol, M. J. Thompson, M. Balbirnie, J. J. W. Wiltzius, H. T. McFarlane, A. Ø. Madsen, C. Riekel and D. Eisenberg, Nature, 2007, 447, 453-457.

20 N. P. Reynolds, J. Adamcik, J. T. Berryman, S. Handschin, A. A. H. Zanjani, W. Li, K. Liu, A. Zhang and R. Mezzenga, Nat. Commun., 2017, 8, 1338.

21 J. Adamcik and R. Mezzenga, Angew. Chem., Int. Ed., 2018, 57, 8370-8382. 
22 P. C. Ke, M.-A. Sani, F. Ding, A. Kakinen, I. Javed, F. Separovic, T. P. Davis and R. Mezzenga, Chem. Soc. Rev., 2017, 46, 6492-6531.

23 I. Javed, T. Yu, G. Peng, A. Sánchez-Ferrer, A. Faridi, A. Kakinen, M. Zhao, R. Mezzenga, T. P. Davis, S. Lin and P. C. Ke, Nano Lett., 2018, 18, 5797-5804.

24 Y. Shen, L. Posavec, S. Bolisetty, F. M. Hilty, G. Nystrom, J. Kohlbrecher, M. Hilbe, A. Rossi, J. Baumgartner, M. B. Zimmermann and R. Mezzenga, Nat. Nanotechnol., 2017, 12, 642-653.

25 S. Bolisetty and R. Mezzenga, Nat. Nanotechnol., 2016, 11, 365-376.

26 G. Wei, Z. Su, N. P. Reynolds, P. Arosio, I. W. Hamley, E. Gazit and R. Mezzenga, Chem. Soc. Rev., 2017, 46, 4661-4708.

27 C. B. Anfinsen, Science, 1973, 181, 223-230.

28 C. M. Dobson, Nat. Rev. Drug Discovery, 2003, 2, 154-160.

29 D. B. Teplow, Amyloid, 1998, 5, 121-142.

30 C. M. Dobson, Trends Biochem. Sci., 1999, 24, 329-332.

31 S. L. Crick, M. Jayaraman, C. Frieden, R. Wetzel and R. V. Pappu, Proc. Natl. Acad. Sci. U. S. A., 2006, 103, 16764-16769.

32 C. L. Hoop, H.-K. Lin, K. Kar, G. Magyarfalvi, J. M. Lamley, J. C. Boatz, A. Mandal, J. R. Lewandowski, R. Wetzel and P. C. A. van der Wel, Proc. Natl. Acad. Sci. U. S. A., 2016, 113, 1546-1551.

33 C. Levinthal, Mössbauer Spectroscopy in Biological Systems: Proceedings of a meeting held at Allerton House, Monticello, Illinois, 1969, pp. 22-24.

34 F. U. Hartl and M. Hayer-Hartl, Nat. Struct. Mol. Biol., 2009, 16, 574-581.

35 J. N. Onuchic and P. G. Wolynes, Curr. Opin. Struct. Biol., 2004, 14, 70-75.

36 J. D. Bryngelson, J. N. Onuchic, N. D. Socci and P. G. Wolynes, Proteins, 1995, 21, 167-195.

37 K. A. Dill and H. S. Chan, Nat. Struct. Biol., 1997, 4, 10-19.

38 H. S. Chan and K. A. Dill, Proteins, 1998, 30, 2-33.

39 P. L. Clark, Trends Biochem. Sci., 2004, 29, 527-534.

40 R. Zhou, Proc. Natl. Acad. Sci. U. S. A., 2003, 100, 13280-13285.

41 M. G. Krone, L. Hua, P. Soto, R. Zhou, B. J. Berne and J. E. Shea, J. Am. Chem. Soc., 2008, 130, 11066-11072.

42 P. Liu, X. Huang, R. Zhou and B. J. Berne, Nature, 2005, 437, 159-162.

43 R. Zhou, X. Huang, C. J. Margulis and B. J. Berne, Science, 2004, 305, 1605-1609.

44 P. Das, D. Kapoor, K. T. Halloran, R. Zhou and C. R. Matthews, J. Am. Chem. Soc., 2013, 135, 1882-1890.

45 B. J. Berne, J. D. Weeks and R. Zhou, Annu. Rev. Phys. Chem., 2009, 60, 85-103.

46 A. J. Geddes, K. D. Parker, E. D. T. Atkins and E. Beighton, J. Mol. Biol., 1968, 32, 343-358.

47 O. S. Makin and L. C. Serpell, FEBS J., 2005, 272, 5950-5961.

48 K. L. Morris and L. C. Serpell, Methods Mol. Biol., 2012, 849, 121-135.
49 M. F. Perutz, J. T. Finch, J. Berriman and A. Lesk, Proc. Natl. Acad. Sci. U. S. A., 2002, 99, 5591-5595.

50 P. Sikorski and E. Atkins, Biomacromolecules, 2005, 6, 425-432.

51 M. Fandrich and C. M. Dobson, EMBO J., 2002, 21, 5682-5690.

52 O. S. Makin, E. Atkins, P. Sikorski, J. Johansson and L. C. Serpell, Proc. Natl. Acad. Sci. U. S. A., 2005, 102, 315-320.

53 A. S. Cohen and E. Calkins, Nature, 1959, 183, 1202-1203.

54 G. G. Glenner, D. Ein, E. D. Eanes, H. A. Bladen, W. Terry and D. L. Page, Science, 1971, 174, 712-714.

55 J. D. Sipe, M. D. Benson, J. N. Buxbaum, S. Ikeda, G. Merlini, M. J. Saraiva and P. Westermark, Amyloid, 2014, 21, 221-224.

56 M. D. Benson, J. N. Buxbaum, D. S. Eisenberg, G. Merlini, M. J. M. Saraiva, Y. Sekijima, J. D. Sipe and P. Westermark, Amyloid, 2018, 25, 215-219.

57 D. F. Waugh, J. Am. Chem. Soc., 1946, 68, 247-250.

58 M. Burke and M. Rougvie, Biochemistry, 1972, 11, 2435-2439.

59 D. A. Kirschner, H. Inouye, L. K. Duffy, A. Sinclair, M. LInd and D. J. Selkoe, Proc. Natl. Acad. Sci. U. S. A., 1987, 84, 6953-6957.

60 P. E. Fraser, J. T. Nguyen, H. Inouye, W. K. Surewicz, D. J. Selkoe, M. B. Podlisny and D. A. Kirschner, Biochemistry, 1992, 31, 10716-10723.

61 A. Clark, G. Cooper, C. Lewis, J. Morris, A. Willis, K. Reid and R. Turner, Lancet, 1987, 2, 231-234.

62 J. Jarvis, D. Craik and M. Wilce, Biochem. Biophys. Res. Commun., 1993, 192, 991-998.

63 C. Blake and L. Serpell, Structure, 1996, 4, 989-998.

64 M. Sunde, L. C. Serpell, M. Bartlam, P. E. Fraser, M. B. Pepys and C. C. Blake, J. Mol. Biol., 1997, 273, 729-739.

65 L. C. Serpell, M. Sunde, P. E. Fraser, P. K. Luther, E. P. Morris, O. Sangren, E. Lundgren and C. C. Blake, J. Mol. Biol., 1995, 254, 113-118.

66 L. Serpell, M. Sunde, M. Benson, G. Tennent, M. Pepys and P. Fraser, J. Mol. Biol., 2000, 300, 1033-1039.

67 C. Goldsbury, K. Goldie, J. Pellaud, J. Seelig, P. Frey, S. A. Muller, J. Kistler, G. J. Cooper and U. Aebi, J. Struct. Biol., 2000, 130, 352-362.

68 J. L. Jimenez, J. I. Guijarro, E. Orlova, J. Zurdo, C. M. Dobson, M. Sunde and H. R. Saibil, EMBO J., 1999, 18, 815-821.

69 J. L. Jimenez, E. J. Nettleton, M. Bouchard, C. V. Robinson, C. M. Dobson and H. R. Saibil, Proc. Natl. Acad. Sci. U. S. A., 2002, 99, 9196-9201.

70 J. Meinhardt, C. Sachse, P. Hortschansky, N. Grigorieff and M. Fandrich, J. Mol. Biol., 2009, 386, 869-877.

71 C. Goldsbury, U. Aebi and P. Frey, Trends Mol. Med., 2001, 7, 582 .

72 L. C. Serpell, C. C. F. Blake and P. E. Fraser, Biochemistry, 2000, 39, 13269-13275.

73 P. Sikorski, E. D. Atkins and L. C. Serpell, Structure, 2003, 11, 915-926. 
74 L. C. Serpell and J. M. Smith, J. Mol. Biol., 2000, 299, 225-231.

75 U. Slotta, S. Hess, K. Spiess, T. Stromer, L. Serpell and T. Scheibel, Macromol. Biosci., 2007, 7, 183-188.

76 O. S. Makin and L. C. Serpell, J. Mol. Biol., 2004, 335, 1279-1288.

77 T. R. Serio, A. G. Cashikar, A. S. Kowal, G. J. Sawicki, J. J. Moslehi, L. Serpell, M. F. Arnsdorf and S. L. Lindquist, Science, 2000, 289, 1317-1321.

78 M. O. Steinmetz, Z. Gattin, R. Verel, B. Ciani, T. Stromer, J. M. Green, P. Tittmann, C. Schulze-Briese, H. Gross, W. F. van Gunsteren, B. H. Meier, L. C. Serpell, S. A. Muller and R. A. Kammerer, J. Mol. Biol., 2008, 376, 898-912.

79 C. C. F. Blake, L. C. Serpell, M. Sunde, O. Sandgren and E. Lundgren, Ciba Found. Symp., 1996, 199, 6-21.

80 J. Berriman, L. C. Serpell, K. A. Oberg, A. L. Fink, M. Goedert and R. A. Crowther, Proc. Natl. Acad. Sci. U. S. A., 2003, 100, 9034-9038.

81 Y. K. Al-Hilaly, S. J. Pollack, D. M. Vadukul, F. Citossi, J. E. Rickard, M. Simpson, J. M. D. Storey, C. R. Harrington, C. M. Wischik and L. C. Serpell, J. Mol. Biol., 2017, 429, 3650-3665.

82 T. R. Jahn, G. A. Tennent and S. E. Radford, J. Biol. Chem., 2008, 283, 17279-17286.

83 K. Pauwels, T. L. Williams, K. L. Morris, W. Jonckheere, A. Vandersteen, G. Kelly, J. Schymkowitz, F. Rousseau, A. Pastore, L. C. Serpell and K. Broersen, J. Biol. Chem., 2012, 287, 5650-5660.

84 K. E. Marshall, M. R. Hicks, T. L. Williams, S. V. Hoffmann, A. Rodger, T. R. Dafforn and L. C. Serpell, Biophys. J., 2010, 98, 330-338.

85 L. C. Serpell, M. Benson, J. J. Liepnieks and P. E. Fraser, Amyloid, 2007, 14, 199-203.

86 K. L. Morris, A. Rodger, M. R. Hicks, M. Debulpaep, J. Schymkowitz, F. Rousseau and L. C. Serpell, Biochem. J., 2013, 450, 275-283.

87 K. Pauwels, T. L. Williams, K. L. Morris, W. Jonckheere, A. Vandersteen, G. Kelly, J. Schymkowitz, F. Rousseau, A. Pastore, L. C. Serpell and K. Broersen, J. Biol. Chem., 2012, 287, 5650-5660.

88 M. Torok, S. Milton, R. Kayed, P. Wu, T. McIntire, C. G. Glabe and R. Langen, J. Biol. Chem., 2002, 277, 40810-40815.

89 A. V. Kajava, U. Aebi and A. C. Steven, J. Mol. Biol., 2005, 348, 247-252.

90 C. P. Jaroniec, C. E. MacPhee, V. S. Bajaj, M. T. McMahon, C. M. Dobson and R. G. Griffin, Proc. Natl. Acad. Sci. U. S. A., 2004, 101, 711-716.

91 A. T. Petkova, Y. Ishii, J. J. Balbach, O. N. Antzutkin, R. D. Leapman, F. Delaglio and R. Tycko, Proc. Natl. Acad. Sci. U. S. A., 2002, 99, 16742-16747.

92 R. Diaz-Avalos, C. Long, E. Fontano, M. Balbirnie, R. Grothe, D. Eisenberg and D. L. D. Caspar, J. Mol. Biol., 2003, 330, 1165-1175.

93 B. Li, P. Ge, K. A. Murray, P. Sheth, M. Zhang, G. Nair, M. R. Sawaya, W. S. Shin, D. R. Boyer, S. Ye, D. S. Eisenberg, Z. H. Zhou and L. Jiang, Nat. Commun., 2018, 9, 3609.
94 R. Nelson, M. R. Sawaya, M. Balbirnie, A. O. Madsen, C. Riekel, R. Grothe and D. Eisenberg, Nature, 2005, 435, 773-778.

95 K. Tsemekhman, L. Goldschmidt, D. Eisenberg and D. Baker, Protein Sci., 2007, 16, 761-764.

96 P. M. Seidler, D. R. Boyer, K. A. Murray, T. P. Yang, M. Bentzel, M. R. Sawaya, G. Rosenberg, D. Cascio, C. K. Williams, K. L. Newell, B. Ghetti, M. A. DeTure, D. W. Dickson, H. V. Vinters and D. S. Eisenberg, J. Biol. Chem., 2019, 294, 16451-16464.

97 M. A. Walti, F. Ravotti, H. Arai, C. G. Glabe, J. S. Wall, A. Bockmann, P. Guntert, B. H. Meier and R. Riek, Proc. Natl. Acad. Sci. U. S. A., 2016, 113, E4976-E4984.

98 M. T. Colvin, R. Silvers, Q. Z. Ni, T. V. Can, I. Sergeyev, M. Rosay, K. J. Donovan, B. Michael, J. Wall, S. Linse and R. G. Griffin, J. Am. Chem. Soc., 2016, 138, 9663-9674.

99 A. Moshe, M. Landau and D. Eisenberg, Methods Mol. Biol., 2016, 1345, 201-210.

100 D. S. Eisenberg and M. R. Sawaya, Proc. Natl. Acad. Sci. U. S. A., 2016, 113, 9398-9400.

101 A. W. P. Fitzpatrick, B. Falcon, S. He, A. G. Murzin, G. Murshudov, H. J. Garringer, R. A. Crowther, B. Ghetti, M. Goedert and S. H. W. Scheres, Nature, 2017, 547, 185-190.

102 D. S. Eisenberg and M. R. Sawaya, Annu. Rev. Biochem., 2017, 86, 69-95.

103 E. Nogales and S. H. Scheres, Mol. Cell, 2015, 58, 677-689.

104 R. Tycko, Annu. Rev. Phys. Chem., 2011, 62, 279-299.

105 K. Iwata, T. Fujiwara, Y. Matsuki, H. Akutsu, S. Takahashi, H. Naiki and Y. Goto, Proc. Natl. Acad. Sci. U. S. A., 2006, 103, 18119-18124.

106 A. K. Paravastu, R. D. Leapman, W. M. Yau and R. Tycko, Proc. Natl. Acad. Sci. U. S. A., 2008, 105, 18349-18354.

107 M. D. Tuttle, G. Comellas, A. J. Nieuwkoop, D. J. Covell, D. A. Berthold, K. D. Kloepper, J. M. Courtney, J. K. Kim, A. M. Barclay, A. Kendall, W. Wan, G. Stubbs, C. D. Schwieters, V. M. Lee, J. M. George and C. M. Rienstra, Nat. Struct. Mol. Biol., 2016, 23, 409-415.

108 L. Bousset, L. Pieri, G. Ruiz-Arlandis, J. Gath, P. H. Jensen, B. Habenstein, K. Madiona, V. Olieric, A. Böckmann, B. H. Meier and R. Melki, Nat. Commun., 2013, 4, 2575.

109 E. H. Egelman, Ultramicroscopy, 2000, 85, 225-234.

110 S. H. Scheres, J. Struct. Biol., 2012, 180, 519-530.

111 Y. Li, C. Zhao, F. Luo, Z. Liu, X. Gui, Z. Luo, X. Zhang, D. Li, C. Liu and X. Li, Cell Res., 2018, 28, 897-903.

112 J. A. Rodriguez, M. I. Ivanova, M. R. Sawaya, D. Cascio, F. E. Reyes, D. Shi, S. Sangwan, E. L. Guenther, L. M. Johnson, M. Zhang, L. Jiang, M. A. Arbing, B. L. Nannenga, J. Hattne, J. Whitelegge, A. S. Brewster, M. Messerschmidt, S. Boutet, N. K. Sauter, T. Gonen and D. S. Eisenberg, Nature, 2015, 525, 486-490.

113 R. Guerrero-Ferreira, N. M. Taylor, D. Mona, P. Ringler, M. E. Lauer, R. Riek, M. Britschgi and H. Stahlberg, eLife, 2018, 7, e36402.

114 B. Falcon, J. Zivanov, W. Zhang, A. G. Murzin, H. J. Garringer, R. Vidal, R. A. Crowther, K. L. Newell, 
B. Ghetti, M. Goedert and S. H. W. Scheres, Nature, 2019, 568, 420-423.

115 Q. Cao, D. R. Boyer, M. R. Sawaya, P. Ge and D. S. Eisenberg, Nat. Struct. Mol. Biol., 2019, 26, 619-627.

116 B. Falcon, W. Zhang, A. G. Murzin, G. Murshudov, H. J. Garringer, R. Vidal, R. A. Crowther, B. Ghetti, S. Scheres and M. Goedert, Nature, 2018, 561, 137-140.

117 L. Radamaker, Y. H. Lin, K. Annamalai, S. Huhn, U. Hegenbart, S. O. Schonland, G. Fritz, M. Schmidt and M. Fandrich, Nat. Commun., 2019, 10, 1103.

118 M. G. Iadanza, R. Silvers, J. Boardman, H. I. Smith, T. K. Karamanos, G. T. Debelouchina, Y. Su, R. G. Griffin, N. A. Ranson and S. E. Radford, Nat. Commun., 2018, 9, 4517.

119 F. Liberta, M. Rennegarbe, R. Rosler, J. Bijzet, S. Wiese, B. P. C. Hazenberg and M. Fandrich, Amyloid, 2019, 26, 164-170.

120 F. Liberta, S. Loerch, M. Rennegarbe, A. Schierhorn, P. Westermark, G. T. Westermark, B. P. C. Hazenberg, N. Grigorieff, M. Fandrich and M. Schmidt, Nat. Commun., 2019, 10, 1104.

121 M. Kato, T. W. Han, S. Xie, K. Shi, X. Du, L. C. Wu, H. Mirzaei, E. J. Goldsmith, J. Longgood, J. Pei, N. V. Grishin, D. E. Frantz, J. W. Schneider, S. Chen, L. Li, M. R. Sawaya, D. Eisenberg, R. Tycko and S. L. McKnight, Cell, 2012, 149, 753-767.

122 D. T. Murray, M. Kato, Y. Lin, K. R. Thurber, I. Hung, S. L. McKnight and R. Tycko, Cell, 2017, 171, 615-627. e616.

123 M. P. Hughes, M. R. Sawaya, D. R. Boyer, L. Goldschmidt, J. A. Rodriguez, D. Cascio, L. Chong, T. Gonen and D. S. Eisenberg, Science, 2018, 359, 698-701.

124 M. Reches and E. Gazit, Science, 2003, 300, 625-627.

125 J. Greenwald and R. Riek, J. Mol. Biol., 2012, 421, 417-426.

126 E. Gazit, Annu. Rev. Biochem., 2018, 87, 533-553.

127 W. T. Astbury, S. Dickinson and K. Bailey, Biochem. J., 1935, 29, 2351-2360.

128 M. Sunde and C. Blake, Adv. Protein Chem., 1997, 50, 123-159.

129 C. Wasmer, A. Lange, H. Van Melckebeke, A. B. Siemer, R. Riek and B. H. Meier, Science, 2008, 319, 1523-1526.

130 C. Lara, N. P. Reynolds, J. T. Berryman, A. Xu, A. Zhang and R. Mezzenga, J. Am. Chem. Soc., 2014, 136, 4732-4739.

131 I. Usov, J. Adamcik and R. Mezzenga, ACS Nano, 2013, 7, 10465-10474.

132 J. Adamcik and R. Mezzenga, Soft Matter, 2011, 7, 5437-5443.

133 S. Assenza, J. Adamcik, R. Mezzenga and P. De Los Rios, Phys. Rev. Lett., 2014, 113, 268103.

134 C. Seuring, J. Verasdonck, P. Ringler, R. Cadalbert, H. Stahlberg, A. Böckmann, B. H. Meier and R. Riek, J. Phys. Chem. B, 2017, 121, 1783-1792.

135 R. Verel, I. T. Tomka, C. Bertozzi, R. Cadalbert, R. A. Kammerer, M. O. Steinmetz and B. H. Meier, Angew. Chem., Int. Ed., 2008, 47, 5842-5845.

136 C. Lara, J. Adamcik, S. Jordens and R. Mezzenga, Biomacromolecules, 2011, 12, 1868-1875.

137 C. Huang, Z. Wang, D. Quinn, S. Suresh and K. J. Hsia, Proc. Natl. Acad. Sci. U. S. A., 2018, 115, 12359-12364.
138 Y. Sawa, F. Ye, K. Urayama, T. Takigawa, V. Gimenez-Pinto, R. L. B. Selinger and J. V. Selinger, Proc. Natl. Acad. Sci. U. S. A., 2011, 108, 6364-6368.

139 J. Adamcik, J.-M. Jung, J. Flakowski, P. De Los Rios, G. Dietler and R. Mezzenga, Nat. Nanotechnol., 2010, 5, 423-428.

140 S. Zhang, M. Andreasen, J. T. Nielsen, L. Liu, E. H. Nielsen, J. Song, G. Ji, F. Sun, T. Skrydstrup, F. Besenbacher, N. C. Nielsen, D. E. Otzen and M. Dong, Proc. Natl. Acad. Sci. U. S. A., 2013, 110, 2798-2803.

141 J. Adamcik, A. Sánchez-Ferrer, N. Ait-Bouziad, N. P. Reynolds, H. A. Lashuel and R. Mezzenga, Angew. Chem., Int. Ed., 2016, 55, 618-622.

142 A. Lomakin, D. S. Chung, G. B. Benedek, D. A. Kirschner and D. B. Teplow, Proc. Natl. Acad. Sci. U. S. A., 1996, 93, 1125-1129.

143 J. T. Jarrett and P. T. Lansbury, Jr., Cell, 1993, 73, 1055-1058.

144 S. I. Cohen, M. Vendruscolo, M. E. Welland, C. M. Dobson, E. M. Terentjev and T. P. Knowles, J. Chem. Phys., 2011, 135, 065105.

145 T. P. Knowles, D. A. White, A. R. Abate, J. J. Agresti, S. I. Cohen, R. A. Sperling, E. J. De Genst, C. M. Dobson and D. A. Weitz, Proc. Natl. Acad. Sci. U. S. A., 2011, 108, 14746-14751.

146 F. Oosawa and M. Kasai, J. Mol. Biol., 1962, 4, 10-21.

147 G. Meisl, X. Yang, E. Hellstrand, B. Frohm, J. B. Kirkegaard, S. I. Cohen, C. M. Dobson, S. Linse and T. P. Knowles, Proc. Natl. Acad. Sci. U. S. A., 2014, 111, 9384-9389.

148 R. Gaspar, G. Meisl, A. K. Buell, L. Young, C. F. Kaminski, T. P. J. Knowles, E. Sparr and S. Linse, Q. Rev. Biophys., 2017, 50, e6.

149 F. A. Ferrone, J. Hofrichter and W. A. Eaton, J. Mol. Biol., 1985, 183, 611-631.

150 A. M. Ruschak and A. D. Miranker, Proc. Natl. Acad. Sci. U. S. A., 2007, 104, 12341-12346.

151 T. Scheidt, U. Łapińska, J. R. Kumita, D. R. Whiten, D. Klenerman, M. R. Wilson, S. I. A. Cohen, S. Linse, M. Vendruscolo, C. M. Dobson, T. P. J. Knowles and P. Arosio, Adv. Sci., 2019, 5, eaau3112.

152 P. Arosio, T. P. Knowles and S. Linse, Phys. Chem. Chem. Phys., 2015, 17, 7606-7618.

153 P. Arosio, R. Cukalevski, B. Frohm, T. P. Knowles and S. Linse, J. Am. Chem. Soc., 2014, 136, 219-225.

154 S. I. A. Cohen, P. Arosio, J. Presto, F. R. Kurudenkandy, H. Biverstal, L. Dolfe, C. Dunning, X. Yang, B. Frohm, M. Vendruscolo, J. Johansson, C. M. Dobson, A. Fisahn, T. P. J. Knowles and S. Linse, Nat. Struct. Mol. Biol., 2015, 22, 207-213.

155 R. M. Koffie, M. Meyer-Luehmann, T. Hashimoto, K. W. Adams, M. L. Mielke, M. Garcia-Alloza, K. D. Micheva, S. J. Smith, M. L. Kim, V. M. Lee, B. T. Hyman and T. L. SpiresJones, Proc. Natl. Acad. Sci. U. S. A., 2009, 106, 4012-4017.

156 J. A. Hardy and G. A. Higgins, Science, 1992, 256, 184-185. 157 D. J. Selkoe and J. Hardy, EMBO Mol. Med., 2016, 8, 595-608. 
158 J. Hardy, J. Alzheimer's Dis., 2006, 9, 151-153.

159 P. T. Lansbury and H. A. Lashuel, Nature, 2006, 443, 774-779.

160 E. N. Cline, M. A. Bicca, K. L. Viola and W. L. Klein, J. Alzheimer's Dis., 2018, 64, S567-S610.

161 F. Kametani and M. Hasegawa, Front. Neurosci., 2018, $12,25$.

162 D. W. Dickson, H. A. Crystal, L. A. Mattiace, D. M. Masur, A. D. Blau, P. Davies, S. H. Yen and M. K. Aronson, Neurobiol. Aging, 1992, 13, 179-189.

163 E. J. Slow, R. K. Graham, A. P. Osmand, R. S. Devon, G. Lu, Y. Deng, J. Pearson, K. Vaid, N. Bissada, R. Wetzel, B. R. Leavitt and M. R. Hayden, Proc. Natl. Acad. Sci. U. S. A., 2005, 102, 11402-11407.

164 M. Arrasate, S. Mitra, E. S. Schweitzer, M. R. Segal and S. Finkbeiner, Nature, 2004, 431, 805-810.

165 D. Morgan, D. M. Diamond, P. E. Gottschall, K. E. Ugen, C. Dickey, J. Hardy, K. Duff, P. Jantzen, G. DiCarlo, D. Wilcock, K. Connor, J. Hatcher, C. Hope, M. Gordon and G. W. Arendash, Nature, 2000, 408, 982-985.

166 J. R. Harrison and M. J. Owen, Br. J. Psychiatry, 2016, 208, 1-3.

167 S. Makin, Nature, 2018, 559, S4-S7.

168 J. D. Harper, S. S. Wong, C. M. Lieber and P. T. Lansbury, Chem. Biol., 1997, 4, 119-125.

169 D. M. Walsh, A. Lomakin, G. B. Benedek, M. M. Condron and D. B. Teplow, J. Biol. Chem., 1997, 272, 22364-22372.

170 M. Shahnawaz and C. Soto, J. Biol. Chem., 2012, 287, 11665-11676.

171 M. Stefani, FEBS J., 2010, 277, 4602-4613.

172 K. W. Tipping, T. K. Karamanos, T. Jakhria, M. G. Iadanza, S. C. Goodchild, R. Tuma, N. A. Ranson, E. W. Hewitt and S. E. Radford, Proc. Natl. Acad. Sci. U. S. A., 2015, 112, 5691-5696.

173 N. Cremades, S. I. A. Cohen, E. Deas, A. Y. Abramov, A. Y. Chen, A. Orte, M. Sandal, R. W. Clarke, P. Dunne, F. A. Aprile, C. W. Bertoncini, N. W. Wood, T. P. J. Knowles, C. M. Dobson and D. Klenerman, Cell, 2012, 149, 1048-1059.

174 A. L. Mahul-Mellier, F. Vercruysse, B. Maco, N. Ait-Bouziad, M. De Roo, D. Muller and H. A. Lashuel, Cell Death Differ., 2015, 22, 2107-2122.

175 M. M. Dorostkar, S. Burgold, S. Filser, S. Barghorn, B. Schmidt, U. R. Anumala, H. Hillen, C. Klein and J. Herms, Brain, 2014, 137, 3319-3326.

176 R. M. Koffie, M. Meyer-Luehmann, T. Hashimoto, K. W. Adams, M. L. Mielke, M. Garcia-Alloza, K. D. Micheva, S. J. Smith, M. L. Kim, V. M. Lee, B. T. Hyman and T. L. Spires-Jones, Proc. Natl. Acad. Sci. U. S. A., 2009, 106, 4012-4017.

177 A. Roher, M. Chaney, Y.-M. Kuo, S. Webster, W. Stine, L. Haverkamp, A. Woods, R. Cotter, J. Tuohy, G. Krafft, B. Bonnell and M. Emmerling, J. Biol. Chem., 1996, 271, 20631-20635.

178 A. R. Upadhaya, I. Lungrin, H. Yamaguchi, M. Fändrich and D. R. Thal, J. Cell. Mol. Med., 2012, 16, 287-295.
179 T. Yang, S. Li, H. Xu, D. M. Walsh and D. J. Selkoe, J. Neurosci., 2017, 37, 152-163.

180 C. D. Borsarelli, L. J. Falomir-Lockhart, V. Ostatna, J. A. Fauerbach, H. H. Hsiao, H. Urlaub, E. Palecek, E. A. Jares-Erijman and T. M. Jovin, Free Radical Biol. Med., 2012, 53, 1004-1015.

181 Y. K. Al-Hilaly, T. L. Williams, M. Stewart-Parker, L. Ford, E. Skaria, M. Cole, W. G. Bucher, K. L. Morris, A. A. Sada, J. R. Thorpe and L. C. Serpell, Acta Neuropathol. Commun., 2013, 1, 83.

182 Y. J. Chang and Y. R. Chen, FEBS J., 2014, 281, 2674-2687. 183 E. N. Cline, A. Das, M. A. Bicca, S. N. Mohammad, L. F. Schachner, J. M. Kamel, N. DiNunno, A. Weng, J. D. Paschall, R. L. Bu, F. M. Khan, M. G. Rollins, A. N. Ives, G. Shekhawat, N. Nunes-Tavares, F. G. de Mello, P. D. Compton, N. L. Kelleher and W. L. Klein, J. Neurochem., 2019, 148, 822-836.

184 N. Piening, P. Weber, T. Hogen, M. Beekes, H. Kretzschmar and A. Giese, Amyloid, 2006, 13, 67-77.

185 K. Teruya, K. Nishizawa, A. Oguma, Y. Sakasegawa, T. Kitamoto and K. Doh-Ura, Biochim. Biophys. Acta, Gen. Subj., 2019, 1863, 384-394.

186 S. S. Vollers, D. B. Teplow and G. Bitan, Methods Mol. Biol., 2005, 299, 11-18.

187 H. A. Lashuel, B. M. Petre, J. Wall, M. Simon, R. J. Nowak, T. Walz and P. T. Lansbury, Jr., J. Mol. Biol., 2002, 322, 1089-1102.

188 M. Jayaraman, R. Kodali, B. Sahoo, A. K. Thakur, A. Mayasundari, R. Mishra, C. B. Peterson and R. Wetzel, J. Mol. Biol., 2012, 415, 881-899.

189 S. A. Kotler, J. R. Brender, S. Vivekanandan, Y. Suzuki, K. Yamamoto, M. Monette, J. Krishnamoorthy, P. Walsh, M. Cauble, M. M. Holl, E. N. Marsh and A. Ramamoorthy, Sci. Rep., 2015, 5, 11811.

190 Y. Sun, A. Kakinen, Y. Xing, E. H. Pilkington, T. P. Davis, P. C. Ke and F. Ding, Biochim. Biophys. Acta, Mol. Basis Dis., 2019, 1865, 434-444.

191 N. D. Younan and J. H. Viles, Biochemistry, 2015, 54, 4297-4306. 192 A. Jan, O. Adolfsson, I. Allaman, A. L. Buccarello, P. J. Magistretti, A. Pfeifer, A. Muhs and H. A. Lashuel, J. Biol. Chem., 2011, 286, 8585-8596.

193 J. C. Stroud, C. Liu, P. K. Teng and D. Eisenberg, Proc. Natl. Acad. Sci. U. S. A., 2012, 109, 7717-7722.

194 R. Kayed, E. Head, J. L. Thompson, T. M. McIntire, S. C. Milton, C. W. Cotman and C. G. Glabe, Science, 2003, 300, 486-489.

195 C. G. Glabe, J. Biol. Chem., 2008, 283, 29639-29643.

196 L. Breydo, D. Kurouski, S. Rasool, S. Milton, J. W. Wu, V. N. Uversky, I. K. Lednev and C. G. Glabe, Biochem. Biophys. Res. Commun., 2016, 477, 700-705.

197 R. Kayed, I. Canto, L. Breydo, S. Rasool, T. Lukacsovich, J. Wu, R. Albay, 3rd, A. Pensalfini, S. Yeung, E. Head, J. L. Marsh and C. Glabe, Mol. Neurodegener., 2010, 5, 57.

198 H. A. Lashuel, D. M. Hartley, B. M. Petre, J. S. Wall, M. N. Simon, T. Walz and P. T. Lansbury, Jr., J. Mol. Biol., 2003, 332, 795-808. 
199 A. Jan, D. M. Hartley and H. A. Lashuel, Nat. Protoc., 2010, 5, 1186-1209.

200 M. Serra-Batiste, M. Ninot-Pedrosa, E. Puig, S. Ciudad, M. Gairi and N. Carulla, Methods Mol. Biol., 2018, 1779, 13-22.

201 S. L. Bernstein, N. F. Dupuis, N. D. Lazo, T. Wyttenbach, M. M. Condron, G. Bitan, D. B. Teplow, J.-E. Shea, B. T. Ruotolo, C. V. Robinson and M. T. Bowers, Nat. Chem., 2009, 1, 326-331.

202 J. Singh, A. T. Sabareesan, M. K. Mathew and J. B. Udgaonkar, J. Mol. Biol., 2012, 423, 217-231.

203 B. Serra-Vidal, L. Pujadas, D. Rossi, E. Soriano, S. Madurga and N. Carulla, ACS Chem. Biol., 2014, 9, 2678-2685.

204 W. Paslawski, S. Mysling, K. Thomsen, T. J. Jorgensen and D. E. Otzen, Angew. Chem., Int. Ed., 2014, 53, 7560-7563.

205 I. Kheterpal, H. A. Lashuel, D. M. Hartley, T. Walz, P. T. Lansbury, Jr. and R. Wetzel, Biochemistry, 2003, 42, 14092-14098.

206 H. A. Scheidt, I. Morgado and D. Huster, J. Biol. Chem., 2012, 287, 22822-22826.

207 A. Potapov, W. M. Yau, R. Ghirlando, K. R. Thurber and R. Tycko, J. Am. Chem. Soc., 2015, 137, 8294-8307.

208 P. C. A. van der Wel, Solid State Nucl. Magn. Reson., 2017, 88, 1-14.

209 J. Chung, H. Yang, M. D. de Beus, C. Y. Ryu, K. Cho and W. Colon, Biochem. Biophys. Res. Commun., 2003, 312, 873-876.

210 C. A. Lasagna-Reeves, U. Sengupta, D. Castillo-Carranza, J. E. Gerson, M. Guerrero-Munoz, J. C. Troncoso, G. R. Jackson and R. Kayed, Acta Neuropathol. Commun., 2014, 2, 56.

211 A. K. R. Dasari, R. M. Hughes, S. Wi, I. Hung, Z. Gan, J. W. Kelly and K. H. Lim, Sci. Rep., 2019, 9, 33.

212 L. Wang, H. A. Lashuel, T. Walz and W. Colon, Proc. Natl. Acad. Sci. U. S. A., 2002, 99, 15947-15952.

213 R. Oropesa-Nunez, S. Seghezza, S. Dante, A. Diaspro, R. Cascella, C. Cecchi, M. Stefani, F. Chiti and C. Canale, Oncotarget, 2016, 7, 44991-45004.

214 M. Diociaiuti, L. Z. Polzi, L. Valvo, F. Malchiodi-Albedi, C. Bombelli and M. C. Gaudiano, Biophys. J., 2006, 91, 2275-2281.

215 M. Bhattacharya, N. Jain, P. Dogra, S. Samai and S. Mukhopadhyay, J. Phys. Chem. Lett., 2013, 4, 480-485.

216 M. Bhattacharya and P. Dogra, Langmuir, 2015, 31, 8911-8922.

217 S. Arya, A. Kumari, V. Dalal, M. Bhattacharya and S. Mukhopadhyay, Phys. Chem. Chem. Phys., 2015, 17, 22862-22871.

218 D. K. Ghosh, A. Roy and A. Ranjan, J. Mol. Biol., 2018, 430, 963-986.

219 J. Lee, Y. H. Kim, F. T. Arce, A. L. Gillman, H. Jang, B. L. Kagan, R. Nussinov, J. Yang and R. Lal, ACS Chem. Neurosci., 2017, 8, 1348-1357.

220 H. Lin, R. Bhatia and R. Lal, FASEB J., 2001, 15, 2433-2444.

221 H. Lin, Y. J. Zhu and R. Lal, Biochemistry, 1999, 38, 11189-11196.

222 N. Patel, S. Ramachandran, R. Azimov, B. L. Kagan and R. Lal, Biochemistry, 2015, 54, 7320-7325.
223 A. Quist, I. Doudevski, H. Lin, R. Azimova, D. Ng, B. Frangione, B. Kagan, J. Ghiso and R. Lal, Proc. Natl. Acad. Sci. U. S. A., 2005, 102, 10427-10432.

224 Y. Hirakura, R. Azimov, R. Azimova and B. L. Kagan, J. Neurosci. Res., 2000, 60, 490-494.

225 Y. Hirakura, I. Carreras, J. D. Sipe and B. L. Kagan, Amyloid, 2002, 9, 13-23.

226 T. A. Mirzabekov, M. C. Lin and B. L. Kagan, J. Biol. Chem., 1996, 271, 1988-1992.

227 M. Anguiano, R. J. Nowak and P. T. Lansbury, Jr., Biochemistry, 2002, 41, 11338-11343.

228 M. J. Volles and P. T. Lansbury, Jr., Biochemistry, 2002, 41, 4595-4602.

229 H. Y. Kim, M. K. Cho, A. Kumar, E. Maier, C. Siebenhaar, S. Becker, C. O. Fernandez, H. A. Lashuel, R. Benz, A. Lange and M. Zweckstetter, J. Am. Chem. Soc., 2009, 131, 17482-17489.

230 R. Kayed, A. Pensalfini, L. Margol, Y. Sokolov, F. Sarsoza, E. Head, J. Hall and C. Glabe, J. Biol. Chem., 2009, 284, 4230-4237.

231 F. J. B. Bäuerlein, I. Saha, A. Mishra, M. Kalemanov, A. Martínez-Sánchez, R. Klein, I. Dudanova, M. S. Hipp, F. U. Hartl, W. Baumeister and R. Fernández-Busnadiego, Cell, 2017, 171, 179-187.

232 M. Goedert, R. Jakes and M. G. Spillantini, J. Parkinson's Dis., 2017, 7, S51-S69.

233 M. Goedert and M. G. Spillantini, in Basic Neurochemistry, ed. S. T. Brady, G. J. Siegel, R. W. Albers and D. L. Price, Academic Press, New York, 8th edn, 2012, pp. 829-843.

234 A.-L. Mahul-Mellier, J. Burtscher, N. Maharjan, L. Weerens, M. Croisier, F. Kuttler, M. Leleu, G. W. Knott and H. A. Lashuel, Proc. Natl. Acad. Sci. U. S. A., 2020, 117, 4971-4982.

235 G. M. Shankar, S. Li, T. H. Mehta, A. Garcia-Munoz, N. E. Shepardson, I. Smith, F. M. Brett, M. A. Farrell, M. J. Rowan, C. A. Lemere, C. M. Regan, D. M. Walsh, B. L. Sabatini and D. J. Selkoe, Nat. Med., 2008, 14, 837-842.

236 F. Panza, M. Lozupone, V. Dibello, A. Greco, A. Daniele, D. Seripa, G. Logroscino and B. P. Imbimbo, Immunotherapy, 2019, 11, 3-6.

237 J. C. de la Torre, N. Engl. J. Med., 2014, 370, 1459-1460.

238 V. Logovinsky, A. Satlin, R. Lai, C. Swanson, J. Kaplow, G. Osswald, H. Basun and L. Lannfelt, Alzheimer's Res. Ther., 2016, 8, 14.

239 J. Cummings, G. Lee, A. Ritter, M. Sabbagh and K. Zhong, Alzheimer's Dementia, 2019, 5, 272-293.

240 D. L. Castillo-Carranza, U. Sengupta, M. J. GuerreroMunoz, C. A. Lasagna-Reeves, J. E. Gerson, G. Singh, D. M. Estes, A. D. Barrett, K. T. Dineley, G. R. Jackson and R. Kayed, J. Neurosci., 2014, 34, 4260-4272.

241 J. E. Gerson, K. M. Farmer, N. Henson, D. L. CastilloCarranza, M. Carretero Murillo, U. Sengupta, A. Barrett and R. Kayed, Mol. Neurodegener., 2018, 13, 13.

242 G. Gustafsson, V. Lindstrom, J. Rostami, E. Nordstrom, L. Lannfelt, J. Bergstrom, M. Ingelsson and A. Erlandsson, J. Neuroinflammation, 2017, 14, 241. 
243 O. El-Agnaf, C. Overk, E. Rockenstein, M. Mante, J. Florio, A. Adame, N. Vaikath, N. Majbour, S. J. Lee, C. Kim, E. Masliah and R. A. Rissman, Neurobiol. Dis., 2017, 104, 85-96.

244 V. Lindstrom, T. Fagerqvist, E. Nordstrom, F. Eriksson, A. Lord, S. Tucker, J. Andersson, M. Johannesson, H. Schell, P. J. Kahle, C. Moller, P. Gellerfors, J. Bergstrom, L. Lannfelt and M. Ingelsson, Neurobiol. Dis., 2014, 69, 134-143.

245 S. Salloway, L. A. Honigberg, W. Cho, M. Ward, M. Friesenhahn, F. Brunstein, A. Quartino, D. Clayton, D. Mortensen, T. Bittner, C. Ho, C. Rabe, S. P. Schauer, K. R. Wildsmith, R. N. Fuji, S. Suliman, E. M. Reiman, K. Chen and R. Paul, Alzheimer's Res. Ther., 2018, 10, 96.

246 T. Yang, Y. Dang, B. Ostaszewski, D. Mengel, V. Steffen, C. Rabe, T. Bittner, D. M. Walsh and D. J. Selkoe, Ann. Neurol., 2019, 86, 215-224.

247 W. I. Rosenblum, Neurobiol. Aging, 2014, 35, 969-974.

248 A. J. Mably, W. Liu, J. M. Mc Donald, J. C. Dodart, F. Bard, C. A. Lemere, B. O'Nuallain and D. M. Walsh, Neurobiol. Dis., 2015, 82, 372-384.

249 T. P. J. Knowles, M. Vendruscolo and C. M. Dobson, Nat. Rev. Mol. Cell Biol., 2014, 15, 384-396.

250 W. Zheng, M.-Y. Tsai, M. Chen and P. G. Wolynes, Proc. Natl. Acad. Sci. U. S. A., 2016, 113, 11835-11840.

251 D. Balchin, M. Hayer-Hartl and F. U. Hartl, Science, 2016, 353, aac4354.

252 J. McLaurin, R. Cecal, M. E. Kierstead, X. Tian, A. L. Phinney, M. Manea, J. E. French, M. H. L. Lambermon, A. A. Darabie, M. E. Brown, C. Janus, M. A. Chishti, P. Horne, D. Westaway, P. E. Fraser, H. T. J. Mount, M. Przybylski and P. St. GeorgeHyslop, Nat. Med., 2002, 8, 1263-1269.

253 J. Bieschke, M. Herbst, T. Wiglenda, R. P. Friedrich, A. Boeddrich, F. Schiele, D. Kleckers, J. M. Lopez del Amo, B. A. Grüning, Q. Wang, M. R. Schmidt, R. Lurz, R. Anwyl, S. Schnoegl, M. Fändrich, R. F. Frank, B. Reif, S. Günther, D. M. Walsh and E. E. Wanker, Nat. Chem. Biol., 2011, 8, 93-101.

254 P. C. Ke, E. H. Pilkington, Y. Sun, I. Javed, A. Kakinen, G. Peng, F. Ding and T. P. Davis, Adv. Mater., 2020, 32, 1901690.

255 C. Soto, E. M. Sigurdsson, L. Morelli, R. Asok Kumar, E. M. Castaño and B. Frangione, Nat. Med., 1998, 4, 822-826.

256 M. J. Krysmann, V. Castelletto, A. Kelarakis, I. W. Hamley, R. A. Hule and D. J. Pochan, Biochemistry, 2008, 47, 4597-4605.

257 R. S. Doody, R. G. Thomas, M. Farlow, T. Iwatsubo, B. Vellas, S. Joffe, K. Kieburtz, R. Raman, X. Sun, P. S. Aisen, E. Siemers, H. Liu-Seifert and R. Mohs, N. Engl. J. Med., 2014, 370, 311-321.

258 S. Salloway, R. Sperling, N. C. Fox, K. Blennow, W. Klunk, M. Raskind, M. Sabbagh, L. S. Honig, A. P. Porsteinsson, S. Ferris, M. Reichert, N. Ketter, B. Nejadnik, V. Guenzler, M. Miloslavsky, D. Wang, Y. Lu, J. Lull, I. C. Tudor, E. Liu, M. Grundman, E. Yuen, R. Black and H. R. Brashear, N. Engl. J. Med., 2014, 370, 322-333.
259 A. Feuerstein, statnews.com, https://www.statnews.com/ 2019/03/21/biogen-eisai-alzheimer-trial-stopped/, March $21,2019$.

260 J. Chen, A. H. Armstrong, A. N. Koehler and M. H. Hecht, J. Am. Chem. Soc., 2010, 132, 17015-17022.

261 J. Bieschke, J. Russ, R. P. Friedrich, D. E. Ehrnhoefer, H. Wobst, K. Neugebauer and E. E. Wanker, Proc. Natl. Acad. Sci. U. S. A., 2010, 107, 7710-7715.

262 F. L. Palhano, J. Lee, N. P. Grimster and J. W. Kelly, J. Am. Chem. Soc., 2013, 135, 7503-7510.

263 Q. Chen, Y. Du, K. Zhang, Z. Liang, J. Li, H. Yu, R. Ren, J. Feng, Z. Jin, F. Li, J. Sun, M. Zhou, Q. He, X. Sun, H. Zhang, M. Tian and D. Ling, ACS Nano, 2018, 12, 1321-1338.

264 A. Gladytz, B. Abel and H. J. Risselada, Angew. Chem., Int. Ed., 2016, 55, 11242-11246.

265 E. N. Gurzov, B. Wang, E. H. Pilkington, P. Chen, A. Kakinen, W. J. Stanley, S. A. Litwak, E. G. Hanssen, T. P. Davis, F. Ding and P. C. Ke, Small, 2016, 12, 1615-1626.

266 D. Kim, J. M. Yoo, H. Hwang, J. Lee, S. H. Lee, S. P. Yun, M. J. Park, M. Lee, S. Choi, S. H. Kwon, S. Lee, S.-H. Kwon, S. Kim, Y. J. Park, M. Kinoshita, Y.-H. Lee, S. Shin, S. R. Paik, S. J. Lee, S. Lee, B. H. Hong and H. S. Ko, Nat. Nanotechnol., 2018, 13, 812-818.

267 M. Li, A. Zhao, K. Dong, W. Li, J. Ren and X. Qu, Nano Res., 2015, 8, 3216-3227.

268 Q. Luo, Y.-X. Lin, P.-P. Yang, Y. Wang, G.-B. Qi, Z.-Y. Qiao, B.-N. Li, K. Zhang, J.-P. Zhang, L. Wang and H. Wang, Nat. Commun., 2018, 9, 1802.

269 M. Mahmoudi, O. Akhavan, M. Ghavami, F. Rezaee and S. M. A. Ghiasi, Nanoscale, 2012, 4, 7322-7325.

270 J. Wang, L. Liu, D. Ge, H. Zhang, Y. Feng, Y. Zhang, M. Chen and M. Dong, Chem. - Eur. J., 2018, 24, 3397-3402.

271 M. Wang, Y. Sun, X. Cao, G. Peng, I. Javed, A. Kakinen, T. P. Davis, S. Lin, J. Liu, F. Ding and P. C. Ke, Nanoscale, 2018, 10, 19995-20006.

272 Y. Zhao, J. Cai, Z. Liu, Y. Li, C. Zheng, Y. Zheng, Q. Chen, H. Chen, F. Ma, Y. An, L. Xiao, C. Jiang, L. Shi, C. Kang and Y. Liu, Nano Lett., 2019, 19, 674-683.

273 A. Kakinen, Y. Xing, N. Hegoda Arachchi, I. Javed, L. Feng, A. Faridi, A. M. Douek, Y. Sun, J. Kaslin, T. P. Davis, M. J. Higgins, F. Ding and P. C. Ke, Nano Lett., 2019, 19, 6535-6546.

274 E. H. Pilkington, M. Lai, X. Ge, W. J. Stanley, B. Wang, M. Wang, A. Kakinen, M.-A. Sani, M. R. Whittaker, E. N. Gurzov, F. Ding, J. F. Quinn, T. P. Davis and P. C. Ke, Biomacromolecules, 2017, 18, 4249-4260.

275 D. M. Fowler, A. V. Koulov, C. Alory-Jost, M. S. Marks, W. E. Balch and J. W. Kelly, PLoS Biol., 2006, 4, e6.

276 I. W. Hamley, Angew. Chem., Int. Ed., 2007, 46, 8128-8147. 277 R. A. Nixon, J. Cell Sci., 2007, 120, 4081-4091.

278 T. Cedervall, I. Lynch, S. Lindman, T. Berggård, E. Thulin, H. Nilsson, K. A. Dawson and S. Linse, Proc. Natl. Acad. Sci. U. S. A., 2007, 104, 2050-2055. 
279 T. E. Finn, A. C. Nunez, M. Sunde and S. B. EasterbrookSmith, J. Biol. Chem., 2012, 287, 21530-21540.

280 E. H. Pilkington, O. J. R. Gustafsson, Y. Xing, J. HernandezFernaud, C. Zampronio, A. Kakinen, A. Faridi, F. Ding, P. Wilson, P. C. Ke and T. P. Davis, ACS Nano, 2018, 12, 6066-6078.

281 Y. Sun, A. Kakinen, Y. Xing, E. H. Pilkington, T. P. Davis, P. C. Ke and F. Ding, Biochim. Biophys. Acta, Mol. Basis Dis., 2019, 1865, 434-444.

282 R. Layfield, J. Fergusson, A. Aitken, J. Lowe, M. Landon and R. J. Mayer, Neurosci. Lett., 1996, 209, 57-60.

283 L. Liao, D. Cheng, J. Wang, D. M. Duong, T. G. Losik, M. Gearing, H. D. Rees, J. J. Lah, A. I. Levey and J. Peng, J. Biol. Chem., 2004, 279, 37061-37068.

284 G. Perry, R. Friedman, G. Shaw and V. Chau, Proc. Natl. Acad. Sci. U. S. A., 1987, 84, 3033-3036.

285 G. Perry, S. Siedlak, P. Richey, M. Kawai, P. Cras, R. Kalaria, P. Galloway, J. Scardina, B. Cordell and B. Greenberg, J. Neurosci., 1991, 11, 3679-3683.

286 K. Wakabayashi, K. Tanji, F. Mori and H. Takahashi, Neuropathology, 2007, 27, 494-506.

287 M. B. Pepys, Philos. Trans. R. Soc., B, 2001, 356, 203-211.

288 G. A. Tennent, L. B. Lovat and M. B. Pepys, Proc. Natl. Acad. Sci. U. S. A., 1995, 92, 4299-4303.

289 A. T. Alexandrescu, Protein Sci., 2005, 14, 1-12.

290 Y. Fu, J. Zhao, Y. Atagi, H. M. Nielsen, C.-C. Liu, H. Zheng, M. Shinohara, T. Kanekiyo and G. Bu, Mol. Neurodegener., 2016, 11, 37.

291 H. C. Christianson and M. Belting, Matrix Biol., 2014, 35, 51-55.

292 M. Li, S. E. Howson, K. Dong, N. Gao, J. Ren, P. Scott and X. Qu, J. Am. Chem. Soc., 2014, 136, 11655-11663.

293 R. Malishev, E. Arad, S. K. Bhunia, S. Shaham-Niv, S. Kolusheva, E. Gazit and R. Jelinek, Chem. Commun., 2018, 54, 7762-7765.

294 W. Wei, C. Xu, N. Gao, J. Ren and X. Qu, Chem. Sci., 2014, 5, 4367-4374.

295 A. Faridi, Y. Sun, Y. Okazaki, G. Peng, J. Gao, A. Kakinen, P. Faridi, M. Zhao, I. Javed, A. W. Purcell, T. P. Davis, S. Lin, R. Oda, F. Ding and P. C. Ke, Small, 2018, 14, e1802825.

296 I. Javed, G. Peng, Y. Xing, T. Yu, M. Zhao, A. Kakinen, A. Faridi, C. L. Parish, F. Ding, T. P. Davis, P. C. Ke and S. Lin, Nat. Commun., 2019, 10, 3780.

297 N. Gao, H. Sun, K. Dong, J. Ren, T. Duan, C. Xu and X. Qu, Nat. Commun., 2014, 5, 3422.

298 J. D. Best and W. K. Alderton, Neuropsychiatr. Dis. Treat., 2008, 4, 567-576.

299 A. V. Kalueff, A. M. Stewart and R. Gerlai, Trends Pharmacol. Sci., 2014, 35, 63-75.

300 P. McGrath and C.-Q. Li, Drug Discovery Today, 2008, 13, 394-401.

301 K. J. Barnham and A. I. Bush, Chem. Soc. Rev., 2014, 43, 6727-6749.

302 J. Geng, M. Li, L. Wu, J. Ren and X. Qu, J. Med. Chem., 2012, 55, 9146-9155.
303 C. Arnold, Nat. Med., 2019, https:/www.nature.com/arti cles/d41591-019-00013-w.

304 P. Lindholm, M. H. Voutilainen, J. Laurén, J. Peränen, V.-M. Leppänen, J.-O. Andressoo, M. Lindahl, S. Janhunen, N. Kalkkinen, T. Timmusk, R. K. Tuominen and M. Saarma, Nature, 2007, 448, 73.

305 M. Lindahl, M. Saarma and P. Lindholm, Neurobiol. Dis., 2017, 97, 90-102.

306 I. L. Derkatch and S. W. Liebman, Prion, 2007, 1, 161-169.

307 B. Y. Ma and R. Nussinov, J. Mol. Biol., 2012, 421, 172-184.

308 R. Morales, I. Moreno-Gonzalez and C. Soto, PLoS Pathog., 2013, 9, 4.

309 T. L. Spires-Jones, J. Attems and D. R. Thal, Acta Neuropathol., 2017, 134, 187-205.

310 I. W. Hamley, Chem. Rev., 2012, 112, 5147-5192.

311 I. Ferrer, R. Blanco, M. Carmona, B. Puig, R. Ribera, M. J. Rey and T. Ribalta, Acta Neuropathol., 2001, 101, 49-56.

312 R. Morales, L. D. Estrada, R. Diaz-Espinoza, D. MoralesScheihing, M. C. Jara, J. Castilla and C. Soto, J. Neurosci., 2010, 30, 4528-4535.

313 E. Masliah, E. Rockenstein, I. Veinbergs, Y. Sagara, M. Mallory, M. Hashimoto and L. Mucke, Proc. Natl. Acad. Sci. U. S. A., 2001, 98, 12245-12250.

314 L. K. Clinton, M. Blurton-Jones, K. Myczek, J. Q. Trojanowski and F. M. LaFerla, J. Neurosci., 2010, 30, 7281-7289.

315 J. L. Guo, D. J. Covell, J. P. Daniels, M. Iba, A. Stieber, B. Zhang, D. M. Riddle, L. K. Kwong, Y. Xu, J. Q. Trojanowski and V. M. Y. Lee, Cell, 2013, 154, 103-117.

316 C. A. Lasagna-Reeves, D. L. Castillo-Carranza, M. J. GuerreroMunoz, G. R. Jackson and R. Kayed, Biochemistry, 2010, 49, 10039-10041.

317 P. T. Kotzbauer, B. I. Giasson, A. V. Kravitz, L. I. Golbe, M. H. Mark, J. Q. Trojanowski and V. M. Y. Lee, Exp. Neurol., 2004, 187, 279-288.

318 K. Ono, R. Takahashi, T. Ikeda and M. Yamada, J. Neurochem., 2012, 122, 883-890.

319 Y. S. Fang, K. J. Tsai, Y. J. Chang, P. Kao, R. Woods, P. H. Kuo, C. C. Wu, J. Y. Liao, S. C. Chou, V. Lin, L. W. Jin, H. S. Yuan, I. H. Cheng, P. H. Tu and Y. R. Chen, Nat. Commun., 2014, 5, 13.

320 B. O'Nuallain, A. D. Williams, P. Westermark and R. Wetzel, J. Biol. Chem., 2004, 279, 17490-17499.

321 M. E. Oskarsson, J. F. Paulsson, S. W. Schultz, M. Ingelsson, P. Westermark and G. T. Westermark, Am. J. Pathol., 2015, 185, 834-846.

322 J. Tran, D. Chang, F. Hsu, H. S. Wang and Z. F. Guo, FEBS Lett., 2017, 591, 177-185.

323 E. M. Jones and W. K. Surewicz, Cell, 2005, 121, 63-72.

324 I. L. Derkatch, S. M. Uptain, T. F. Outeiro, R. Krishnan, S. L. Lindquist and S. W. Liebman, Proc. Natl. Acad. Sci. U. S. A., 2004, 101, 12934-12939.

325 Y. A. Vitrenko, E. O. Gracheva, J. E. Richmond and S. W. Liebman, J. Biol. Chem., 2007, 282, 1779-1787.

326 G. L. Devlin, T. P. J. Knowles, A. Squires, M. G. McCammon, S. L. Gras, M. R. Nilsson, C. V. Robinson, C. M. Dobson and C. E. MacPhee, J. Mol. Biol., 2006, 360, 497-509. 
327 M. R. H. Krebs, L. A. Morozova-Roche, K. Daniel, C. V. Robinson and C. M. Dobson, Protein Sci., 2004, 13, 1933-1938.

328 M. Reches and E. Gazit, Isr. J. Chem., 2005, 45, 363-371.

329 P. Tamamis, L. Adler-Abramovich, M. Reches, K. Marshall, P. Sikorski, L. Serpell, E. Gazit and G. Archontis, Biophys. J., 2009, 96, 5020-5029.

330 N. Al Hafid and J. Christodoulou, Transl. Pediatr., 2015, 4, 304.

331 E. L. MacLeod and D. M. Ney, Annales Nestlé (English ed.), 2010, 68, 58-69.

332 J. E. Embury, C. E. Charron, A. Martynyuk, A. G. Zori, B. Liu, S. F. Ali, N. E. Rowland and P. J. Laipis, Brain Res., 2007, 1127, 136-150.

333 T. D. Do and M. T. Bowers, Anal. Chem., 2015, 87, 4245-4252.

334 H. W. German, S. Uyaver and U. H. Hansmann, J. Phys. Chem. A, 2014, 119, 1609-1615.

335 A. De Luigi, A. Mariani, M. De Paola, A. R. Depaolini, L. Colombo, L. Russo, V. Rondelli, P. Brocca, L. AdlerAbramovich and E. Gazit, Sci. Rep., 2015, 5, 15902.

336 C. M. Mak, H.-C. H. Lee, A. Y.-W. Chan and C.-W. Lam, Crit. Rev. Clin. Lab. Sci., 2013, 50, 142-162.

337 S. Shaham-Niv, L. Adler-Abramovich, L. Schnaider and E. Gazit, Sci. Adv., 2015, 1, e1500137.

338 D. Banik, A. Roy, N. Kundu and N. Sarkar, J. Phys. Chem. B, 2016, 120, 11247-11255.

339 S. Shaham-Niv, P. Rehak, L. Vuković, L. Adler-Abramovich, P. Král and E. Gazit, Isr. J. Chem., 2017, 57, 729-737.

340 O. Tavassoly, D. Sade, S. Bera, S. Shaham-Niv, D. J. Vocadlo and E. Gazit, J. Mol. Biol., 2018, 430, 3847-3862.

341 D. Pinotsi, A. K. Buell, C. M. Dobson, G. S. Kaminski Schierle and C. F. Kaminski, ChemBioChem, 2013, 14, 846-850.

342 N. Amdursky, M. Molotskii, D. Aronov, L. AdlerAbramovich, E. Gazit and G. Rosenman, Nano Lett., 2009, 9, 3111-3115.

343 S. Shaham-Niv, Z. A. Arnon, D. Sade, A. Lichtenstein, E. A. Shirshin, S. Kolusheva and E. Gazit, Angew. Chem., Int. Ed., 2018, 57, 12444-12447.

344 E. Mossou, S. C. Teixeira, E. P. Mitchell, S. A. Mason, L. Adler-Abramovich, E. Gazit and V. T. Forsyth, Acta Crystallogr., Sect. C: Struct. Chem., 2014, 70, 326-331.

345 Y. Porat, A. Abramowitz and E. Gazit, Chem. Biol. Drug Des., 2006, 67, 27-37.

346 S. Shaham-Niv, P. Rehak, D. Zaguri, A. Levin, L. AdlerAbramovich, L. Vuković, P. Král and E. Gazit, Commun. Chem., 2018, 1, 25.

347 S. Shaham-Niv, P. Rehak, D. Zaguri, S. Kolusheva, P. Král and E. Gazit, Chem. Commun., 2018, 54, 4561-4564.

348 B. G. Anand, K. Dubey, D. S. Shekhawat and K. Kar, Sci. Rep., 2017, 7, 11146.

349 D. Sade, S. Shaham-Niv, Z. A. Arnon, O. Tavassoly and E. Gazit, Open Biol., 2018, 8, 170229.

350 D. Laor, D. Sade, S. Shaham-Niv, D. Zaguri, M. Gartner, V. Basavalingappa, A. Raveh, E. Pichinuk, H. Engel and K. Iwasaki, Nat. Commun., 2019, 10, 62.
351 T. F. Outeiro and S. Lindquist, Science, 2003, 302, 1772-1775.

352 R. Aizen, K. Tao, S. Rencus-Lazar and E. Gazit, J. Nanopart. Res., 2018, 20, 125.

353 S. Guerin, S. A. M. Tofail and D. Thompson, NPG Asia Mater., 2019, 11, 10.

354 G. T. Westermark, M. Fändrich and P. Westermark, Annu. Rev. Pathol.: Mech. Dis., 2015, 10, 321-344.

355 M. B. Pepys, Annu. Rev. Med., 2006, 57, 223-241.

356 G. Merlini, A. Dispenzieri, V. Sanchorawala, S. O. Schönland, G. Palladini, P. N. Hawkins and M. A. Gertz, Nat. Rev. Dis. Primers, 2018, 4, 38.

357 O. B. Suhr, E. Lundgren and P. Westermark, J. Intern. Med., 2017, 281, 337-347.

358 R. Kisilevsky, L. J. Lemieux, P. E. Fraser, X. Kong, P. G. Hultin and W. A. Szarek, Nat. Med., 1995, 1, 143-148.

359 G. P. Gellermann, T. R. Appel, A. Tannert, A. Radestock, P. Hortschansky, V. Schroeckh, C. Leisner, T. Lütkepohl, S. Shtrasburg, C. Röcken, M. Pras, R. P. Linke, S. Diekmann and M. Fändrich, Proc. Natl. Acad. Sci. U. S. A., 2005, 102, 6297-6302.

360 M. Winter, A. Tholey, A. Kristen and C. Röcken, Proteomics, 2017, 17, 1700236.

361 P. Swuec, F. Lavatelli, M. Tasaki, C. Paissoni, P. Rognoni, M. Maritan, F. Brambilla, P. Milani, P. Mauri, C. Camilloni, G. Palladini, G. Merlini, S. Ricagno and M. Bolognesi, Nat. Commun., 2019, 10, 1269.

362 M. Schmidt, S. Wiese, V. Adak, J. Engler, S. Agarwal, G. Fritz, P. Westermark, M. Zacharias and M. Fändrich, Nat. Commun., 2019, 10, 5008.

363 L. Radamaker, Y.-H. Lin, K. Annamalai, S. Huhn, U. Hegenbart, S. O. Schönland, G. Fritz, M. Schmidt and M. Fändrich, Nat. Commun., 2019, 10, 1103.

364 K. Annamalai, K.-H. Gührs, R. Koehler, M. Schmidt, H. Michel, C. Loos, P. M. Gaffney, C. J. Sigurdson, U. Hegenbart, S. Schönland and M. Fändrich, Angew. Chem., Int. Ed., 2016, 55, 4822-4825.

365 K. Annamalai, F. Liberta, M.-T. Vielberg, W. Close, H. Lilie, K.-H. Gührs, A. Schierhorn, R. Koehler, A. Schmidt, C. Haupt, U. Hegenbart, S. Schönland, M. Schmidt, M. Groll and M. Fändrich, Angew. Chem., Int. Ed., 2017, 56, 7510-7514.

366 M. A. Gertz, M. L. Mauermann, M. Grogan and T. Coelho, Brain Behav., 2019, 9, e01371.

367 C. E. Bulawa, S. Connelly, M. DeVit, L. Wang, C. Weigel, J. A. Fleming, J. Packman, E. T. Powers, R. L. Wiseman, T. R. Foss, I. A. Wilson, J. W. Kelly and R. Labaudinière, Proc. Natl. Acad. Sci. U. S. A., 2012, 109, 9629-9634.

368 D. Otzen and R. Riek, Cold Spring Harbor Perspect. Biol., 2019, 11, a033860.

369 R. Hervas, M. J. Rau, Y. Park, W. Zhang, A. G. Murzin, J. A. J. Fitzpatrick, S. H. W. Scheres and K. Si, Science, 2020, 367, 1230-1234.

370 H. Mohammad-Beigi, L. Kjaer, H. Eskandari, F. Aliakbari, G. Christiansen, G. Ruvo, J. L. Ward and D. E. Otzen, Front. Plant Sci., 2019, 10, 148. 
371 R. Riek and D. S. Eisenberg, Nature, 2016, 539, 227-235.

372 R. B. Wickner, H. K. Edskes, F. P. Shewmaker, D. Kryndushkin, J. Nemecek, R. McGlinchey and D. Bateman, Wiley Interdiscip. Rev.: RNA, 2010, 1, 81-89.

373 F. Shewmaker, R. P. McGlinchey, K. Thurber, P. McPhie, F. Dyda, R. Tycko and R. B. Wickner, J. Biol. Chem., 2009, 284, 25065-25076.

374 M. R. Chapman, L. S. Robinson, J. S. Pinkner, R. Roth, J. Heuser, M. Hammar, S. Normark and S. J. Hultgren, Science, 2002, 295, 851-855.

375 L. P. Blanco, M. L. Evans, D. R. Smith, M. P. Badtke and M. R. Chapman, Trends Microbiol., 2012, 20, 66-73.

376 M. L. Evans and M. R. Chapman, Biochim. Biophys. Acta, 2014, 1843, 1551-1558.

377 N. Van Gerven, R. D. Klein, S. J. Hultgren and H. Remaut, Trends Microbiol., 2015, 23, 693-706.

378 M. S. Dueholm, M. Albertsen, D. Otzen and P. H. Nielsen, PLoS One, 2012, 7, e51274.

379 M. M. Barnhart and M. R. Chapman, Annu. Rev. Microbiol., 2006, 60, 131-147.

380 S. A. Tursi and Ç. Tükel, Microbiol. Mol. Biol. Rev., 2018, 82, e00028.

381 T. Kikuchi, Y. Mizunoe, A. Takade, S. Naito and S. i. Yoshida, Microbiol. Immunol., 2005, 49, 875-884.

382 W. H. DePas, D. A. Hufnagel, J. S. Lee, L. P. Blanco, H. C. Bernstein, S. T. Fisher, G. A. James, P. S. Stewart and M. R. Chapman, Proc. Natl. Acad. Sci. U. S. A., 2013, 110, 2629-2634.

383 M. R. Chapman, L. S. Robinson, J. S. Pinkner, R. Roth, J. Heuser, M. Hammar, S. Normark and S. J. Hultgren, Science, 2002, 295, 851-855.

384 J. N. Buxbaum and R. P. Linke, J. Mol. Biol., 2012, 421, 142-159.

385 Q. Shu, S. L. Crick, J. S. Pinkner, B. Ford, S. J. Hultgren and C. Frieden, Proc. Natl. Acad. Sci. U. S. A., 2012, 109, 6502-6507.

386 M. T. Brandl, M. Q. Carter, C. T. Parker, M. R. Chapman, S. Huynh and Y. Zhou, PLoS One, 2011, 6, e25553.

387 Y. Zhou, D. Smith, B. J. Leong, K. Brannstrom, F. Almqvist and M. R. Chapman, J. Biol. Chem., 2012, 287, 35092-35103.

388 A. A. Nenninger, L. S. Robinson, N. D. Hammer, E. A. Epstein, M. P. Badtke, S. J. Hultgren and M. R. Chapman, Mol. Microbiol., 2011, 81, 486-499.

389 E. A. Epstein, M. A. Reizian and M. R. Chapman, J. Bacteriol., 2009, 191, 608-615.

390 P. Goyal, P. V. Krasteva, N. Van Gerven, F. Gubellini, I. Van den Broeck, A. Troupiotis-Tsailaki, W. Jonckheere, G. Pehau-Arnaudet, J. S. Pinkner, M. R. Chapman, S. J. Hultgren, S. Howorka, R. Fronzes and H. Remaut, Nature, 2014, 516, 250-253.

391 L. S. Robinson, E. M. Ashman, S. J. Hultgren and M. R. Chapman, Mol. Microbiol., 2006, 59, 870-881.

392 N. D. Hammer, X. Wang, B. A. McGuffie and M. R. Chapman, J. Alzheimer's Dis., 2008, 13, 407-419.

393 S. K. Collinson, J. M. R. Parker, R. S. Hodges and W. W. Kay, J. Mol. Biol., 1999, 290, 741-756.
394 W. H. DePas and M. R. Chapman, Res. Microbiol., 2012, 163, 592-606.

395 S. K. Collinson, L. Emody, K. H. Muller, T. J. Trust and W. W. Kay, J. Bacteriol., 1991, 173, 4773-4781.

396 B. Cao, Y. Zhao, Y. Kou, D. Ni, X. C. Zhang and Y. Huang, Proc. Natl. Acad. Sci. U. S. A., 2014, 111, E5439-E5444.

397 D. L. Gibson, A. P. White, C. M. Rajotte and W. W. Kay, Microbiology, 2007, 153, 1131-1140.

398 Q. Shu, A. M. Krezel, Z. T. Cusumano, J. S. Pinkner, R. Klein, S. J. Hultgren and C. Frieden, Proc. Natl. Acad. Sci. U. S. A., 2016, 113, 7130-7135.

399 T. Schubeis, J. Spehr, J. Viereck, L. Köpping, M. Nagaraj, M. Ahmed and C. Ritter, FEBS Lett., 2018, 592, 1020-1029.

400 P. Larsen, M. Dueholm, G. Christiansen, J. L. Nielsen, D. E. Otzen and P. H. Nielsen, Environ. Microbiol., 2007, 9, 3077-3090.

401 L. F. B. Christensen, N. Schafer, A. M. Wolf-Perez, D. J. Madsen and D. E. O. Otzen, in Biological and Bioinspired Nanomaterials: Assembly Mechanisms and Properties, ed. S. Perrett, A. K. Buell and T. J. Knowles, Springer Press, 2019, ch. 4.

402 M. S. Dueholm, S. V. Petersen, M. Sønderkær, P. Larsen, G. Christiansen, K. L. Hein, J. J. Enghild, J. L. Nielsen, K. L. Nielsen, P. H. Halkjær and D. E. Otzen, Mol. Microbiol., 2010, 77, 1009-1020.

403 S. L. Rouse, W. J. Hawthorne, J. L. Berry, D. S. Chorev, S. A. Ionescu, S. Lambert, F. Stylianou, W. Ewert, U. Mackie, R. M. L. Morgan, D. E. Otzen, F. A. Herbst, P. H. Nielsen, M. Dueholm, H. Bayley, C. V. Robinson, S. Hare and S. Matthews, Nat. Commun., 2017, 8, 263.

404 G. Zeng, B. S. Vad, M. S. Dueholm, G. Christiansen, M. Nilsson, T. Tolker-Nielsen, P. H. Nielsen, R. L. Meyer and D. E. Otzen, Front. Microbiol., 2015, 6, 1099.

405 S. L. Rouse, F. Stylianou, H. Y. G. Wu, J. L. Berry, L. Sewell, R. M. L. Morgan, A. C. Sauerwein and S. Matthews, J. Mol. Biol., 2018, 430, 3863-3871.

406 X. Wang, N. D. Hammer and M. R. Chapman, J. Biol. Chem., 2008, 283, 21530-21539.

407 X. Wang, D. R. Smith, J. W. Jones and M. R. Chapman, J. Biol. Chem., 2007, 282, 3713-3719.

408 M. M. Barnhart, J. Lynem and M. R. Chapman, J. Bacteriol., 2006, 188, 5212-5219.

409 F. Shewmaker, R. P. McGlinchey, K. R. Thurber, P. McPhie, F. Dyda, R. Tycko and R. B. Wickner, J. Biol. Chem., 2009, 284, 25065-25076.

410 P. Tian, W. Boomsma, Y. Wang, D. E. Otzen, M. H. Jensen and K. Lindorff-Larsen, J. Am. Chem. Soc., 2015, 137, 22-25.

411 X. Wang, Y. Zhou, J.-J. Ren, N. D. Hammer and M. R. Chapman, Proc. Natl. Acad. Sci. U. S. A., 2010, 107, 163-168.

412 X. Wang and M. R. Chapman, Prion, 2008, 2, 57-60.

413 N. D. Hammer, J. C. Schmidt and M. R. Chapman, Proc. Natl. Acad. Sci. U. S. A., 2007, 104, 12494-12499.

414 S. L. Rouse, S. J. Matthews and M. S. Dueholm, J. Mol. Biol., 2018, 430, 3685-3695.

415 M. Stenvang, M. S. Dueholm, B. S. Vad, T. Seviour, G. Zeng, S. Geifman-Shochat, M. T. Søndergaard, G. Christiansen, 
R. L. Meyer, S. Kjelleberg, P. H. Nielsen and D. E. Otzen, J. Biol. Chem., 2016, 291, 26540-26553.

416 Z. Najarzadeh, H. Mohammad-Beigi, J. N. Pedersen, G. Christiansen, T. V. Sønderby, S. Shojaosadati, D. Morshedi, K. Strømgaard, G. Meisl, D. Sutherland, J. S. Pedersen and D. E. Otzen, Biomolecules, 2019, 9, 659. 417 N. Lorenzen, S. B. Nielsen, A. K. Buell, J. D. Kaspersen, P. Arosio, B. S. Vad, W. Paslawski, G. Christiansen, Z. Valnickova-Hansen, M. Andreasen, J. J. Enghild, J. S. Pedersen, C. M. Dobson, T. J. Knowles and D. E. Otzen, J. Am. Chem. Soc., 2014, 136, 3859-3868.

418 W. Paslawski, S. Mysling, K. Thomsen, T. J. D. Jørgensen and D. E. Otzen, Angew. Chem., Int. Ed., 2014, 53, 7560-7563.

419 M. Andreasen, G. Meisl, J. D. Taylor, T. C. T. Michaels, D. E. Otzen, M. Chapman, C. M. Dobson, S. Matthews and T. P. J. Knowles, mBio, 2018, 10, e02279.

420 C. Rasmussen, G. Christiansen, B. S. Vad, J. J. Enghild, C. Lynggaard, M. Andreasen and D. E. Otzen, Protein Sci., 2019, 28, 633-642.

421 L. F. B. Christensen, J. S. Nowak, T. V. Sønderby, S. A. Frank and D. E. Otzen, bioRxiv, 2020, DOI: 10.1101/ 2020.03.09.983882.

422 M. Bucciantini, E. Giannoni, F. Chiti, F. Baroni, L. Formigli, J. Zurdo, N. Taddei, G. Ramponi, C. M. Dobson and M. Stefani, Nature, 2002, 416, 507-511.

423 M. L. Evans, E. Chorell, J. D. Taylor, J. Aden, A. Gotheson, F. Li, M. Koch, L. Sefer, S. J. Matthews, P. WittungStafshede, F. Almqvist and M. R. Chapman, Mol. Cell, 2015, 57, 445-455.

424 J. D. Taylor, W. J. Hawthorne, J. Lo, A. Dear, N. Jain, G. Meisl, M. Andreasen, C. Fletcher, M. Koch, N. Darvill, N. Scull, A. Escalera-Maurer, L. Sefer, R. Wenman, S. Lambert, J. Jean, Y. Xu, B. Turner, S. G. Kazarian, M. R. Chapman, D. Bubeck, A. de Simone, T. P. J. Knowles and S. J. Matthews, Sci. Rep., 2016, 6, 24656.

425 N. Jain, J. Aden, K. Nagamatsu, M. L. Evans, X. Li, B. McMichael, M. I. Ivanova, F. Almqvist, J. N. Buxbaum and M. R. Chapman, Proc. Natl. Acad. Sci. U. S. A., 2017, 114, 12184-12189.

426 V. Sivanathan and A. Hochschild, Nat. Protoc., 2013, 8, 1381-1390.

427 P. Q. Nguyen, Z. Botyanszki, P. K. Tay and N. S. Joshi, Nat. Commun., 2014, 5, 4945.

428 C. Zhong, T. Gurry, A. A. Cheng, J. Downey, Z. Deng, C. M. Stultz and T. K. Lu, Nat. Nanotechnol., 2014, 9, 858-866.

429 T. P. J. Knowles and R. Mezzenga, Adv. Mater., 2016, 28, 6546-6561.

430 C. A. E. Hauser, S. Maurer-Stroh and I. C. Martins, Chem. Soc. Rev., 2014, 43, 5326-5345.

431 C. X. Li, J. Adamcik and R. Mezzenga, Nat. Nanotechnol., 2012, 7, 421-427.

432 C. X. Li, S. Bolisetty and R. Mezzenga, Adv. Mater., 2013, 25, 3694-3700.

433 C. X. Li, A. K. Born, T. Schweizer, M. Zenobi-Wong, M. Cerruti and R. Mezzenga, Adv. Mater., 2014, 26, 3207-3215.
434 T. P. J. Knowles, T. W. Oppenheim, A. K. Buell, D. Y. Chirgadze and M. E. Welland, Nat. Nanotechnol., 2010, 5, 204-207.

435 A. Aslund, A. Herland, P. Hammarstrom, K. P. R. Nilsson, B. H. Jonsson, O. Inganas and P. Konradsson, Bioconjugate Chem., 2007, 18, 1860-1868.

436 A. Rizzo, N. Solin, L. J. Lindgren, M. R. Andersson and O. Inganas, Nano Lett., 2010, 10, 2225-2230.

437 A. Herland, P. Bjork, P. R. Hania, I. G. Scheblykin and O. Inganas, Small, 2007, 3, 318-325.

438 A. Herland, P. Bjork, K. P. R. Nilsson, J. D. M. Olsson, P. Asberg, P. Konradsson, P. Hammarstrom and O. Inganas, Adv. Funct. Mater., 2005, 17, 1466-1471.

439 G. Nystrom, M. Arcari and R. Mezzenga, Nat. Nanotechnol., 2018, 13, 330-336.

440 S. Boothroyd, A. F. Miller and A. Saiani, Faraday Discuss., 2013, 166, 195-207.

441 J. Gao, C. Tang, M. A. Elsawy, A. M. Smith, A. F. Miller and A. Saiani, Biomacromolecules, 2017, 18, 826-834.

442 S. Bolisetty, L. Harnau, J. M. Jung and R. Mezzenga, Biomacromolecules, 2012, 13, 3241-3252.

443 V. Jayawarna, M. Ali, T. A. Jowitt, A. E. Miller, A. Saiani, J. E. Gough and R. V. Ulijn, Adv. Mater., 2006, 18, 611-620.

444 M. N. Bongiovanni and S. L. Gras, Biomaterials, 2015, 46, 105-116.

445 M. N. Bongiovanni, D. B. Scanlon and S. L. Gras, Biomaterials, 2011, 32, 6099-6110.

446 S. L. Gras, A. K. Tickler, A. M. Squires, G. L. Devlin, M. A. Horton, C. M. Dobson and C. E. MacPhee, Biomaterials, 2008, 29, 1553-1562.

447 N. P. Reynolds, M. Charnley, R. Mezzenga and P. G. Hartley, Biomacromolecules, 2014, 15, 599-608.

448 N. P. Reynolds, K. E. Styan, C. D. Easton, Y. L. Li, L. Waddington, C. Lara, J. S. Forsythe, R. Mezzenga, P. G. Hartley and B. W. Muir, Biomacromolecules, 2013, 14, 2305-2316.

449 G. A. Silva, C. Czeisler, K. L. Niece, E. Beniash, D. A. Harrington, J. A. Kessler and S. I. Stupp, Science, 2004, 303, 1352-1355.

450 Y. P. Cao, S. Bolisetty, J. Adamcik and R. Mezzenga, Phys. Rev. Lett., 2018, 120, 158103.

451 R. S. Jacob, D. Ghosh, P. K. Singh, S. K. Basu, N. N. Jha, S. Das, P. K. Sukul, S. Patil, S. Sathaye, A. Kumar, A. Chowdhury, S. Malik, S. Sen and S. K. Maji, Biomaterials, 2015, 54, 97-105.

452 S. Das, K. Zhou, D. Ghosh, N. N. Jha, P. K. Singh, R. S. Jacob, C. C. Bernard, D. I. Finkelstein, J. S. Forsythe and S. K. Maji, NPG Asia Mater., 2016, 8, e304.

453 C. X. Li, M. M. Alam, S. Bolisetty, J. Adamcik and R. Mezzenga, Chem. Commun., 2011, 47, 2913-2915.

454 S. Chaves, L. M. Pera, C. L. Avila, C. M. Romero, M. Baigori, F. E. M. Vieyra, C. D. Borsarelli and R. N. Chehin, $R S C A d v$., 2016, 6, 8528-8538.

455 A. Udomprasert, M. N. Bongiovanni, R. J. Sha, W. B. Sherman, T. Wang, P. S. Arora, J. W. Canary, S. L. Gras and N. C. Seeman, Nat. Nanotechnol., 2014, 9, 537-541. 
456 S. Bolisetty, N. Reinhold, C. Zeder, M. N. Orozco and R. Mezzenga, Chem. Commun., 2017, 53, 5714-5717.

457 M. Peydayesh, S. Bolisetty, T. Mohammadi and R. Mezzenga, Langmuir, 2019, 35, 4161-4170.

458 M. Peydayesh, M. Pauchard, S. Bolisetty, F. Stellacci and R. Mezzenga, Chem. Commun., 2019, 55, 11143-11146.

459 Q. R. Zhang, S. Bolisetty, Y. P. Cao, S. Handschin, J. Adamcik, Q. M. Peng and R. Mezzenga, Angew. Chem., Int. Ed., 2019, 58, 6012-6016.

460 S. Bolisetty, M. Arcari, J. Adamcik and R. Mezzenga, Langmuir, 2015, 31, 13867-13873.

461 G. Nystrom, M. P. Fernandez-Ronco, S. Bolisetty, M. Mazzotti and R. Mezzenga, Adv. Mater., 2016, 28, 472-484.

462 S. Bolisetty, J. Adamcik, J. Heier and R. Mezzenga, Adv. Funct. Mater., 2012, 22, 3424-3428.

463 D. Li, H. Furukawa, H. X. Deng, C. Liu, O. M. Yaghi and D. S. Eisenberg, Proc. Natl. Acad. Sci. U. S. A., 2014, 111, 191-196.

464 D. Li, E. M. Jones, M. R. Sawaya, H. Furukawa, F. Luo, M. Ivanova, S. A. Sievers, W. Y. Wang, O. M. Yaghi, C. Liu and D. S. Eisenberg, J. Am. Chem. Soc., 2014, 136, 18044-18051.

465 O. N. Antzutkin, R. D. Leapman, J. J. Balbach and R. Tycko, Biochemistry, 2002, 41, 15436-15450.

466 C. Sachse, C. Xu, K. Wieligmann, S. Diekmann, N. Grigorieff and M. Fändrich, J. Mol. Biol., 2006, 362, 347-354.

467 S. E. Marsh, E. M. Abud, A. Lakatos, A. Karimzadeh, S. T. Yeung, H. Davtyan, G. M. Fote, L. Lau, J. G. Weinger, T. E. Lane, M. A. Inlay, W. W. Poon and M. Blurton-Jones, Proc. Natl. Acad. Sci. U. S. A., 2016, 113, E1316-E1325.

468 J. Rogers, R. Li, D. Mastroeni, A. Grover, B. Leonard, G. Ahern, P. Cao, H. Kolody, L. Vedders, W. P. Kolb and M. Sabbagh, Neurobiol. Aging, 2006, 27, 1733-1739.

469 R. A. Bessen and R. F. Marsh, J. Virol., 1994, 68, 7859-7868.

470 J. Collinge, K. C. L. Sidle, J. Meads, J. Ironside and A. F. Hill, Nature, 1996, 383, 685-690.

471 J. Safar, H. Wille, V. Itri, D. Groth, H. Serban, M. Torchia, F. E. Cohen and S. B. Prusiner, Nat. Med., 1998, 4, 1157-1165.

472 M. L. Cohen, C. Kim, T. Haldiman, M. ElHag, P. Mehndiratta, T. Pichet, F. Lissemore, M. Shea, Y. Cohen, W. Chen, J. Blevins, B. S. Appleby, K. Surewicz, W. K. Surewicz, M. Sajatovic, C. Tatsuoka, S. Zhang, P. Mayo, M. Butkiewicz, J. L. Haines, A. J. Lerner and J. G. Safar, Brain, 2015, 138, 1009-1022.
473 F. Langer, Y. S. Eisele, S. K. Fritschi, M. Staufenbiel, L. C. Walker and M. Jucker, J. Neurosci., 2011, 31, 14488.

474 J. Stöhr, C. Condello, J. C. Watts, L. Bloch, A. Oehler, M. Nick, S. J. DeArmond, K. Giles, W. F. DeGrado and S. B. Prusiner, Proc. Natl. Acad. Sci. U. S. A., 2014, 111, 10329-10334.

475 M. Meyer-Luehmann, J. Coomaraswamy, T. Bolmont, S. Kaeser, C. Schaefer, E. Kilger, A. Neuenschwander, D. Abramowski, P. Frey, A. L. Jaton, J.-M. Vigouret, P. Paganetti, D. M. Walsh, P. M. Mathews, J. Ghiso, M. Staufenbiel, L. C. Walker and M. Jucker, Science, 2006, 313, 1781-1784.

476 W. Qiang, W.-M. Yau, J.-X. Lu, J. Collinge and R. Tycko, Nature, 2017, 541, 217-221.

477 R. P. Friedland and M. R. Chapman, PLoS Pathog., 2017, 13, e1006654.

478 K. Lundmark, G. T. Westermark, A. Olsén and P. Westermark, Proc. Natl. Acad. Sci. U. S. A., 2005, 102, 6098-6102.

479 M.-M. Wang, D. Miao, X.-P. Cao, L. Tan and L. Tan, Ann. Transl. Med., 2018, 6, 177.

480 R. Nortley, N. Korte, P. Izquierdo, C. Hirunpattarasilp, A. Mishra, Z. Jaunmuktane, V. Kyrargyri, T. Pfeiffer, L. Khennouf, C. Madry, H. Gong, A. Richard-Loendt, W. Huang, T. Saito, T. C. Saido, S. Brandner, H. Sethi and D. Attwell, Science, 2019, 365, eaav9518.

481 O. Eriksson, O. Korsgren, R. K. Selvaraju, M. Mollaret, Y. de Boysson, F. Chimienti and M. Altai, Acta Diabetol., 2018, 55, 49-57.

482 C. S. Hampe, A. R. Wallen, M. Schlosser, M. Ziegler and I. R. Sweet, Exp. Clin. Endocrinol. Diabetes, 2005, 113, 381-387.

483 Y.-F. C. Chau, C.-K. Wang, L. Shen, C. M. Lim, H.-P. Chiang, C.-T. C. Chao, H. J. Huang, C.-T. Lin, N. T. R. N. Kumara and N. Y. Voo, Sci. Rep., 2017, 7, 16817.

484 A. Kakinen, Y. Sun, I. Javed, A. Faridi, E. H. Pilkington, P. Faridi, A. W. Purcell, R. Zhou, F. Ding, S. Lin, P. C. Ke and T. P. Davis, Sci. Bull., 2019, 64, 26.

485 M. Ankarcrona, B. Winblad, C. Monteiro, C. Fearns, E. T. Powers, J. Johansson, G. T. Westermark, J. Presto, B. G. Ericzon and J. W. Kelly, J. Intern. Med., 2016, 280, 177-202.

486 R. H. Falk, K. M. Alexander, R. Liao and S. Dorbala, J. Am. Coll. Cardiol., 2016, 68, 1323-1341.

487 D. Adams, H. Koike, M. Slama and T. Coelho, Nat. Rev. Neurol., 2019, 15, 387-404.

488 V. Latza, P. A. Guerette, D. Ding, S. Amini, A. Kumar, I. Schmidt, S. Keating, N. Oxman, J. C. Weaver, P. Fratzl, A. Miserez and A. Masic, Nat. Commun., 2015, 6, 8313. 